\title{
FRONTEIRA DE EFICIÊNCIA EM SERVIÇOS DE SANEAMENTO NO ESTADO DE SÃO PAULO
}

\author{
THELMA HARUMI OHIRA
}

Dissertação apresentada à Escola Superior de Agricultura "Luiz de Queiroz", Universidade de São Paulo, para obtenção do Título de Mestre em Ciências, Área de Concentração: Economia Aplicada.

P I R A C I C A B A

Estado de São Paulo - Brasil

Fevereiro - 2005 


\title{
FRONTEIRA DE EFICIÊNCIA EM SERVIÇOS DE SANEAMENTO NO ESTADO DE SÃO PAULO
}

\section{THELMA HARUMI OHIRA}

Bacharel em Ciências Econômicas

Orientador: Prof. Dr. RICARDO SHIROTA

\author{
Dissertação apresentada à Escola Superior de \\ Agricultura "Luiz de Queiroz", Universidade de São \\ Paulo, para obtenção do Título de Mestre em Ciências, \\ Área de Concentração: Economia Aplicada.
}

P I R A C I C A B A

Estado de São Paulo - Brasil

Fevereiro - 2005 


\section{Dados Internacionais de Catalogação na Publicação (CIP) DIVISÃO DE BIBLIOTECA E DOCUMENTAÇÃO - ESALQ/USP}

Ohira, Thelma Harumi

Fronteira de eficiência em serviços de saneamento no Estado de São Paulo / Thelma Harumi Ohira. - - Piracicaba, 2005.

$109 \mathrm{p}$.

Dissertação (Mestrado) - - Escola Superior de Agricultura Luiz de Queiroz, 2005.

Bibliografia.

1. Eficiência econômica 2. Saneamento básico 3. São Paulo (SP) I. Título

CDD 628

"Permitida a cópia total ou parcial deste documento, desde que citada a fonte - O autor" 


\section{DEDICO}

Aos meus pais, Eliani N. Ikeguchi Ohira e Yasuhiro Ohira, e meus irmãos Marcos Ikeguchi Ohira e Marcelo Ikeguchi Ohira; pelos esforços que nos submetemos e o apoio que sempre recebi para minha realização pessoal e profissional. 


\section{AGRADECIMENTOS}

Aos meus pais e meus irmãos pelo grande amor e apoio em todas as minhas decisões e ainda pelas palavras de incentivo e presença constante, tanto nas alegrias quanto nas dificuldades que passei. Sem eles minha caminhada seria muito difícil.

Ao meu orientador, Prof. Ricardo Shirota, pela amizade, compreensão e ensinamentos nessa jornada de crescimento. Pelas contribuições e sugestões, agradeço também a Prof ${ }^{a}$. Ana Maria Pereira Amaral, Prof. Roberto Arruda de Souza Lima e Prof. João Martines. Ao departamento de Economia, Sociologia e Administração da ESALQ/USP, em especial à Maielli, Helena, Ligiana e Álvaro.

Ao SEMAE de São José do Rio Preto, SEMAE de Piracicaba e ETA do Campus da ESALQ/USP, pela colaboração e informações solicitadas.

"I get by with a little help from my friends", já diziam Lennon e McCartney, em 1967. Os amigos foram importantes na conclusão desta trajetória. Em especial: Louise Oliveira, Andrea Ferro, Alexandre Nicolella, Luciana Torrezan, César Alves, Gustavo Sbrissia, Sílvio, Davi, Sérgio Sakurai, Maria Mazoni, Taciana Uehara, Mariângela Grola, Carina Ito, Farid 81 e 12, Mariana Pessini, Carlos Soncin, Felipe Hirata, SS, Naligia Longatto, Laura Rodrigues, Gustavo Silva, Ana Menegatti, Leila Harfuch, Luciane Schneider, Mariusa Pitelli, Tabatas e muitos que pequei por não citar.

Agradecimentos ao amigo Frederico Araújo Turolla, pela atenção, disponibilidade, palavras de ânimo e pelos engrandecedores "palpites", que às vezes precisei na resolução de dúvidas e questionamentos de minha dissertação.

Por fim, obrigada a todos que contribuíram direta e indiretamente na conclusão deste trabalho. 


\section{SUMÁRIO}

Página

LISTA DE FIGURAS …............................................................................... vii

LISTA DE QUADROS ................................................................................. viii

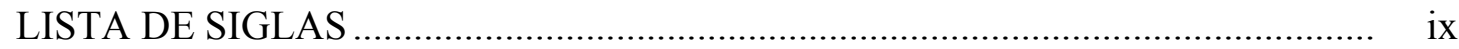

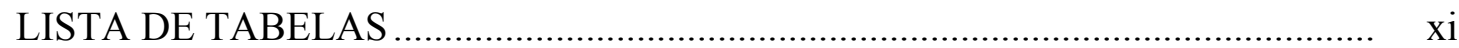

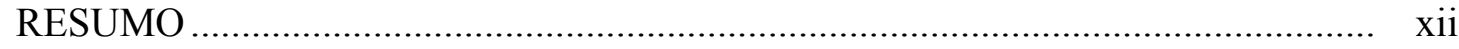

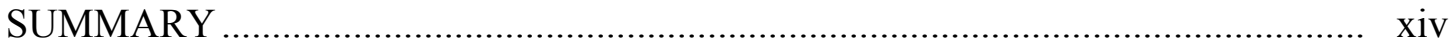

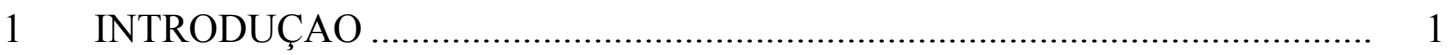

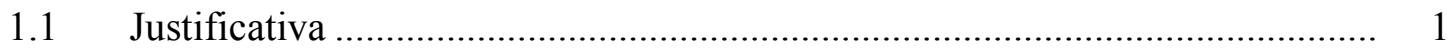

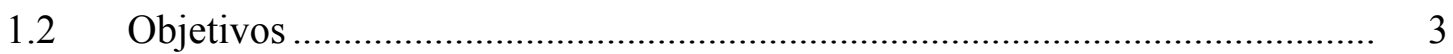

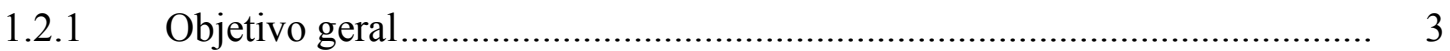

1.2.2 Objetivos específicos ......................................................................... 3

1.2.3 Estrutura de apresentação........................................................................ 4

2 REVISÃO DE LITERATURA ….......................................................... 5

2.1 Coleta, distribuição e devolução de um sistema de saneamento básico ........... 5

2.2 O sistema de saneamento e sua importância ..................................................... 8

2.2.1 Evolução histórica ............................................................................. 15

2.2.2 Evolução do setor no Brasil ..................................................................... 18

2.3 Análise econômica do setor ..................................................................... 25

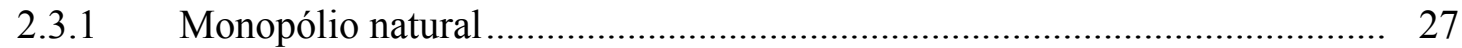

2.3.2 Eficiência e o setor público ................................................................... 31

2.4 Eficiência econômica ........................................................................... 35

3 MATERIAL E MÉTODOS _...................................................................... 41

3.1 Modelo econômico.................................................................................... 41 


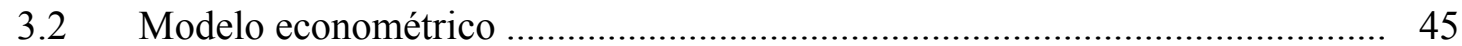

3.3 Base de dados e caracterização da amostra................................................. 54

3.4 Estimação da fronteira da função custo ......................................................... 66

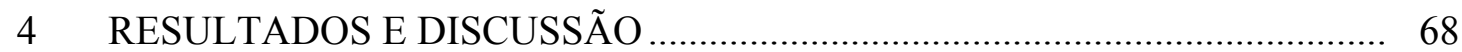

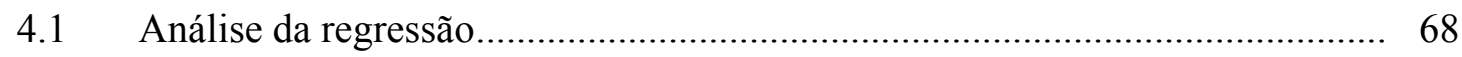

4.2 Ordenação dos municípios ........................................................................ 86

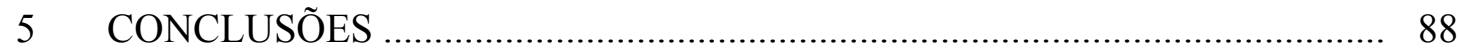

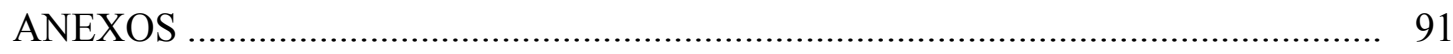

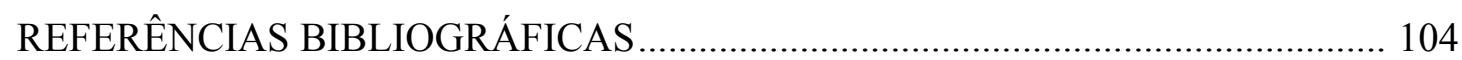




\section{LISTA DE FIGURAS}

Página

1 Sistema de saneamento básico ............................................................................ 7

2 Porcentagem de internações por motivos de problemas no aparelho digestivo no Brasil, no ano de 1997 ................................................................................... 12

3 Sub-aditividade sem economia de escala global ............................................... 30

4 Medidas de eficiência segundo a análise de Farrel ............................................... 37

5 Distribuição das empresas de acordo com a participação das despesas com serviços terceirizados no custo operacional, 2002 .............................................. 59

6 Distribuição das empresas de saneamento básico acordo com as classes de participação de de serviços de terceirizados sobre o custo operacional, 2002......

7 Distribuição das empresas de acordo com a participação das despesas com produtos químicos no custo operacional, 2002

8 Distribuição das empresas de saneamento básico acordo com as classes de participação de serviços de terceirizados sobre o custo operacional, 2002 ....

9 Relação entre custo operacional (dex_1) com a razão entre despesas com energia elétrica (dee) no custo operacional (dex_1), em 2002. 


\section{LISTA DE QUADROS}

Página

1 Doenças relacionadas à falta ou inadequação de saneamento.

2 Evolução histórica dos aspectos de saúde pública e meio ambiente no setor de saneamento no Brasil

3 Principais programas federais em saneamento no Brasil, na década de 1990 


\section{LISTA DE SIGLAS}

ANA - Agência Nacional de Águas

ANEEL - Agência Nacional de Energia Elétrica

BID - Banco Interamericano de Desenvolvimento

BIRD - Banco Mundial

BNDES - Banco Nacional de Desenvolvimento Econômico e Social

BNH - Banco Nacional de Habitação

Capes - Coordenação de Aperfeiçoamento de Pessoal de Nível Superior

Cnpq - Conselho Nacioanl de Desenvolvimento Científico e Tenológico

FCP/SAN - Programa de Financiamento a Concessionárias Privadas de Saneamento

FGTS - Fundo de Garantia do Tempo de Serviço

FINEP - Financiadora de Estudos e Projetos

FUNASA - Fundação Nacional da Saúde

IBGE - Instituto Brasileiro de Geografia e Estatística

MC - Ministério das Cidades

MF - Ministério da Fazenda

MME - Ministério de Minas e Energia

MS - Ministério da Saúde

OGU - Orçamento Geral da União 
OMS - Organização Mundial da Saúde

ONU - Organização ds Nações Unidas

PASS - Programa de Ação Social em Saneamento

PLANASA - Plano Nacional de Saneamento

PMSS - Programa Nacional de Informação sobre Saneamento

PNCDA - Programa Nacional de Combate ao Desperdício de Água

PNS - Política Nacional de Saneamento

PNSB - Pesquisa Nacional de Saneamento Básico

PRONURB - Programa de Saneamento para Núcleos Urbanos

PROPAR - Programa de Assistência Técnica à Parceria Público-Privado em Saneamento

PROSAB - Programa de Pesquisa em Saneamento Básico

PROSEGE - Programa de Ação Social em Saneamento

SABESP - Companhia de Sanemento Básico do Estado de São Paulo

SEADE - Fundação Sistema Estadual de Análise de Dados

SEDU/PR - Secretaria Especial de Desenvolvimento Urbano da Presidência da República

SEMA - Secretaria Especial de Meio Ambiente

SNSA - Sistema Nacional de Saneamento Ambiental

SUS - Sistema Único de Saúde

UNICEF - United Nations of Children's Fundation 


\section{LISTA DE TABELAS}

Página

1 Coeficientes estimados para a fronteira estocástica função custo ${ }^{\mathrm{a}}$, modelo i. .... 68

2 Coeficientes estimados para a fronteira estocástica função custo ${ }^{\mathrm{b}}$, modelo ii ..... 70

3 Matriz de correlação das variáveis dos modelos i. e ii...................................... 71

4 Coeficientes estimados para a fronteira estocástica função custo ${ }^{\mathrm{a}}$, modelo iii.... 73

5 Coeficientes estimados para a fronteira estocástica função custo ${ }^{\mathrm{b}}$, modelo iv .... 74

6 Matriz de correlação das variáveis dos modelos iii. e iv .................................... 76

7 Coeficientes estimados para a fronteira estocástica função custo ${ }^{\mathrm{a}}$, modelo v ..... 77

8 Coeficientes estimados para a fronteira estocástica função custo ${ }^{\mathrm{b}}$, modelo vi .... 78

9 Matriz de correlação das variáveis dos modelos v. e vi...................................... 79

10 Coeficientes estimados para a fronteira estocástica função custo ${ }^{\mathrm{a}}$, modelo vii ... 80

11 Coeficientes estimados para a fronteira estocástica função custo ${ }^{\mathrm{b}}$, modelo viii.. 81

12 Matriz de correlação das variáveis dos modelos vii. e viii .................................. 83

13 Coeficientes estimados para a fronteira estocástica função custo ${ }^{\mathrm{a}}$, modelo ix .... 84

14 Coeficientes estimados para a fronteira estocástica função custo ${ }^{\mathrm{b}}$, modelo x ..... 85

15 Matriz de correlação das variáveis dos modelos ix. e x....................................... 86 


\title{
FRONTEIRA DE EFICIÊNCIA EM SERVIÇOS DE SANEAMENTO NO ESTADO DE SÃO PAULO
}

\author{
Autor: THELMA HARUMI OHIRA \\ Orientador: RICARDO SHIROTA
}

\section{RESUMO}

Dado que as inter-relações entre saúde, saneamento, conservação ambiental e crescimento econômico, são fundamentais para o planejamento sistemático de saneamento básico, programas que têm como foco o saneamento básico podem ser considerados como mecanismos de prevenção de doenças e epidemias de veiculação hídrica. Entretanto, na literatura existe um consenso quanto às dificuldades na tarefa de detecção causa-efeito num sistema de saneamento básico. Assim, o objetivo do presente trabalho é mensurar, de forma alternativa, a eficiência no setor. Verificando a existência de eficiência econômica entre empresas de saneamento básico no Estado de São Paulo, de acordo com as diferentes determinações de produtos, assumindo dois tipos de distribuições do erro sistêmico (meio-normal e normal-truncada), assim como das esferas de abrangência deste setor: regional e local. Para isso, avaliou-se a existência da eficiência no setor de saneamento básico, no Estado de São Paulo, utilizando os dados do Sistema Nacional de Informação sobre Saneamento (SNIS) referentes ao ano de 
2002, do das Cidades (Brasil, 2004); por meio da estimação de 10 modelos de fronteiras estocásticas da função custo para cada tipo de produto utilizado como variável dependente. É possível concluir que de acordo com as diferentes determinações de produtos e distribuição assumida do erro sistêmico, os resultados dos modelos podem apresentar resultados diferentes, ou seja, a determinação de eficiência é sensível à escolha do produto. Testes realizados demonstraram que a diferenciação por esfera de abrangência (regional e local) não foi significativa para a determinação de um resultado. Por fim, a ordenação dos municípios para os modelos que apresentaram resultados significativos, variam de acordo com a escolha dos produtos, comprovando que a eficiência não é sensível à distribuição do erro estocástico, assim como da esfera de abrangência do serviço. 


\title{
EFICIENCY FRONTIER OF SANITATION SERVICE IN STATE OF SÃO PAULO
}

\author{
Autor: THELMA HARUMI OHIRA \\ Orientador: RICARDO SHIROTA
}

\section{SUMMARY}

By the fact that the inter-relationship between health, sanitation, environmental conservation and economic growth, are essential for the systematical basic sanitary planning, programs that are focused on basic sanitation are considered to be as a mitigation mechanism to avoid diseases and epidemics spread by water bodies. However, in literature there is well known that there are some difficulties on the effectcause detection on a basic sanitations system. That way, the objective of the present study, is measure, in an alternative way, the efficiency in the sector. Verifying the existence of economical efficiency among basic sanitation companies on Sao Paulo State, according to the different products determination, assuming two types of systematical errors (half-normal and truncated-normal), as well as, the covered services: regional and local. To perform that, it has been evaluated the efficiency existence on the companies, on Sao Paulo State, using the data from the 'Sistema Nacional de Informação sobre Saneamento' (SNIS), of 2002, from Cities Ministry (Brasil, 2004); through 10 stochastic frontier models of cost function to each type of output used as the 
dependent variable. It is possible to conclude that, according to the different determinations of outputs, and the assumed distribution of the systematic error, the results has presented different results. That way, the determination of the efficiency is sensible to the choice of output. Performed tests have showed that covered services of the companies were not significant to determine a result. Finally, the ranking of the municipals in the model have presented different results, and they vary according to the choice of output, proving that efficiency is not sensible to the stochastic error, as well as the reach ness of the services provided by the companies. 


\section{INTRODUÇAO}

\subsection{Justificativa}

A água é um dos recursos mais importantes da natureza pois é um solvente universal. É um recurso classificado de acordo com sua cor, turbidez, sabor, cheiro e composição química. Pode ser utilizado para diversas finalidades: abastecimento para consumo humano, insumo na produção de energia, navegação, irrigação, recreação e pesca. É um recurso renovável e ainda apresenta a capacidade de se reciclar, podendo ser reutilizada para outros fins, como jardinagem e manejo florestal, que são atividades que não exigem a potabilidade da água.

Sendo um elemento fundamental à vida e um fator determinante para a formação das aglomerações populacionais, o recurso água deve ser gerido de forma consciente. Devem-se impor restrições para otimizar seus múltiplos usos e melhorar as condições de potabilidade para consumo humano, assim como estabelecer parâmetros de qualidade de devolução ao corpo hídrico, evitando-se externalidades negativas, predatório ao meio ambiente.

Infecções causadas pela falta de ações sanitárias, podem provocar diferentes doenças tais como diarréias e desidratações, impedindo a habilidade comum de digestão e absorção de alimentos e causando perda de nutrientes. Assim, quando a ação sanitária é pobre, doenças aparecem e o custo médico aumenta. Estima-se que as pessoas que vivem em áreas simultaneamente sem ação sanitária, carente financeiramente, com educação higiênica deficitárias, gastam seis vezes mais em tratamentos médicos do que pessoas que podem ter acesso aos serviços United Nations of Children's Fundation (UNICEF)(2003b). 
Além disso, haveria perda de capital humano e produtividade, pois doenças prejudicam a economia nacional medida em que as pessoas deixam de ir à escola ou ao trabalho. Os setores agrícola e de turismo também podem ser atingidos e, ainda, a comunidade estaria sujeita a surtos de doenças infecciosas.

De acordo com a UNICEF (2003a), o acesso às facilidades sanitárias é um direito humano fundamental de salva-guarda a saúde e a dignidade humana. No Brasil, esse direito foi expresso no artigo Segundo da Lei 8.080 de 19/09/1990, que relaciona o saneamento e saúde, no qual garante que a saúde é um direito fundamental do ser humano, devendo o Estado prover as condições indispensáveis ao seu pleno exercício.

Porém, segundo a Secretaria Nacional de Saneamento Ambiental (SNSA), o setor de saneamento possui ainda grandes deficiências com cerca de 15 milhões de brasileiros, representando 3,4 milhões de domicílios, sem acesso à água encanada. Cerca de 60 milhões de brasileiros, ou 9,6 milhões de domicílios urbanos, não possuem rede coletora de esgoto. Existe também grande deficiência no tratamento de esgoto coletado, já que, ainda segundo o SNSA, cerca de $75 \%$ do esgoto coletado nas cidades é despejado sem nenhum tratamento em corpos hídricos, contribuindo para o aumento da poluição (Brasil, 2004).

Nesse cenário, estima-se que seriam necessários investimentos de cerca de R\$ 178 bilhões, nos próximos vinte anos, para a universalização dos serviços de saneamento. De acordo com o Ministério das Cidades, os investimentos realizados em 2000 foram de R\$2,0 bilhões e nos dois anos seguintes atingiram R\$2,7 e R\$2,8 bilhões. Em 2003, esse investimento cai para R\$ 2,5 bilhões. Esses dados evidenciam o descompasso existente entre o investimento necessário e o realizado (Brasil, 2004).

Partindo da hipótese que o setor de saneamento básico das cidades deve desempenhar seu papel fundamental - garantia na eficiência e com isso assegurar o atendimento pelos serviços para que os indivíduos fiquem livres de externalidades ${ }^{1}$

\footnotetext{
${ }^{1}$ Externalidade: acontecem quando o bem-estar de um consumidor ou o produto de uma empresa é afetado por decisões de consumo ou produção de outros (Randall, 1987).
} 
negativas à saúde. O presente trabalho estuda o setor de saneamento, no Estado de São Paulo, através da fronteira estocástica da função custo realizando assim, a análise de eficiência das empresas nas esferas municipal e estadual de atendimento de serviços de água e esgoto.

\subsection{Objetivos}

\subsubsection{Objetivo geral}

O objetivo geral da pesquisa é testar a hipótese da existência de diferenças de eficiência econômica entre as empresas de saneamento básico no Estado de São Paulo.

\subsubsection{Objetivos específicos}

Os objetivos específicos do trabalho são:

- identificar e caracterizar o setor saneamento básico do Estado de São Paulo, através da aplicação empírica de um método adequado para a avaliação da eficiência econômica deste setor em esferas de abrangência: regional (empresa estadual) e locais (empresas municipais);

- formatar uma base de dados compatível ao método proposto, utilizando os dados do Sistema Nacional de Informações sobre Saneamento (SNIS), que faz parte do Programa de Modernização do Setor de Saneamento (PMSS) do Ministério das Cidades, para o ano de 2002 (Brasil, 2004); e,

- aplicar o método à base de dados para avaliar as diferenças de eficiência entre empresas deste setor. 


\subsubsection{Estrutura de apresentação}

A introdução e os objetivos geral e específico deste trabalho estão descritos no capítulo 1. Em seguida é apresentado a revisão bibliográfica e o histórico do setor de saneamento básico que embasa o trabalho. No capítulo 3 apresentam-se modelo econômico e econométrico aplicados à base de dados. Os resultados e discussões são descritos no capítulo 4 e as conclusões são apresentadas no capítulo 5. 


\section{REVISÃO DE LITERATURA}

\subsection{Coleta, distribuição e devolução de um sistema de saneamento básico}

Sem um tratamento adequado de seu resíduo, o sistema de esgotamento poderá induzir a uma deterioração do corpo receptor, de acordo com Soares et al. (2002). Isso pode tornar inviável o uso da água de rios, lagos e reservatórios para o consumo e até mesmo para irrigação.

As características técnicas das operações de saneamento podem ser ordenadas, a começar pela coleta de água e seu tratamento, distribuição pelas redes até ponto de consumo e a coleta e devolução do esgoto tratado ao meio. Assim, as operações podem ser ordenadas e foram detalhadas, segundo North West Water (1994) ${ }^{2}$, citado por Turolla (1999), da seguinte forma:

1. Coleta e armazenamento bruto:

A "água bruta" é a água que pode ser coletada de rios e lagos ou pode vir de aqüíferos através de poços artesianos. É considerada fresca, mas não pura, uma vez que pode apresentar risco de contaminação (por dejetos animais, por exemplo). Locais em que a demanda pela água é maior nem sempre apresentam fontes naturais de armazenagem. Nesses casos, são construídos reservatórios para armazenamento da “água bruta”. Isso facilita o processo de limpeza da água, através da decantação, mas sem esquecer que a fonte e a rede coletoras são determinantes quanto classificação da qualidade da água.

${ }^{2}$ NORTH WEST WATER. The advanced water cicle. North West Water Groups PLC, 1994. 


\section{Tratamento da água:}

Existem diversas etapas no processo de tratamento da água: peneiração, controle de pH com produtos químicos, sedimentação ou flotação de sólidos, filtração primária e secundária (com areia fina, membranas, carbono ativado), desinfecção bacteriológica, redução do carbonato de cálcio são os mais comuns. No caso água marinha a dessalinização é necessária.

3. Rede de distribuição:

As redes são responsáveis pelo transporte da água dos reservatórios até as estações de tratamento. Posteriormente a água tratada é conduzida até os pontos de consumo, através de canos e tubos.

Após o consumo a água residual é descartada através da rede de esgoto. É importante notar que a rede esgoto não deve receber águas pluviais. As águas das chuvas devem ser drenadas por uma rede específica.

4. Tratamento de esgoto:

O processo de tratamento de esgoto inicia-se com a separação de sólidos, com peneiras (ou grades, ou telas) que podem ser de 3 diferentes tipos e com desareação, através da sedimentação. O tratamento primário, começa com o processo de decantação, é utilizado para separar sólidos que se depositam (lodo) e depois o fluxo passa pela peneira rotativa que separa sólidos com granulação superior aos furos das telas. Tratamento secundário é realizado em tanques de aeração onde microorganismos aeróbios removem a matéria orgânica existente no esgoto, transformando-a em gás carbônico, água e material celular (lodo ativado $^{3}$ ), depois de passar pelo decantador secundário. Esse processo utiliza o lodo ativado, bombeando ar para que as bactérias circulem pelo tanque de resíduo e o efluente do decantador secundário pode retornar ao corpo receptor ou pode ter a função de reuso na própria estação ou atividades menos nobres. $\mathrm{O}$ esgoto em tratamento necessita alcançar alguns padrões de qualidade, como

\footnotetext{
${ }^{3}$ Material celular gerado pelos microorganismos anaeróbios, depois de decantado.
} 
índices de qualidade exigidos pelo Ministério do Meio Ambiente e estar apta a retornar ao ambiente. O lodo é o resíduo gerado dessa etapa e requer certos tratamentos e cuidados. Soluções alternativas podem ser tomadas como: a água pode ser retirada, se economicamente viável, aquecendo-se o lodo resultante e assim, este liberará metano produzindo energia. O material seco restante pode ser utilizado como fertilizante, incinerado e como matéria prima para construção civil.

O sistema de saneamento pode ser representado, a seguir:

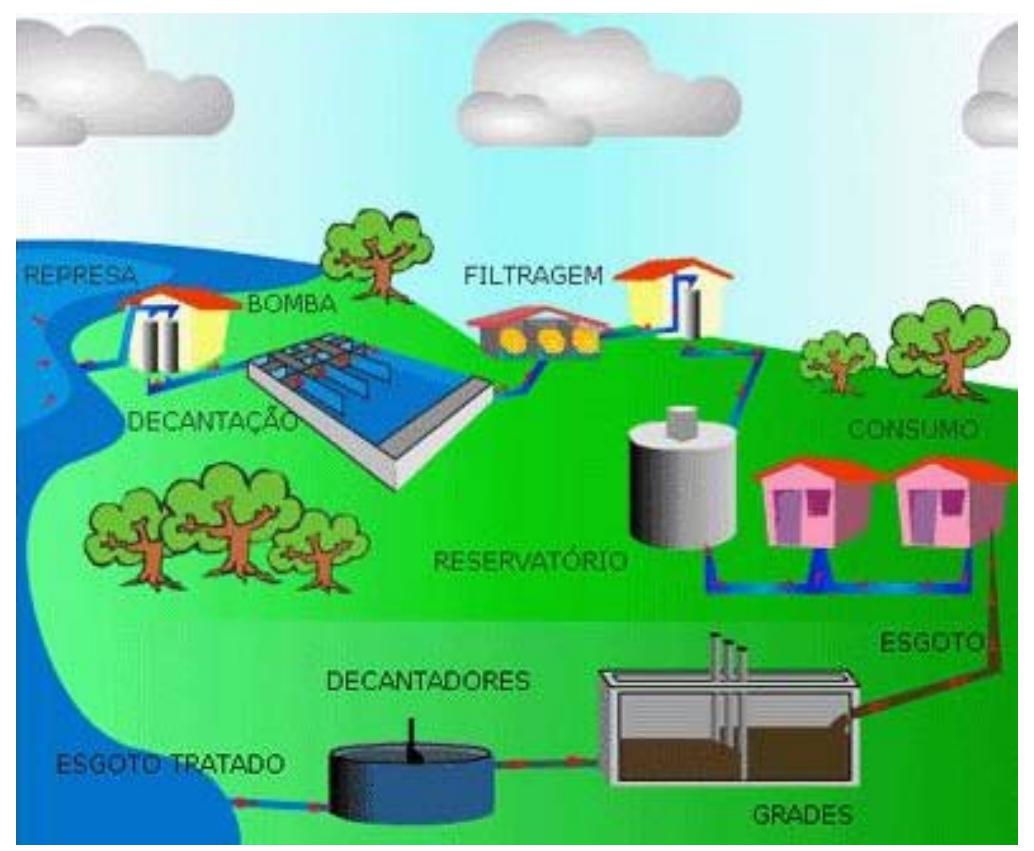

Figura 1 - Sistema de saneamento básico

Fonte: Companhia de Saneamento Básico do Estado de São Paulo (SABESP) (2003)

O marco da gestão dos recursos hídricos pode ser identificado pela legislação do "Código das Águas", de 1934, que prioriza o abastecimento público, mas é deficiente até hoje, pois ainda não se adaptou plenamente para controlar questões referentes a balanços hídricos de bacias hídricas, contaminação da água e conflitos de usuários e também sua interdependência. 
Atualmente a Agência Nacional das Águas (ANA), criada em junho de 2000, com a missão de regular o uso da água de rios e lagos de domínio da União e implementar o Sistema Nacional de Gerenciamento de Recurso Hídricos. Analisa uma melhor adequação para essas questões, assim como uma aplicação efetiva de uma nova regulamentação, sendo capaz de determinar domínios das bacias hídricas, ou seja, direitos e deveres de municípios da nascente a foz, outorgar a disputa de direito de uso da água, determinar subsídios e pagamentos pelo uso da água, por exemplo.

Assim, o uso deve ser gerido para que este recurso não gere externalidades negativas no bem-estar das pessoas. Ou seja, tornando-se um bem escasso devido ao consumo inadequado, retorno ao meio sem o mínimo de qualidade exigida para o consumo ou ainda tornando-se um veículo dos vetores transmissores de doenças gerando danos à saúde.

\subsection{O sistema de saneamento e sua importância}

Saneamento pode ser definido como o "controle de todos os fatores do meio físico do Homem que exercem ou podem exercer efeito deletério sobre seu bem-estar físico, mental e social”, segundo a Organização Mundial de Saúde (OMS) (1993).

O setor de saneamento abrange uma grande gama de atividades tais como: abastecimento de água, esgotamento sanitário, coleta de lixo ou resíduos sólidos e drenagem urbana. Saneamento básico engloba somente o abastecimento de água e esgotamento sanitário. O presente trabalho será realizado sob este enfoque.

O espaço geográfico também exerce papel determinante na água, pois as diferenças climáticas, geográficas e topográficas entre as regiões, podem alterar tanto a quantidade, quanto a qualidade. Com o aumento das aglomerações humanas e de suas atividades, houve a necessidade de se criar novas tecnologias para atender a demanda, tanto em relação à estocagem e tratamento da água para o consumo humano, quanto à sua devolução ao meio, depois de utilizada (Amaral, 2000). 
Água potável é limpa e transparente, não contém microorganismos nem substâncias que possam transmitir e/ou causar doenças ao ser humano. Para que a água distribuída na casa das pessoas seja potável, as empresas de saneamento básico procuram obtê-la de fontes limpas e utilizam diversas tecnologias que controlam a sua qualidade para garantir a saúde da população.

Essa garantia de qualidade deve ser assegurada, pois o consumidor não consegue analisar padrões de qualidade, níveis e parâmetros específicos para consumo humano. A verificação fica somente a nível sensorial, como cor, cheiro e gosto, não sendo possível checar outros parâmetros, como: bacteriológicos, metais pesados, $\mathrm{pH}$, condutibilidade etc. Assim a captação, tratamento, distribuição e devolução do efluente ao meio, devem ser fiscalizadas para que os direitos previstos pela Lei sejam garantidos.

Resumidamente, os objetivos principais do saneamento básico no Brasil são ordenados da seguinte forma:

- $\quad$ Abastecimento de água (em quantidade e qualidade);

- Coleta e disposição de águas residuárias (esgotos domésticos e resíduos líquidos industriais).

Os principais problemas encontrados no setor de abastecimento de água nas Américas estão relacionados com: deficiências no abastecimento; à desinfecção inadequada da água para consumo humano e, ao aumento da contaminação de águas subterrâneas e superficiais devido à falta de um sistema de esgotamento sanitário adequado (OPAS, 2002).

Estudos epidemiológicos não conseguem isolar e captar os impactos de intervenções governamentais, já que existem muitas interações a serem consideradas (Heller, 1997). Assim, intervenções governamentais de infra-estrutura apresentam caráter necessário, mas não suficientes. Para que se tornem suficientes, as intervenções devem estar aliadas a ações de conscientização e educação ambiental, assim como ações com enfoque na higiene básica humana. 
Um exemplo de intervenção seria a implantação ou ampliação de serviços de saneamento básico. Alguns estudos epidemiológicos tendem a subestimar os efeitos de obras de abastecimento de água e superestimar os efeitos de obras de esgotamento sanitário, por considerar que o tratamento do resíduo gerado após o consumo da água seja mais eficiente que o tratamento para o consumo. Mas obras de infra-estrutura, referentes à água e esgoto, devem ser consideradas em conjunto com outras frentes de mesma relevância, como ações de higiene básica para mitigação do risco de doenças e educação ambiental e ecológica, pois os impactos de cada ação isolada não seriam captados diretamente na saúde humana. Deve-se considerar que as ações de intervenção e essas outras frentes de combate a doenças e saneamento básico são complementares e interdependentes.

Outro fator a ser considerado na análise das ações sanitárias é de que a parcela da população sujeita à falta de saneamento geralmente reside em locais impróprios para habitação, impactando e gerando conseqüências à saúde e ao meio ambiente. Neste caso, as perdas econômicas estão relacionadas à produção e a produtividade de trabalho. A morbidade (dias de permanência em internações hospitalares) e a mortalidade, no caso de doenças de veiculação hídrica, podem diminuir a produtividade do trabalhador que está debilitado e conseqüentemente a produção total. Um outro custo que pode ser citado é a reposição das condições anteriores às explorações ou degradações. A poluição dos rios, principalmente no caso de populações que residem em lugares impróprios para habitação, não terá atenção prioritária, já que os gastos serão destinados a itens de consumo imediato, como alimentos, vestuários e medicamentos (Banco Mundial, 2002).

De fato, determinantes ambientais e sociais causam impactos sobre a saúde. Podem ser relatados de acordo com a transmissão de agentes e doenças infecciosas, de excreta humana e animal, exposição a compostos químicos tóxicos e/ou radioativos, degradação ambiental, demanda por medicina preventiva, produção de todo tipo de resíduos e de vetores de doenças. Porém, devido a existência de interdependência entre 
as variáveis ambientais, sociais, econômicas, culturais entre outros fatores, torna-se difícil a definição e a determinação do indivíduo saudável ${ }^{4}$ (OMS, 2003).

De acordo com estatísticas internacionais, cerca de $80 \%$ das doenças e $30 \%$ das mortes são causadas pela ingestão de água contaminada (Ponzetto, 2002). As doenças vinculadas à má qualidade do sistema de saneamento básico estão contidas no quadro 1:

\begin{tabular}{|c|l|}
\hline $\begin{array}{c}\text { Falta ou } \\
\text { Inadequação }\end{array}$ & \multicolumn{1}{|c|}{ Doenças } \\
\hline Água & $\begin{array}{l}\text { Hepatite, poliomielite, cólera, febre tifóide e paratifóide, } \\
\text { diarréias, conjuntivite, leptospirose, esquistossomose, malária, } \\
\text { verminoses. }\end{array}$ \\
\hline Esgoto & Diarréias, verminoses, esquistossomoses, cisticercose, teníase. \\
\hline
\end{tabular}

Quadro 1 - Doenças relacionadas à falta ou inadequação de saneamento básico

Fonte: Brasil (2003)

No Brasil, existe uma grande preocupação com relação ao saneamento e à saúde e a interligação dessas suas áreas. Essa preocupação pode ser demonstrada com a Pesquisa Nacional de Saneamento Básico (PNSB) realizada em 2000, pelo Instituto Brasileiro de Geografia e Estatística (IBGE) e com o Diagnóstico dos Serviços de Água e Esgotos, do Sistema Nacional de Informação de Saneamento (SNIS) (Brasil, 2004). O diagnóstico informa que do volume total de esgoto produzido no país por dia, uma quantidade superior a 10 bilhões de litros são lançados, in natura, nos rios, lagos e mares. A preocupação ressaltada por Carmo \& Távora (2003), quanto ao risco para a

\footnotetext{
${ }^{4}$ Renda e nível social, educação, ambiente físico ou acesso aos recursos naturais, suporte social, genética do indivíduo, acesso a serviços de saúde, sexo do indivíduo.
} 
vida humana decorre devido ao fato de que os rios serem responsáveis por $51 \%$ da água consumida.

É possível observar que as internações pelo motivo de doenças do sistema digestivo, no número total de internações possuem maior incidência nas faixas etárias extremas. Conforme pode ser observado na figura 2, a seguir:

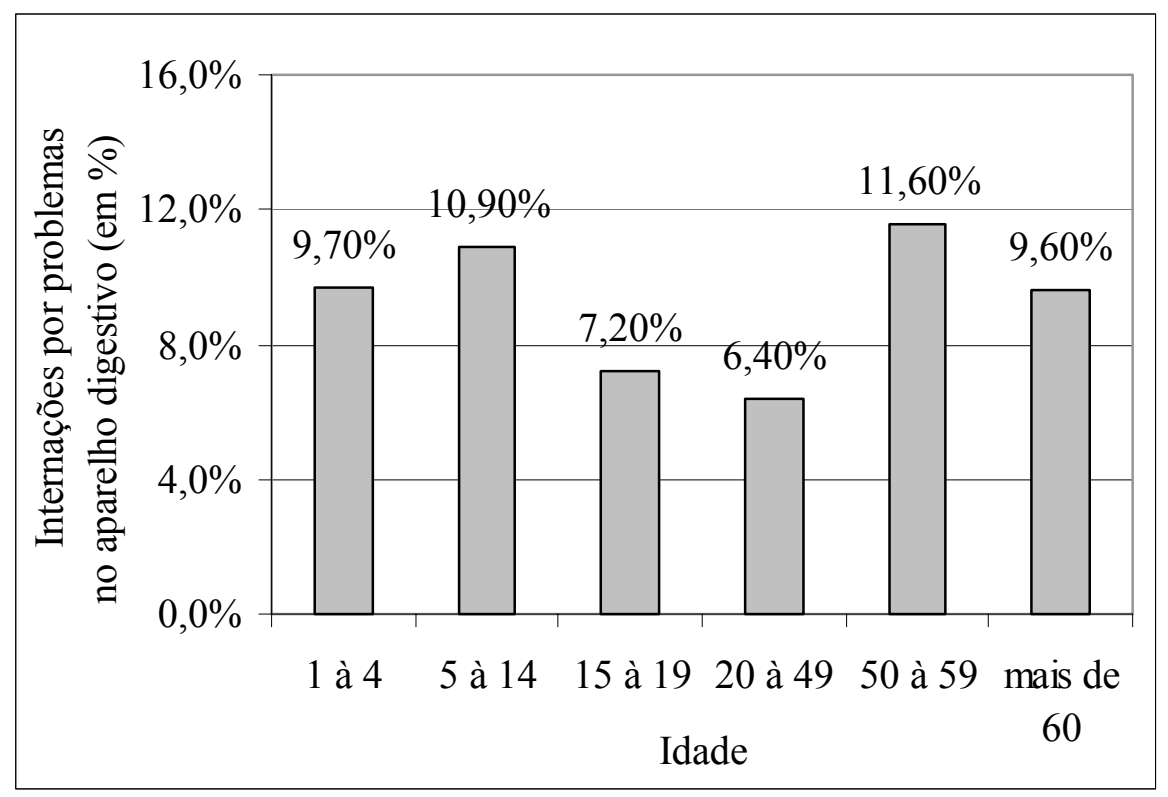

Figura 2 - Porcentagem de internações por motivos de problemas no aparelho digestivo, no Brasil, para o ano de 2001

Fonte: Brasil (2001)

Seguindo esta visão epidemiológica, esses dados podem revelar que a morbidade hospitalar, ou seja, as internações hospitalares, por doenças referentes ao aparelho digestivo na faixa etária abaixo dos 14 anos e acima dos 50, apresentam-se em maior freqüência, conforme as informações da figura 2 acima. Doenças de origens gastro-intestinais geralmente ocorrem por veiculação hídrica. Assim, evidencia-se a preocupação existente quanto às inter-relações no sistema de saneamento básico, citadas 
anteriormente, apesar de não ser possível determinar a relação de causalidade direta ou indireta no que se refere à qualidade da água, assim como, as estatísticas apresentadas pelo SUS, com informações não permitem e também não diferenciam os motivos mais detalhados pelo qual houve a internação.

Apesar das dificuldades para relacionar dois pontos de vista, epidemiológico e inadequação sanitária, alguns autores realizaram estudos, que tentam, indiretamente, interligar poluição hídrica e saúde. Um dos estudos que pode ser destacado foi o realizado por Motta et al. (1992). O autor estima perdas econômicas associadas ao custo da saúde humana, no Brasil. Em sua pesquisa, o autor analisa que parte da produção é sacrificada devido à perda de dias de trabalho por morte ou doenças ligadas à poluição hídrica doméstica. E quando a doença ocorre, a outra forma de mensurar a perda é dada de acordo com os gastos médicos que poderiam estar sendo aplicados e utilizados para outros fins. O total das perdas seria a soma da produção sacrificada por morbidade, mortalidade e os gastos médicos, mas não leva em consideração o decréscimo do nível de bem-estar dos agentes econômicos, causados pela doença, desconforto, dor e outras restrições. As estimativas encontradas pelo mesmo autor, em seu trabalho são de que $60 \%$ dos óbitos e $90 \%$ das causas de morbidades estão ligadas às condições impróprias de saneamento básico.

Segundo Mendonça et al. (2003), são verificados altos índices de internação hospitalar pela carência de saneamento básico no Brasil, o que reflete sobre a saúde da população em particular em regiões mais carente como no norte e nordeste. O resultado desta pesquisa, diz que perdas podem impactar negativamente na produtividade do trabalho gerando supostamente uma diminuição no produto nacional devido às perdas de produtividade do trabalho.

Heller et al. (2003), estudou o impacto do saneamento básico, do meio ambiente e de práticas higiênicas sobre a ocorrência de diarréia entre crianças menores de 5 anos, residentes na área urbana. Nesse estudo foi possível detectar que a diarréia está associada veiculação hídrica como inadequadas condições de saneamento básico reservatórios e tratamento de água, rede coletora de esgoto e tratamento deste antes da 
devolução ao corpo hídrico - e, além disso, pode estar associado a outros fatores que ocasionam o aumento a incidência de diarréias como a falta de higiene alimentar, armazenamento e disposição final do lixo, presença de animais vetores de doenças e ocorrência de acúmulo de água ou inundação em terrenos de residências. Assim, o autor conclui em seu estudo que, de fato existe falta de adequação e ainda outras prioridades a serem atendidas além das intervenções no setor de saneamento.

Em outro estudo de caso, realizado por Heller (1998), analisou-se a associação entre saneamento ambiental (água, lixo, drenagem, higiene básica) e saúde. Esse estudo foi realizado na cidade de Betim, na região metropolitana de Belo Horizonte, Minas Gerais, a partir de uma amostra de 1000 crianças até 5 anos de idade com diagnóstico de diarréia e a mesma quantidade de crianças selecionadas aleatoriamente no município. Do risco total, passível de ser mensurado, foram calculados os riscos relativos de cada fator ambiental sobre a ocorrência de diarréia, assim como os respectivos intervalos de confiança. Os riscos relativos de ocorrência de diarréia na cidade de Betim podem ser representados pelos resultados obtidos pelo autor, destacando-se: a inadequação das condições de saneamento básico representado 2,38\%, num intervalo de confiança de $1,8 \%$ a $3 \%$ do risco total de se adquirir diarréia, não acesso a facilidades sanitárias 1,91\%, num intervalo de $1,5 \%$ a 3,8\% do risco total, assegurar cuidados no armazenamento de água representa um risco relativo de 1,91\%, entre $1 \%$ e $3,7 \%$ de intervalo e falta de higiene alimentar apontando um risco relativo de $2,87 \%$ no intervalo de confiança de $1,6 \%$ a $5,1 \%$ de se contrair diarréia na cidade de Betim.

Carmo \& Távora (2003) concordam com o estudo de Heller ao dizer que, investir no saneamento do município melhora a qualidade de vida da população, assim como a preocupação com a proteção ao meio ambiente urbano, podem evitar a incidência de doenças transmissíveis pela água como cólera, disenteria entre outras. Combinado as políticas de saúde e habitação, o saneamento básico e do meio ambiente, o número de internações hospitalares podem vir a diminuir, já que o conjunto dessas políticas tendem a não comprometer e ate contribuir para conservação dos recursos 
hídricos disponíveis, o abastecimento de água de qualidade e coleta e tratamento do esgoto.

Numa análise empírica da demanda por saneamento no Brasil, Mendonça et al. (2003) conclui que embora exista a idéia de que o déficit de saneamento seja gerado preponderantemente por fatores ligados à falta de oferta desses serviços, o fator acesso ao saneamento básico é considerado pelas pessoas como uma característica secundária dos domicílios. Outro fato detectado seria de que o custo de ampliação da rede de esgotamento pode ser reduzido pela facilidade de acesso à água, e que os benefícios de políticas educacionais, mostrar-se-iam eficientes em um sistema completo de saneamento num programa eficiente de investimentos no setor.

\subsubsection{Evolução histórica}

As inter-relações do sistema entre saúde, saneamento, conservação ambiental e crescimento econômico, são fundamentais para o planejamento sistemático de saneamento básico, enfatizando a eficiência deste setor.

Desde o início das civilizações, a preocupação com a infra-estrutura, ou sistemas de tratamento de água e esgoto doméstico, é um assunto importante na qualidade de vida e saúde pública. $\mathrm{O}$ armazenamento de água em potes de barros, surge por volta de 9.000 A.C. A invenção da cerâmica, 2.000 anos depois, foi fundamental para o incremento dos cuidados na capacidade de armazenamento (Silva, 1998).

A primeira represa para armazenar água, data de 2900 A.C., e foi construída pelo faraó Menes para abastecer Memphis, capital do Egito. Existem relatos da preocupação com abastecimento de água e hábitos sanitários em culturas antigas, no vale do Indo, Índia. Por volta de 2.000 A.C., os povos egípcios e cretenses, apresentavam em suas civilizações noções de tratamento da água, como cuidados com fervura e filtragem com cascalhos, e engenharia sanitária com o destaque para as redes de escoamento, aquedutos e cuidados com o destino dos dejetos, podendo ser destacada a presença de 
canais que transportam água até as residências, sanitários e rede de esgotamento e drenagem nas ruas (Silva, 1998).

A civilização greco-romana também se destacou no esforço em apresentar relações causais de determinantes físicos do ambiente sobre a saúde. As práticas sanitárias coletivas, com as termas, banhos públicos, aquedutos, redes de esgotos e tendo como marco histórico a Cloaca Máxima de Roma. A Cloaca Máxima tem importância histórica por ser capaz de drenar o esgoto urbano e livrar o centro cívico da cidade das ameaças de inundações e possível contaminação urbana. Antes de sua construção, o esgoto in natura e as águas de chuva eram despejados diretamente no rio.

No ocidente, a primeira estação de tratamento de água foi inaugurada em Londres, em 1829. A água do rio Tâmisa era filtrada pela areia e o tratamento feito com adição de cloro. Em 1951, a adição de flúor também passou a ser incorporada no tratamento da água.

As ações, desde a antiguidade até o atual momento, apresentam enfoque de ação sanitarista, mas que está baseado nos fatores que impactam na saúde pública e meio ambiente.

Alguns autores afirmam que a preocupação com o termo saúde pública passou a existir a partir do momento em que os indivíduos perceberam que viver em sociedade era ao mesmo tempo estar exposto a riscos e perigos à saúde humana. A definição de saúde pública é dada pelo desenvolvimento e crescimento da ação coletiva social que evoluiu na mesma medida dos hábitos, regras e leis, referentes à prática de saneamento (Heller, 1997).

Heller (1997) agrupa estudos que buscaram relacionar saneamento, saúde e pesquisas de classificação de doenças de acordo com características ambientais em ordem cronológica em vários países. O mesmo autor cita dois estudo na França, no final do século XIX, os quais demonstram um aumento na esperança de vida no período posterior a melhoria nos serviços de saneamento básico. O outro estudo, realizado na Costa Rica, entre a década de 40 e 80, relata uma relação inversa da taxa de mortalidade 
por diarréia e de doenças gastro-intestinais, dado o aumento da taxa de cobertura populacional por abastecimento de água.

Apesar de apresentarem alguns resultados e conclusões importantes, esses estudos realizados até a década de 60 , são marcados por incertezas no que tange a relação entre tratamento de água, saneamento, práticas de higiene básica e os impactos sobre saúde. As incertezas são referentes à veracidade das informações, a disponibilidade de dados históricos para realização de análises ao longo de um período de tempo e ainda às dificuldades no estabelecimento da relação de causa-efeito entre doenças e falta de saneamento básico.

Em 1961, foi elaborado a "Carta de Punta del Este", pelos países das Américas, definindo novas diretrizes sobre o atendimento de serviços de água e esgoto, sendo estabelecido que, a partir daquele momento, as metas eram de que $70 \%$ das populações urbanas deveriam ser atendidas pelos serviços, assim como $50 \%$ das populações rurais. Essas metas deveriam ser cumpridas de acordo com planos decenais (Turolla, 2002).

A evolução setor pode ser observada a partir da década de 70 , já que os países teriam que alcançar as metas. Foi possível se observar que somente os países desenvolvidos conseguiram atingir as metas das diretrizes estabelecidas na década anterior. Países que não conseguiam atingir as metas estabelecidas pela carta, justificavam-se através do argumento da falta de evolução tecnológica e da não intervenção governamental.

Economicamente e financeiramente, medidas profiláticas, ou seja, que tem como objetivo evitar o aparecimento de doenças (que englobam programas como, por exemplo, o de re-hidratação oral, vacinas e controle da malária e ainda o de incentivo ao aleitamento materno $)^{5}$ são menos custosos uma medida preventiva como, intervenção na infra-estrutura sanitária de um município ou conscientização e educação ambiental, por exemplo. Evidentemente essa comparação foi feita com relação aos custos que

\footnotetext{
5 Atenção Primária a Saúde (programa de fomento internacional do UNICEF).
} 
incorporam as tarifas e taxas pagas pela sociedade. Uma análise mais adequada poderia ser feita através da dedução desses encargos sociais e sua confrontação com o custo de tratamentos curativos.

A preocupação internacional torna-se mais visível no início de 80 , quando a Organização das Nações Unidas (ONU) (2002) e United Nations Educational Scientific and Cultural Organization (UNESCO) (2003), lança a "Década Internacional do Abastecimento e Esgotamento Sanitário: 1980-1990" que visava aprofundar a discussão e aumentar a compreensão das relações entre saneamento básico, saúde e preocupação ecológica e ambiental com recurso água.

Essa preocupação ecológica e ambiental, a partir dos anos 90, passa a ser ressaltada pelas ações de combate a inadequação de saneamento básico, criando de um cenário econômico que incorpora variáveis que contemplam informações ambientais, conceitos de sustentabilidade (criação de indicadores de sustentabilidade ambiental) dada a preocupação com a escassez de recursos naturais. Novas leis, protocolos e acordos firmados entre os países, como pode ser observado no relatório do Banco Mundial de 1992. Isso também pode ser visto, por exemplo, pelo estudo de Kamogawa (2004), que realiza uma análise de crescimento econômico sob o pressuposto da existência de dessa preocupação ambiental, citando o Protocolo de Kyoto e Código da Águas. O meio ambiente deve ser tratado como um recurso ambiental ${ }^{6}$, no sentido econômico, e não visto somente como oportunidade de extração ou descarte de resíduos.

\subsubsection{Evolução do setor no Brasil}

As deficiências existentes com relação à quantidade e qualidade no serviço de abastecimento são problemas históricos no Brasil. Isso decorre da falta de fiscalização e até mesmo da inexistência de alguns parâmetros relativos à qualidade. $\mathrm{O}$

\footnotetext{
6 Recurso ambiental: bens e serviços que podem ser utilizados diretamente da natureza, sem transformação. São escassos e podem ser considerados como fator de produção (insumos) ou como bens e serviços de consumo (Randall, 1987).
} 
Governo do Estado de São Paulo destaca-se frente aos demais estados do Brasil, devido às ações governamentais de atendimento à demanda por serviços de saneamento básico que acompanhou o crescimento da urbanização dos municípios. Segundo Turolla (2002), alguns dados de meados da década de 30 , quando confrontados com observações do censo de 1940, demonstram que houve incentivos à construção de sistemas de água e esgoto, os serviços de saneamento básico atingissem cerca de 57\% dos 369 municípios existentes no estado, sendo que 40 destes já contavam com tratamento químico em estações apropriadas e 127 dispunham de rede de esgoto.

Na década de 1950, foi criada a Fundação Nacional da Saúde (FUNASA), o órgão responsável pelo combate de epidemias de saúde e atuante em operações de assistência dos serviços de saneamento dos municípios. Tinha como critério a alocação dos recursos financeiros para ações de saneamento a partir de avaliações epidemiológicos.

Após o Golpe Militar de 1964 foi instituído um regime novo de governo. Uma das metas do governo militar era a ampliação da cobertura dos serviços de saneamento. Apesar disso, nesta época, as políticas governamentais para o setor foram pontuais, esporádicas e não coordenadas, uma vez que aconteciam de acordo com a pressão da demanda devido ao rápido processo de urbanização e geralmente essa ação acontecia em detrimento da produção de outros bens e serviços. Segundo Turolla (1999), os efeitos desse posicionamento governamental frente à necessidade de políticas alternativas mais eficazes e a falta de investimentos nesse setor foram refletidos em altas taxas de mortalidade infantil e no agravamento da deterioração sanitária.

A evolução do setor de saneamento básico pode ser apresentada, segundo Soares et al. (2002), em conjunto com ações que estariam ligadas à saúde. A evolução do setor pode ser observada através do quadro 2, a seguir: 


\begin{tabular}{|c|c|}
\hline Perí & Características \\
\hline $\begin{array}{c}\text { Fim do } \\
\text { séc.XIX e } \\
\text { início do } \\
\text { séc.XX }\end{array}$ & $\begin{array}{l}\text { - Estruturação das ações de saneamento sob o paradigma do higienismo, isto } \\
\text { é, como uma ação de saúde, contribuindo para a redução da morbi- } \\
\text { mortalidade por doenças infecciosas, parasitárias e até mesmo não } \\
\text { infecciosas. } \\
\text { - Organização dos sistemas de saneamento como resposta a situações } \\
\text { epidêmicas, mesmo antes da identificação dos agentes causadores das } \\
\text { doenças. }\end{array}$ \\
\hline $\begin{array}{c}\text { Início do } \\
\text { séc.XX } \\
\text { até a dec. }\end{array}$ & $\begin{array}{l}\text { - Intensa agitação política em torno da questão sanitária, com a saúde } \\
\text { ocupando lugar central na agenda pública: saúde pública em bases } \\
\text { científicas modernas a partir das pesquisas de Oswaldo Cruz. } \\
\text { - Incremento no número de cidades com abastecimento de água e da } \\
\text { mudança na orientação do uso da tecnologia em sistemas de esgotos, em um } \\
\text { processo marcado pelo trabalho de Saturnino de Brito, que defendia planos } \\
\text { estritamente relacionados com as exigências sanitárias (visão higienista). }\end{array}$ \\
\hline & $\begin{array}{l}\text { - Elaboração do Código das Águas (1934), que representou o primeiro } \\
\text { instrumento de controle do uso de recursos hídricos no Brasil, } \\
\text { estabelecimento do abastecimento público como prioritário. } \\
\text { - Coordenação das ações de saneamento (sem prioridade) e assistência } \\
\text { médica (predominante) essencialmente pelo setor da saúde. }\end{array}$ \\
\hline $\begin{array}{c}\text { Dec.50 e } \\
\text { dec. } 60\end{array}$ & $\begin{array}{l}\text { - Surgimento de iniciativas para estabelecer as primeiras qualificações e os } \\
\text { primeiros parâmetros físicos, químicos e bacteriológicos definidores da } \\
\text { qualidade das águas, por meio de legislações estaduais e em âmbito federal. } \\
\text { - Permanência das dificuldades em relacionar os benefícios do saneamento } \\
\text { com a saúde restando dúvidas inclusive quanto sua existência efetiva. }\end{array}$ \\
\hline
\end{tabular}

Quadro 2 - Evolução histórica dos aspectos de saúde pública e meio ambiente no setor de saneamento no Brasil 


\begin{tabular}{|l|l|}
\hline Períodos & \multicolumn{1}{|c|}{ Características } \\
\hline Dec.70 & $\begin{array}{l}\text { - Predomínio da visão de que avanços nas áreas de abastecimento de água e } \\
\text { de esgotamento sanitário em países em desenvolvimento resultariam na } \\
\text { redução das taxas de mortalidade, ausentes dos programas de atenção } \\
\text { primária à saúde. } \\
\text { - Consolidação do Plano Nacional de Saneamento (PLANASA), com ênfase } \\
\text { no incremento dos índices de atendimento por sistemas de abastecimento de } \\
\text { água. } \\
\text { - Inserção da preocupação ambiental na agenda política brasileira, com a } \\
\text { consolidação dos conceitos de ecologia e meio ambiente e a criação da } \\
\text { Secretaria Especial de Meio Ambiente (SEMA), em 1973. }\end{array}$ \\
\hline Dec.80 & $\begin{array}{l}\text { Formulação mais rigorosa dos mecanismos responsáveis pelo } \\
\text { comprometimento das condições de saúde da população, na ausência de } \\
\text { condições adequadas de saneamento (água e esgoto). } \\
\text { - Instauração de instrumentos legais de âmbito nacional definidores de } \\
\text { políticas e ações do governo brasileiro, como a Política Nacional de Meio } \\
\text { Ambiente (1981). } \\
\text { - Revisão técnica das legislações pertinentes aos padrões de qualidade da } \\
\text { água. } \\
\text { conservação do meio ambiente e particularmente dos recursos hídricos, } \\
\text { refletindo diretamente no planejamento das ações de saneamento. } \\
\text { - Instituição da Política e do Sistema Nacional de Gerenciamento de } \\
\text { Recursos Hídricos (Lei 9.433/97). } \\
\text { - Incremento da avaliação dos efeitos e conseqüências de atividades de } \\
\text { saneamento que importem impacto ao meio ambiente. }\end{array}$ \\
\hline Eec.90 e
\end{tabular}

Quadro 2 - Evolução histórica dos aspectos de saúde pública e meio ambiente no setor de saneamento no Brasil

Fonte: Soares et al. (2002) 
Segundo a PNSB, entre 1964 à 1985, a política e as ações referentes ao setor de saneamento foram centralizadas pelo governo federal fazendo com que os governos locais se limitassem somente à operação do serviço (Brasil, 2004). Os recursos para o financiamento do setor de saneamento básico passaram a ser gerenciado pelo Banco Nacional de Habitação (BNH), através do Plano Nacional de Saneamento (PLANASA), incentivando a criação de companhias estaduais, sob forma de economia mista, e a concessão dos serviços pelos municípios aos estados. O objetivo principal era a eliminação do déficit do abastecimento de água e do esgotamento sanitário.

Em parceria com o IBGE, o Ministério da Saúde, realizou em 1974 o primeiro levantamento sobre saneamento no Brasil. Em 1977, o IBGE ficou responsável por toda a pesquisa. Mesmo que tardio, desorganizado e necessitando de reformulações, esse fato demonstra o interesse governamental na investigação das interfaces saneamento básico e saúde.

O Governo Federal estipulou metas para o setor, na década de 80, marcadas por grande otimismo, ou seja, o atendimento dos serviços deveria alcançar $90 \%$ da população urbana por abastecimento de água e $65 \%$ da população por serviços de esgotamento sanitário. No início dessa mesma década, aliada ao modelo de poder e recursos centralizado do $\mathrm{BNH}$, o país enfrentou uma crise econômica que resultou numa política seletiva, privilegiando somente grandes empresas estaduais de grande porte e que necessitavam de altos níveis de investimento e que tinhas recursos comprometidos devido ao alto grau de endividamento. Isso acabou prejudicando prefeituras e interesses locais devido a não aderência ao plano pelos municípios, dificultando o cumprimento das metas estipuladas no início da década.

Com a extinção do BNH, em 1986, a Caixa Econômica Federal tornou-se responsável pelos papéis referentes às dívidas contraídas pelas empresas estaduais e pelo financiamento do Sistema Financeiro do Saneamento, impondo fortes restrições orçamentárias e redução de oferta de recursos a todo setor de saneamento.

Após o colapso da PLANASA, o único mecanismo articulado de financiamento do setor em análise, a política nacional de saneamento permaneceu por 
toda a década de 90 sem regulamentação (Turolla, 2002). O mesmo autor destaca aspectos relevantes desse setor como: descompassos do aparato legal, evolução do marco legal entre outros pontos conforme pode ser visto no quadro 3, a seguir:

\begin{tabular}{|c|c|c|c|}
\hline Programa & Período & Financiamento & Benefícios / Desdobramentos \\
\hline PRONURB & $1990 / 1994$ & $\begin{array}{c}\text { FGTS e } \\
\text { contrapartida }\end{array}$ & $\begin{array}{l}\text { População urbana em geral, prioridade } \\
\text { a baixa renda. }\end{array}$ \\
\hline $\begin{array}{l}\text { PRÓ- } \\
\text { SANEAMENTO }\end{array}$ & 1995 & $\begin{array}{l}\text { FGTS e } \\
\text { contrapartida }\end{array}$ & $\begin{array}{l}\text { Preponderantemente em áreas com } \\
\text { famílias com renda de até } 12 \text { salários } \\
\text { mínimos. }\end{array}$ \\
\hline PASS & 1996 & $\begin{array}{c}\text { OGU e } \\
\text { contrapartida } \\
\text { BID E BIRD }\end{array}$ & $\begin{array}{l}\text { População de baixa renda e municípios } \\
\text { com maior concentração de pobreza. }\end{array}$ \\
\hline PROSEGE & $1992 / 1999$ & $\begin{array}{l}\text { BID e } \\
\text { contrapartida }\end{array}$ & $\begin{array}{l}\text { População de baixa renda, priorizando } \\
\text { aquelas com renda de até } 7 \text { salários } \\
\text { mínimos. }\end{array}$ \\
\hline FUNASA-SB & $\begin{array}{l}\text { desde } \\
1950\end{array}$ & $\begin{array}{c}\text { OGU e } \\
\text { contrapartida }\end{array}$ & $\begin{array}{l}\text { Apoio técnico e financeiro no } \\
\text { desenvolvimento de ações com base } \\
\text { em critérios epidemiológicos e sociais. }\end{array}$ \\
\hline PMSS I & $1992 / 2000$ & $\begin{array}{l}\text { BIRD e } \\
\text { contrapartida }\end{array}$ & $\begin{array}{l}\text { Estudos e } \\
\text { estados e } \\
\text { nacional, municípios em âmia técnica aos } \\
\text { modernização empresarial e aumento } \\
\text { da cobertura de cobertura. }\end{array}$ \\
\hline
\end{tabular}

Quadro 3 - Principais programas federais em saneamento no Brasil, na década de 1990 


\begin{tabular}{|l|c|c|l|}
\hline Programa & Período & Financiamento & \multicolumn{1}{|c|}{ Benefícios / Desdobramentos } \\
\hline PMSS II & $1998 / 2004$ & $\begin{array}{c}\text { BIRD e } \\
\text { contrapartida }\end{array}$ & $\begin{array}{l}\text { Passa a financiar companhias do N, NE } \\
\text { e CO estudos de desenvolvimento } \\
\text { institucional. }\end{array}$ \\
\hline PNCDA & 1997 & OGU e & $\begin{array}{l}\text { Uso racional de água em prestadores de } \\
\text { serviços de saneamento, fornecedores e } \\
\text { segmento de usuários. }\end{array}$ \\
\hline FCP/SAN & 1998 & $\begin{array}{l}\text { FGTS, BNDES } \\
\text { e contrapartida }\end{array}$ & $\begin{array}{l}\text { Concessionários privados em } \\
\text { empreendimentos de ampliação de } \\
\text { cobertura em áreas com renda até 12 } \\
\text { salários mínimos. }\end{array}$ \\
\hline PROPAR & 1998 & BNDES & $\begin{array}{l}\text { Estados, municípios e concessionários } \\
\text { contratando para } \\
\text { viabilização de parceria público- } \\
\text { privado. }\end{array}$ \\
\hline PROSAB & 1996 & $\begin{array}{l}\text { Finep, CNPq, } \\
\text { CAPES }\end{array}$ & $\begin{array}{l}\text { Desenvolvimento de pesquisa em } \\
\text { tecnologia de saneamento ambiental. }\end{array}$ \\
\hline
\end{tabular}

Quadro 3 - Principais programas federais em saneamento no Brasil, na década de 1990 Fonte: Turolla (2002)

O quadro 3 acima, mostra que parte dos programas federais, da década de 1990, enfocava as desigualdades sócio-econômicas, ou seja, o destino da verba para saneamento contemplaria, com a maior parte dos recursos, os sistemas que não sobreviveriam sem auxílio ou subsídios governamentais. Dentre esses Pró-Saneamento e o PASS destacam-se por conseguir capturar mais de três quartos dos recursos federais no setor de saneamento.

No ano de 1999 a parceria entre o IBGE, a Secretaria Especial de Desenvolvimento Urbano da Presidência da República - SEDU/PR, a FUNASA e a 
Caixa Econômica Federal, resultou no início de 2000, na Pesquisa Nacional de Saneamento Básico (PNSB), contando também com a colaboração da OPAS nas áreas de planejamento e execução (IBGE, 2000).

Atualmente, no redesenho de políticas públicas para o setor, as variáveis a serem consideradas são: fortalecimento da participação municipal; a busca de novas parcerias, inclusive do setor privado; novas fontes de financiamento compatíveis com as atividades desenvolvidas; novo arranjo institucional; concessão de subsídios explícitos às camadas menos favorecidas por parte dos três níveis de governo; e atuação em bases empresariais. Assim, o Programa de Modernização do Setor de Saneamento (PMSS), se destaca por introduzir uma linha de aperfeiçoamento institucional e o financiamento tradicional. Esse programa pertence ao Sistema Nacional de Informação de Saneamento (SNIS) e reúne os esforços para avaliação política, mensuração de desempenho do setor, divulgando bases com dados para possíveis intervenções no setor.

O SNIS tem concebido e administrado o PMSS, no qual se faz um levantamento anual de informações sobre a prestação de serviços de água e esgoto, em caráter operacional, gerencial, financeiro, contábil e de qualidade de serviços prestados, desde 1995 até 2002, o "Diagnóstico dos serviços de água e esgoto" concebido pela SNSA do Ministério das Cidades. Essas informações devem servir de suporte para planejamento e execução de políticas públicas, ampliação de investimentos, construção de estratégias e avaliações dos serviços. Além desse suporte, os dados serão utilizados como importante fonte para análise de eficiência e eficácia das prestadoras de serviços.

\subsection{Análise econômica do setor}

Segundo o Ministério da Saúde, as prioridades de investimento em saneamento obedecem a critérios epidemiológicos para garantir que esses recursos cheguem aos municípios que necessitam reduzir a incidência de doenças causadas pela falta ou inadequação de saneamento e são amparadas também pela Lei no 8080 de 19 de setembro de 1990 (Brasil, 2003, 2004). 
O Ministério da Fazenda (MF) demonstra as despesas do governo, de acordo com o orçamento fiscal e de seguridade social da União ao longo dos anos, são separadas por funções (Brasil, 2004). Para a função saneamento e saúde, de 1980 até 1999, os gastos líquidos do governo apareciam em uma na mesma conta e representavam em média $3,65 \%$ do total de despesas do governo em cada ano. A partir de 2000, essas contas foram separadas e os gastos se tornaram duas contas: uma de saneamento outra de saúde. De 2000 ao primeiro trimestre de 2004, a média de despesas anuais líquidas em saneamento representa $0,017 \%$ do total de despesas do governo.

A separação das funções de recursos destinados ao saneamento e à saúde, realizados pelo MF a partir do ano de 2000, dão uma indicação sobre os critérios adotados pelo governo, mostrando que a saúde tem um peso maior na pauta de gasto do governo e evidenciando a prioridade epidemiológica e não à mitigação de possíveis problemas.

O significado econômico dos serviços e obras que se realizam no campo do saneamento básico está relacionado às propriedades visuais, químicas e físicas do líquido, ou seja, a qualidade da água. Além disso, custos econômicos devem levar em consideração em primeiro lugar, a disponibilidade da água, essencial nas atividades humanas, e também o atendimento aos processos produtivos, assim como na oferta às populações. Em segundo lugar, como conseqüência do uso da água, seu manejo posterior tem de ser levado em consideração para que haja um controle da poluição, possibilidade de reuso e também adequação quanto ao destino final dos resíduos.

Apesar dessas informações serem de importantes, os parâmetros de qualidade da água, tanto consumida, quanto devolvida ao meio hídrico e sua utilização em diversos processos produtivos ficarão fora do escopo deste trabalho. No presente trabalho, a função de custo para o setor de saneamento básico será composta pela produção e preços de fatores. 


\subsubsection{Monopólio natural}

O saneamento básico, como outros serviços de infra-estrutura, é caracterizado pela presença de custos fixos elevados em capital específico, como por exemplo, construção e manutenção de reservatórios, estações de tratamento de água e esgoto, redes de distribuição e coleta e equipamentos. Além de custos incrementais, os quais envolvem custos de curto prazo, como materiais de tratamento, energia, depreciação de instalações.

Os custos fixos são mais significativos que os incrementais e isso faz com que o conjunto de vetores de produção relevantes recaia sobre a faixa em que o custo médio é declinante. Nesse contexto, se o produto for único e existir economia de escala, Baumol \& Willig (1981), define um monopólio natural, onde um único produtor apresentará maior eficiência econômica.

Braeutigam (1989) afirma que caracterização de uma indústria como monopólio natural seria o principal argumento econômico para uma regulação e organização de um setor. $\mathrm{O}$ mesmo autor analisa estudos realizados após a década de 1970, que discutem a visão tradicional de monopólio natural e a preocupação existente com relação à regulação desse tipo de indústria.

Resumidamente, o mesmo autor diz que o conceito de monopólio natural descreve que a uma dada tecnologia da indústria ou características do serviço e com produto único, o consumidor pode ser atendido por uma única empresa que opera a um custo mínimo ou receita líquida máxima. Neste caso, o custo médio declina com o aumento da produção, e, portanto, uma única empresa servindo o mercado inteiro teria custos médios menores que quaisquer outras empresas rivais menores entrantes. Em outras palavras um monopólio natural, com uma única firma, pode gerar economias de escala, e que apresenta custo unitário menor que para duas ou mais firmas.

Segundo Shirota (1996), no caso de produção de um único produto, a economia de escala existe quando uma unidade de custo de produção diminuir de acordo com o aumento em mesmo nível de produção. 
Randall (1987) diz que serviços tipicamente providos por agências públicas ou regulados pelo estado possuem essas características de monopólio natural. O papel do governo é garantir que empresas não utilizem seu poder monopolista para geração de lucros excessivos ou que esse restrinja quantidade e qualidade dos serviços providos.

A situação de monopólio natural não é definitiva em uma indústria de serviços públicos, já que a indústria pode passar por estágios, segundo Shepherd ${ }^{7}$, citado por Turolla (1999):

a) Início: com a invenção do sistema;

b) Crescimento: sistema criado cresce rapidamente, em geral substituindo outro do serviço antigo. Economias de escalas são muito intensas neste estágio;

c) Maturidade: sistema cresce e se torna completo em termos tanto de tecnologia quanto de saturação de mercado. As economias de escala tornam-se menos significativas devido ao surgimento de novas tecnologias, e;

d) Reversão à competição: setor reverte para o sistema competitivo convencional, deixa de ser serviço público e perde características de monopólio natural.

A existência de economias de escala na indústria é discutida já que, isso depende estritamente da tecnologia da indústria. Em processos produtivos com produto único, e com preços de fatores constantes, essa noção de economia de escala pode ser aplicada porque o custo médio diminui na medida em que aumenta a oferta de produtos.

A noção tradicional de monopólio natural baseia-se na existência de economia de escala em toda a produção relevante no mercado. Essa economia de escala pode significar que gere grandes ineficiências com comportamento desenfreado das empresas e preços instáveis. Por tudo isso seria necessária alguma intervenção governamental com relação à regulamentação. Turola (1999) confirma essa necessidade citando em seu estudo, alguns trabalhos que argumentam que a regulação acontece justamente pela existência de falhas de mercados, caracterizada pelo monopólio natural.

\footnotetext{
${ }^{7}$ SHEPHERD, W.G. The economics of industrial organization. Englewood Cliffs: Prentice-Hall, 566p.
} 
Apesar dessas falhas serem difíceis de ser avaliadas, as potenciais falhas de mercado, de estado e de regulação servem para justificar a forma de intervenção requerida por cada indústria. De maneira geral, a existência de competição entre firmas de uma indústria reduz sensivelmente a necessidade de regulação, fazendo com que as falhas inerentes ao monopólio natural, causem um custo social mais elevado que as falhas do mercado livre.

Baumol \& Willig (1981) definem uma indústria como monopólio natural quando existem vetores de produtos relevantes mais baratos, produzidos na indústria por uma única firma que por um conjunto ou combinação de firmas. Para isso, a função custo da firma na indústria deve ser sub-aditivada. Tratando-se de empresas multiprodutos, alguns conceitos devem ser considerados, dado que a noção tradicional de economia de escala não é apropriada para definição e caracterização dessas empresas. Para isso, o conceito de custos sub-aditivados devem ser incorporados na análise do setor de saneamento básico.

Segundo Braeutigam (1989) através da teoria de custo sub-aditivado sustenta-se uma melhor definição, que economia de escala, para uma indústria multiproduto quando esta for monopólio natural. Baumol et al. $(1982$, p.17) definem que a função de custo $\mathrm{C}(\mathrm{y})$ é estritamente sub-aditiva em y, se para toda e qualquer quantidade de produtos $\mathrm{y}^{1}, \ldots, \mathrm{y}^{\mathrm{k}}, \mathrm{y}^{\mathrm{j}} \neq \mathrm{y}, \mathrm{j}=1, \ldots, \mathrm{k}$, em que:

$$
\begin{aligned}
& \sum_{j=1}^{k} y^{j}=y ; e \\
& C(y)<\sum_{j=1}^{k} C\left(y^{j}\right)
\end{aligned}
$$

A equação (1) indica o vetor y de produtos de uma indústria. Este pode ser produzido com um custo menor por uma única firma que por um conjunto de firmas que 
produzem individualmente a soma dos vetores de produtos da mesma indústria que produz y, de acordo com a equação (2) acima.

Desde que o custo é sub-aditivado, é necessário definir os vetores de produtos y relevantes para a indústria. Assim, a definição de monopólio natural dada por Baumol et al. (1982) é de que uma indústria é monopólio natural, sobre todo o conjunto de produtos, a função custo da firma seja sub-aditivada.

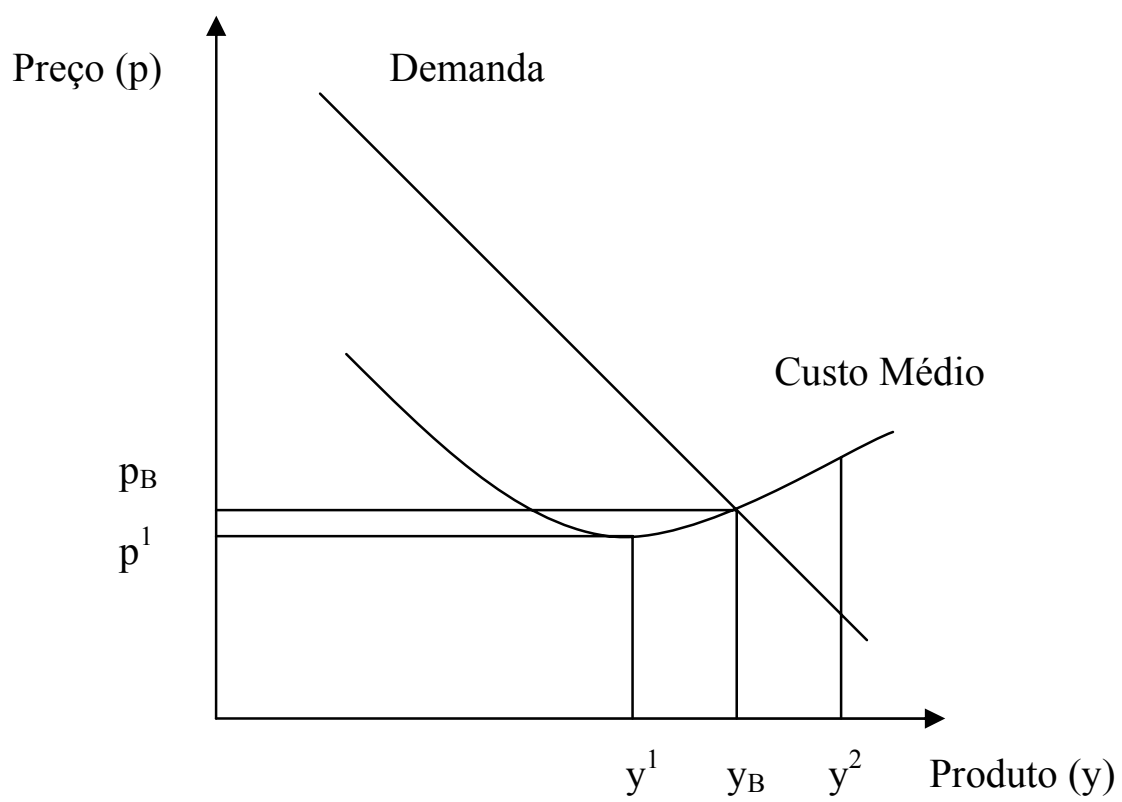

Figura 3 - Sub-aditividade sem economia de escala global Fonte: Braeutigam (1989)

Conforme ilustra a figura 3, a sub-aditividade da estrutura de custo não precisa demonstrar economias de escala sobre todo o conjunto relevante de produtos. Neste exemplo dado por Braeutigam (1989), o nível de produto associado ao custo mínimo, $\mathrm{y}^{1}$, é menor que $\mathrm{y}_{\mathrm{B}}$, o nível de produto em que a demanda esperada intercepta o custo médio esperado. Este custo médio tem tipicamente a forma de "U", e a subaditividade pode ser apresentada entre $0<\mathrm{y}<\mathrm{y}^{2}$, apesar de ser possível encontrar 
economia de escala do produto no conjunto de $0<\mathrm{y}<\mathrm{y}_{\mathrm{B}}$. Assim, quando o produto é único, a sub-aditividade não implica em economia de escala, mas o contrário é verdadeiro.

Portanto, tratando-se de empresas multi-produto e monopolista natural, a economia de escala não implica em sub-aditividade, isso também é justificado por Baumol et al. (1982), dado um conjunto de vários custos complementares e economias de produção somadas, espera-se que economia de escala não represente de maneira adequada o caso do multi-produto.

Considerando esses pontos apresentados acima, devido às características do setor de saneamento básico e suas implicações, é possível observar que essa indústria apresenta desafios pertinentes quanto à obtenção de um ponto de equilíbrio entre eficiência econômica e custos.

\subsubsection{Eficiência e o setor público}

Como visto no capítulo 2.3.1, o setor de saneamento básico deve ser analisado de acordo com o conjunto de produtos do sistema dado uma tecnologia de produção, ou seja, serviços de água e esgoto. A prestação conjunta de serviços é considerada vantajosa, devido à grande dimensão dessas obras de infra-estrutura, necessidade de capital específico e ainda a divisão de custos administrativos.

Para que ocorra uma expansão dos serviços, o crescimento populacional deve ser tamanho a pressionar a demanda. Além de significar melhorias de infraestrutura e aumento de bem-estar das pessoas, associada a esses pontos, vem acompanhada também a elevação do nível de renda desta população.

As características do setor de saneamento são destacadas quanto sua eficiência num contexto monopolístico em que, segundo Turolla (2002), apresenta custos fixos elevados em capital específico. 
Resumidamente, devido à crise nos anos 80 o modelo PLANASA, apresentou ineficiência operacional, ineficiências com relação ao atendimento de populações com menores rendas, valores tarifários absurdos, alta centralização de recursos na União, monopólio de Companhias Estaduais de Saneamento Básico (CESB), limitação de financiamentos e investimentos e rigidez tecnológica. Houve então a desestruturação do setor, dada a carência de financiamentos e cobertura, e falta de investimentos em geral. Interpretações errôneas da constituição de 1988, sobre a responsabilidade dos municípios, também contribuíram para fim do modelo.

Turolla (1999), cita que essas interpretações estão relacionadas à competência de atuação em saneamento básico, que ora menciona existir uma distinção entre os três níveis de poderes, União, Estado e Município, ora não faz essa diferenciação. Outra interpretação que deixa brechas jurídicas está relacionada ao tipo de integração das competências: vertical entre as três esferas governamentais e, horizontal que descreve a interface entre saneamento, saúde pública, meio ambiente e gerenciamento de recursos hídricos. O setor voltou a receber atenção novamente somente em 1990, quando recursos do Fundo de Garantia por Tempo de Serviço (FGTS) foram liberados para o setor, colocando um fim aos monopólios das CESBs.

Outra preocupação ressaltada, seria com a não existência de regulação específica, uma vez que essa não foi estritamente elaborada para que o processo de privatização ocorresse. Isso geraria um impasse entre as companhias e municípios sobre as competências e direitos dos serviços.

A reestruturação e modernização do setor, a partir de 1990, deram sustentação para a implementação da Política Nacional de Saneamento (PNS). A PNS foi caracterizada principalmente pela descentralização das ações de forma a conduzir a resolução dos problemas conforme a capacidade e as limitações de cada local ou região, tanto do ponto de vista técnico, quanto econômico e de divisão de recursos. Segundo Silva e Alves (2002), para melhoria das condições de saneamento brasileiro, o governo federal, estabeleceu seguintes objetivos: 
- Universalização do atendimento, visando oferecer os serviços básicos de abastecimento de água, esgoto sanitário, coleta e destino de resíduos sólidos;

- Criar ambiente de modernidade e de eficiência na prestação de serviços;

- Fomentar a participação de diversos agentes envolvidos na gestão dos serviços; e,

- Descentralizar ações.

Estima-se que a meta de universalização dos serviços de saneamento à população urbana, em 2010, demande investimentos anuais de US\$ 2,7 bilhões, ou praticamente $0,38 \%$ do Produto Interno Bruto (PIB) do Brasil (Carmo \& Távora, 2003).

Neste novo modelo, o poder público torna-se responsável pela formulação de política do setor com objetivos de longo prazo. A regulação e controle dos serviços seriam executados por uma agência independente, com representantes do governo, prestadores de serviços públicos ou privados e consumidores, de forma mais eficiente e não visando cobrir somente custos operacionais, como acontecia anteriormente no PLANASA.

O desenvolvimento dessas ações permitiria reformas e eficiência dos prestadores públicos de serviços, bem como a indução e viabilização da reforma institucional do setor. Foram estabelecidos novas estruturas de regulação, fiscalização, controle de qualidade e a capacidade de financiamento do setor, que culminaram no Plano de Modernização do Setor de Saneamento (PMSS):

A nova estruturação do PMSS, engloba três níveis de governos e determina as responsabilidades de cada um:

- União: formulação da Política Nacional de Saneamento (diretrizes e objetivos do setor, mobilização e gerenciamento de recursos para investimentos);

- Estados: formulação de Lei Estadual de Prestação de Serviços, Política Estadual de Saneamento e criação de Agência reguladora; e, 
- Municípios: execução dos serviços, definição de formato do serviço a ser prestado e a criação de Agência reguladora municipal, quando necessário.

Existem diversos riscos envolvendo os diversos participantes do setor (Estado, prestadora e indivíduos consumidores). Dentre outros, destacam-se: o preço a ser cobrado pelas prestadoras; a qualidade do serviço; a possibilidade de expropriação pelo governo do capital investido; e, distorções tarifárias devido a intervenções governamentais.

O novo modelo mostrou-se bastante diferenciado dos planos anteriores, isso pode ser justificado pelo surgimento da preocupação com a eficiência do setor quanto às esferas de abrangência dos serviços, regional, local ou microrregional.

De acordo com Varian (1990), um plano de produção é eficiente tecnologicamente se não existir uma outra forma variável de produzir mais com a mesma quantidade de fatores ou produzir a mesma quantidade de produtos, utilizando menor quantidade de fatores.

Segundo Moita (2000), para fazer com que empresas funcionem de maneira eficiente é necessário que as tarifas cubram os custos e remunerem adequadamente o sistema. Porém, pode haver conflito entre objetivos de eficiência versus o acesso universal ao serviço. Regiões onde o nível econômico é mais baixo, podem ser incapazes de pagar o custo do serviço (tanto de investimento quanto de operação e manutenção). Nesses casos, a prestação do serviço poderá depender de subsídios governamentais. Para tentar solucionar esse problema, o autor estima matematicamente tarifas e taxas para que a eficiência seja alcançada, considerando a universalização dos serviços, ou seja, a não exclusão de populações carentes economicamente.

A eficiência pode ser medida através da função de produção, calculando a proporção entre fatores e produto. Analisando o setor no Brasil, Carmo \& Távora (2003) estimam o grau de eficiência técnica de vinte e seis empresas estaduais de saneamento, através da metodologia não-paramétrica, DEA (Data Envelopment Analysis), para obter a fronteira de eficiência. A escolha do fator de produção e do produto alisados influencia 
diretamente no alcance da eficiência. Os autores levam em consideração dois modelos, o primeiro tem como produto volume faturado de esgoto e como fator de produção o volume de esgoto coletado; o segundo modelo considera a quantidade de economias ativas como produto e volume faturado de esgoto como fator de produção. As empresas analisam as empresas como produtoras de um único produto e constata-se que estas apresentam retornos crescentes à escala, justificada pelo grau de diferença na produção de cada companhia. De acordo com a localização, observou-se que a região mais eficiente foi a Sudeste.

Na Ásia, Estache \& Martin (2002), utilizaram a metodologia paramétrica de fronteiras estocásticas aplicadas através da função custo para determinar a eficiência regional de companhias de água, de acordo com a natureza de atuação da empresa. O estudo concluiu que a eficiência não é significativamente diferente entre as companhias com participação privada ou pública.

Racionalmente a análise econômica considera que a mensuração da eficiência do setor público se torna fundamental para análise de reformas, como projetos de privatização e introdução de novos mecanismos de regulação.

O presente trabalho corrobora com a preocupação do novo modelo apresentado neste capítulo no tocante à preocupação com a eficiência do setor quanto às esferas de abrangência dos serviços, regional e local, no Estado de São Paulo. A apresentação de uma análise de eficiência para o setor poderá contribuir, tanto em aspectos legais, para a regulação do setor, titularidade e definições de políticas tarifárias, de preços e de subsídios, quanto aos aspectos sociais, como a abrangência geográfica e determinação das prioridades de uma sociedade, saúde e/ou saneamento.

\subsection{Eficiência econômica}

Farrell (1957) é considerado o autor pioneiro no estudo de eficiência econômica. De acordo com a teoria microeconômica, o conceito de eficiência econômica tem dois componentes: técnico e alocativo. Com relação à utilização de insumos, o 
mesmo autor propõe as seguintes definições: i) eficiência técnica é a capacidade da firma em obter o máximo de produto dada a quantidade de fatores disponível; e, ii) eficiência alocativa é descrita de acordo com uma determinada tecnologia e preços, a capacidade da firma utilizar os fatores de produção em proporção ótima, que minimize os custos de produção. Por fím, Pinilla (2001) define ainda a ocorrência de: iii) eficiência de escala quando uma firma tem produção ótima, permite-se que os benefícios sejam maximizados.

De fato, pode existir qualquer combinação desses tipos de eficiências, isso dependerá de como e qual o objetivo a empresa tem a cumprir. A estimativa de eficiência está baseada nas funções de fronteiras.

Assim, Farrell (1957) em seu estudo sobre a eficiência econômica relaciona a medida de eficiência de uma firma com o melhor possível observado (ou eficiência) e para conseguir isso propôs um modelo, construído através de observações de valores de fatores de produção e produtos.

Conforme a representação gráfica de análise de Farrell (1957), a Figura 4 apresenta uma explanação sobre a eficiência técnica, alocativa e econômica. Coelli et al. (1998) descrevem a ilustração de Farrell considerando uma firma que utiliza dois fatores de produção $\left(\mathrm{x}_{1}\right.$ e $\left.\mathrm{x}_{2}\right)$ utilizados na produção de um único produto $(\mathrm{y})$. Admite-se que a tecnologia pode ser resumida pela função de produção linearmente homogênea $y=f\left(x_{1}\right.$, $\mathrm{x}_{2}$ ). Em seu estudo, Farrell (1957) assume que as firmas apresentam retornos constantes à escala e representa a isoquanta pode ser escrita como $1=\mathrm{f}\left(\mathrm{x}_{1} / \mathrm{y}, \mathrm{x}_{2} / \mathrm{y}\right)$. 


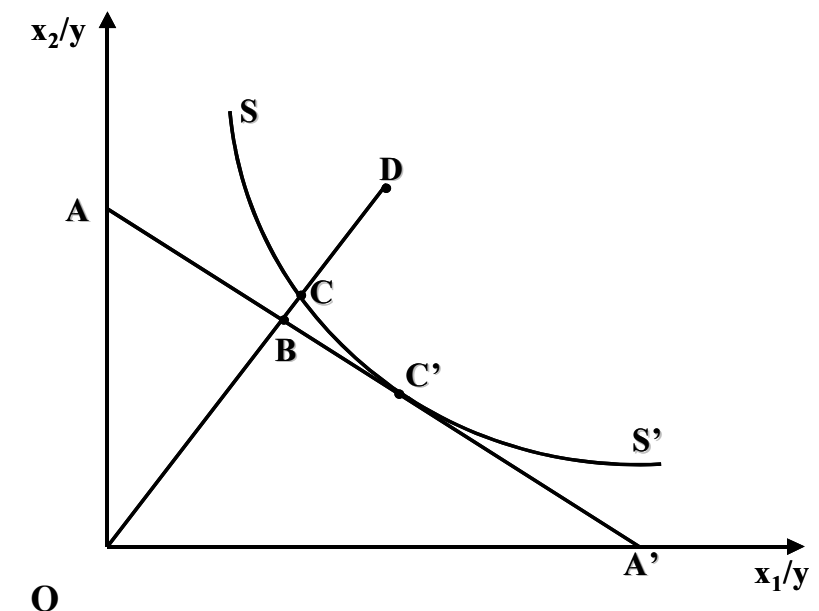

Figura 4 - Medidas de eficiência segundo a análise de Farrell Fonte: Farrell (1957)

A curva SS' representa a isoquanta unitária da firma eficiente, caracterizando a tecnologia de fronteira. Coelli et al. (1998) alertam para o fato de que na prática, essa função é desconhecida e deve ser estimada, permitindo a mensuração da eficiência técnica da firma. Se uma firma utiliza uma quantidade de $\mathrm{x}_{1}$ e $\mathrm{x}_{2}$ de fatores de produção para produção de y definido pelo ponto $\mathrm{D}$, a ineficiência técnica da firma poderá ser representada pela distância DC, ou seja, essa distância representa a quantidade de fatores que podem ser proporcionalmente reduzidos mantendo o produto da isoquanta. A eficiência técnica (ET) da firma é mensurada de acordo com a razão:

$$
\mathrm{ET}=\frac{\mathrm{OC}}{\mathrm{OD}}
$$

O ET apresenta valor entre zero e um e indica o grau de eficiência técnica da firma. Se a firma assume valor igual a um, isso indica que a firma é tecnicamente 
eficiente. Uma observação importante é que a administração e escala de operação de uma firma afetam a eficiência técnica.

A eficiência alocativa (EA) está relacionada com a proporção dos fatores de produção e seus impactos sobre os custos de produção. A EA é medida através da comparação do custo de uma firma no ponto $\mathrm{C}^{\prime}$ (custo mínimo) em relação à outro no ponto C. Assim, a eficiência alocativa da firma, operando em D é definido como:

$$
\mathrm{EA}=\frac{\mathrm{OB}}{\mathrm{OC}}
$$

Ainda analisando a firma no ponto D, a distância entre B e C representa a redução de custo se a firma opera, tanto em eficiência alocativa quanto em eficiência técnica. Em C uma firma será tecnicamente eficiente, pois se encontra sobre a mesma isoquanta, mas é ineficiente alocativamente se comparado a B.

O produto entre ET e EA resulta na eficiência econômica (EE). Assim, EE pode ser obtido conforme (5), dado que função de produção é conhecida:

$$
\begin{aligned}
& \mathrm{EE}=\mathrm{ET} \cdot \mathrm{EA}=\frac{\mathrm{OC}}{\mathrm{OD}} \cdot \frac{\mathrm{OB}}{\mathrm{OC}} \\
& \mathrm{EE}=\frac{\mathrm{OB}}{\mathrm{OD}}
\end{aligned}
$$

Portanto, o clássico estudo de Farrell realiza a análise de eficiência econômica separando em componentes: técnicos e alocativos, através dos fatores de produção, a um dado nível de produção y. Duas possíveis interpretações podem ser obtidas sobre (in) eficiência, as quais: i) mais fatores empregados que o necessário; ou, 
ii) fatores são empregados na produção de forma incorreta, considerando as relações de preços.

Após Farrell, outros estudos foram realizados e desenvolvidos na literatura econômica de métodos diferentes de estimação para fronteira (através da análise determinísticas e estocásticas; não-paramétrica e paramétrica). Cada método apresenta vantagens e desvantagens, mas que não as classificam como melhor ou pior entre as escolhas. Alguns autores como Shirota (1996), Coelli et al. (1998) e Pinilla (2001), exemplificam as diferentes formas de estimação de uma função fronteira.

Sob a análise do setor público, um produto público não é vendido como no mercado competitivo, gerando problemas quanto sua definição teórica e mensuração prática. A ausência de mercado competitivo impede que a oferta e demanda se ajustem e com isso o preço ou a valoração não sejam dados no ponto de equilíbrio. Os problemas do controle de produção pública ocorrem devido ao caráter monopolístico, já que na ausência de competição e carência de bases adequadas de comparação ou formas alternativas de produção, podem impor um caráter incerto e difuso à relação fatores/produtos (ou tecnologia de produção). Assim, devido à ausência de competição, preços e quantidades de equilíbrio e a não expulsão de empresas, que não conseguem minimizar custos dado à restrição de fatores, os resultados gerados podem apresentar-se ineficientes sob o ponto de vista econômico.

O conceito de eficiência no setor público deve ser tratado com algumas restrições para que quantificações não se tornem indicadores distorcidos. Em toda valoração de setor público, uma diversidade de objetivos e critérios podem influenciar o foco principal, gerando conflitos como o trade-off entre eficiência e equidade. Não existem dúvidas quanto à importância da valoração de serviços públicos (saneamento, educação e serviços de ação local) no âmbito social. Claramente essa argumentação apóia-se no conceito de eficiência técnica, já que a valoração da eficiência alocativa geraria problemas de alcance de serviços como os de necessidade primária, devido à ausência de preços e a existência dados calcados principalmente em quantidades. 
Assim, o conceito de eficiência econômica deve-se ajustar as peculiaridades do setor público que em muitos casos não apresenta uma regulação governamental organizada com controle adequado. Dessa forma o grau de eficiência deve ser intra-setorial, ou seja, analisado de acordo com um grupo de unidades produtivas que apresentam características como estrutura burocrática, ambiental e competências (funções) parecidas.

A estimação de (in) eficiência requer uma padronização para que se possa comparar o que ocorre de fato e um cenário ideal dentro de um sistema. No presente trabalho a eficiência será analisada através da estimativa de uma função econométrica (estocástico) de fronteira. A contribuição dada por Farrel apresentada neste capítulo a título de referencial teórico da literatura sobre eficiência, com a separação da (in) eficiência técnica e alocativa, aumento ou diminuição do custo médio de uma empresa, fogem do escopo do presente trabalho. A análise deste trabalho busca medir a (in) eficiência média de acordo com os determinados produtos das empresas de saneamento básico do Estado de São Paulo. 


\section{MATERIAL E MÉTODOS}

\subsection{Modelo econômico}

A análise de eficiência das empresas prestadoras de serviços de saneamento básico nos municípios pode ser realizada através de diferentes métodos. Podem ser paramétricos ou não paramétricos; e, estocásticos ou determinísticos. Dentre os diferentes métodos, os paramétricos são mais exigentes, pois pressupõem uma função de produção, ou de custo, ou de lucro que devem ser estimadas; porém, são mais ricos e consistentes com relação à realização de testes de hipótese. Um outro método, chamado de DEA (Data Envelopment Analysis) é classificado de não paramétrico, porque não propõe a determinação de uma função com os parâmetros a serem estimados e por não associar aos modelos qualquer estrutura de probabilidade. Mas, implicitamente, gera uma função de produção, via programação linear.

A fronteira estocástica explicitamente associa ao modelo uma estrutura de probabilidade, pela forma que se define o termo do erro da regressão; desta forma é mais rica em testes de hipótese (Souza, 2003).

Sarafidis $^{8}$ citado por Souza (2003), realizou um estudo sobre a utilização de técnicas paramétricas para o cálculo de índices de eficiência e concluiu que a escolha entre métodos; regressão simples, fronteira estocástica e a DEA, não é uma tarefa trivial. A justificativa para essa conclusão é de que as técnicas são fundamentalmente diferentes e, conseqüentemente geram, resultados diferentes. Todos os métodos enfrentam seus próprios problemas tanto teóricos, quanto práticos e isso implica que as estimativas

\footnotetext{
${ }^{8}$ SARAFIS, V. An assessment of comparative efficiency measurement techniques. Europe Economics. London, 2002. 21p. (Occasional paper, 2)
} 
finais da eficiência não devem ser interpretadas como sendo medidas definitivas de ineficiência. $\mathrm{O}$ presente trabalho adota o método econométrico estocástico e paramétrico com erro composto.

Parte significativa dos estudos sobre estrutura de produção utiliza o conceito de função de produção que depende de informações sobre quantidades de fatores de produção e produtos para descrever uma tecnologia de produção. Segundo Kumbhakar \& Lovell (2000), adicionando informações de preços de fatores de produção e produtos, promove-se uma melhor caracterização da estrutura tecnológica de produção. Essa caracterização através dos preços de fatores pode ser provida somente em fronteiras de custo, renda e lucro.

Enquanto uma fronteira de produção descreve a melhor que pode ser alcançado tecnicamente, as outras fronteiras, como a de custo, de lucro, descrevem o melhor que pode se alcançar economicamente, fornecendo padrões contra os quais a performance econômica pode ser mensurada.

O presente estudo adota a abordagem da função custo e a especificação do modelo empírico de fronteira estocástica paramétrica, conforme a seguinte equação (Shirota, 1996):

$$
\mathrm{C}_{\mathrm{i}}=\mathrm{C}\left(\mathrm{y}_{\mathrm{i}}, \mathrm{w}_{\mathrm{i}} \mid \theta\right)+\varepsilon_{\mathrm{i}}
$$

Em que : $\quad C_{i}$ é o custo observado da i-ésima empresa;

C(.) é uma versão paramétrica da função custo;

$\mathrm{y}_{\mathrm{i}} \in \mathrm{R}^{\mathrm{m}}+$ é o vetor de quantidade de produto para a i-ésima observação;

$\mathrm{w}_{\mathrm{i}} \in \mathrm{R}_{++}^{\mathrm{n}}$ é o vetor de preços de fatores de produção para a i-ésima observação; e,

$\theta \in \mathrm{R}^{\mathrm{k}}$ é o vetor de k parâmetros implícitos definidos em $\mathrm{C}($.$) .$ 
A estimativa da parte sistêmica do modelo de fronteira estocástica da função custo, ou seja, o mínimo realizável para um determinado conjunto de produtos, preços de fatores, e variáveis de controle, podem ser representados pelo termo erro que é decomposto em duas partes:

$$
\varepsilon_{\mathrm{i}}=\mathrm{v}_{\mathrm{i}}+\mathrm{u}_{\mathrm{i}}
$$

Em que : $\quad \mathrm{v}_{\mathrm{i}} \sim \mathrm{N}\left(0, \sigma_{\mathrm{v}}{ }^{2}\right)$; e,

$\mathrm{u}_{\mathrm{i}} \geq 0$ uma dada variável aleatória.

A aplicação econométrica empírica, à um banco de dados, requer que as informações das variáveis relevantes, como C, y e w, estejam já definidas e mensuradas. O passo seguinte é determinar a forma funcional do C(.), ou seja, a forma paramétrica da função custo.

Conforme (7), o componente $v_{i}$ captura os efeitos (para a firma i) do ruído estocástico e assume uma distribuição identicamente independente (iid) e segue distribuição $\mathrm{N}\left(0, \sigma_{\mathrm{v}}{ }^{2}\right)$. O componente $\mathrm{u}_{\mathrm{i}}$ computa erros de medida de erro e outros fatores aleatórios, assim como desvios que ocorrem devido a falta de especificação na estimativa da função custo. $\mathrm{O}$ passo seguinte requer, portanto, a aproximação econométrica para o termo erro $u$. $O$ componente $u_{i}$ representa o custo da ineficiência e assume-se distribuição independente de $\mathrm{v}_{\mathrm{i}}$ e dos parâmetros da regressão. Assim, esse termo deve ser estimado para que não haja imposição de uma distribuição ao modelo. Com isso é possível realizar testes com essa variável, os quais indicaram se os desvios da fronteira de eficiência estão ligados inteiramente ao ruído, ou se representam de fato a ineficiência da firma.

Por fim, é necessário encontrar um método de realização da estimação do vetor $\theta$, assim como vetor de k parâmetros implicitamente definida em $C($.$) .$ 
Para fronteira multi-produto da função custo são desejáveis algumas propriedades, como propor uma função custo que sob o posto de vista neoclássico minimize a função custo e ainda, ser possível utilizar observações com valor zero, ou seja, quando existir um valor de custo mas produto zero e vice-versa e por fim, a forma funcional utilizada na análise empírica não deveria impor restrições ex-ante nas propriedades da função custo. Outro ponto a ser ressaltado é que a forma deve ser maleável o bastante deixando com que a base de dados determine o nível tecnológico (Shirota, 1996).

Como a maioria das formas funcionais existentes na literatura viola uma ou mais propriedades desejáveis para a função custo e ainda podem gerar problemas como viés em estimativas de parâmetros do modelo, optou-se no presente trabalho pela escolha da forma funcional Cobb-Douglas.

Assim, a escolha da forma funcional de estimativas empíricas possibilita focar a análise a ser realizada, no termo de erro, o qual contém informações sobre a ineficiência no custo. A Cobb-Douglas é uma das formas mais simples e também mais utilizadas em modelos empíricos. Esse tipo de forma funcional exige que alguns pressupostos sejam assegurados.

De acordo com Coelli et al. (1998), a transformação logarítmica que acontece com essa forma funcional, fornece um modelo linear nos logaritmos dos fatores de produção, tornando-se uma forma mais simples de se estimar. Entretanto, isso implica em algumas restrições, como por exemplo, a função de produção possui elasticidades de fatores de produção constantes para as firmas da amostra. Assim, fixando as elasticidades de todos os fatores de produção, já que a função deve ser homogênea, as elasticidades de substituição para uma função Cobb-Douglas serão iguais a 1. Outro ponto refere-se à representação da tecnologia de produção, pois é complexa e na forma funcional da Cobb-Douglas isso deve ser considerado, já que o erro, foco da análise empírica a ser realizada neste trabalho, pode viesar a análise as estimativas de ineficiência de custo. 
Entre as diferentes estimativas de parâmetros, neste trabalho se optou por escolher o método de Máxima Verossimilhança, a ser demonstrado no próximo tópico deste trabalho. A justificativa para a escolha deste método, segundo Shirota (1996), é que o termo de intercepto gera um viés direto no componente aleatório de $\varepsilon$ se estimado por outra metodologia, como mínimos quadrados ordinários. Isso devido ao fato de que $\mathrm{E}(\varepsilon) \neq 0$. Através do método de máxima verossimilhança, as funções de verossimilhança são não lineares nos parâmetros e a estimação requer algoritmos numéricos. Através dos resultados gerais obtidos por máxima verossimilhança, alguns processos, como a própria estimação do modelo e alguns testes, que serão discutidos na análise de resultados podem ser executados.

\subsection{Modelo econométrico}

A metodologia de mensuração paramétrica e estocástica de eficiência da firma foi originalmente sugerida por Aigner et al. (1977) e Meeusen \& Van den Broeck (1977), em estudos de fronteiras de eficiência para função de produção.

Conforme a metodologia original apresentada pelos autores citados acima, Coelli et al. (1998) e Kumbhakar \& Lovell (2000) descrevem a equação de fronteira estocástica de produção levando em consideração a forma funcional de uma log-linear Cobb-Douglas como:

$$
\ln \mathrm{y}_{\mathrm{i}}=\beta_{0}+\sum_{\mathrm{n}} \beta_{\mathrm{n}} \ln \mathrm{x}_{\mathrm{ni}}+\mathrm{v}_{\mathrm{i}}-\mathrm{u}_{\mathrm{i}}
$$

O diferencial desse estudo para o tradicional foi a introdução do termo de erro composto de duas partes, onde o termo de erro que estima os desvios da função fronteira, dado pela variável u e o erro aleatório normal dado pelo termo v. O modelo de fronteira estocástica permite a estimação de erros padronizados e testes de hipótese 
usando método de máxima verossimilhança, não permitidos em modelos determinísticos.

Assim, erro v, termo de erros aleatórios, assume ser uma variável aleatória normal independente e identicamente distribuída com média 0 e variância $\sigma_{\mathrm{v}}^{2} \mathrm{O}$ erro u pode ser interpretado como os desvios da fronteira que refletem a ineficiência e a não capacidade de algumas firmas alcançarem uma dada tecnologia ou fronteira econômica. Existem algumas diferentes formas de distribuição do termo erro $u$, na fronteira de função custo.

Uma das críticas ao modelo de fronteira estocástica, de acordo com Coelli et al. (1998), é que não existe uma justificativa geral a priori para a escolha da forma da distribuição do erro sistêmico, ou seja, aquele que irá determinar a (in) eficiência de determinada amostra analisada.

Uma distribuição sugerida na literatura mais utilizada na estimativa de eficiência técnica é a distribuição meio-normal, em que segundo Coelli et al. (1998) e Kumbhakar \& Lovell (2000), considerando um modelo de fronteira estocástica de eficiência como a equação (6), assume-se que as distribuições devem ser:

(i) $\quad \mathrm{V}_{\mathrm{i}} \sim \operatorname{iid~} \mathrm{N}\left(0, \sigma^{2}{ }_{\mathrm{v}}\right)$;

(ii) $\mathrm{u}_{\mathrm{i}} \sim \mathrm{N}^{+}\left(0, \sigma_{\mathrm{u}}^{2}\right)$, ou seja, não negativa meio-normal; e,

(iii) $v_{i}$ e $u_{i}$ são distribuídos independentemente um do outro e dos regressores.

Assim, essa última pressuposição gera alguns conflitos, visto que partindo do pressuposto que o componente erro é composto por duas partes, desde que o produtor tenha alguma informação sobre sua ineficiência técnica, isso pode influenciar sua escolha de fatores de produção.

A função densidade de probabilidade (fdp) de $u \geq 0$ é dada pela seguinte equação: 


$$
f(u)=\frac{2}{\sqrt{2 \pi} \sigma_{u}} \cdot \exp \left\{-\frac{u^{2}}{2 \sigma_{u}^{2}}\right\}
$$

A função densidade de v, pode ser demonstrada conforme segue:

$$
f(v)=\frac{1}{\sqrt{2 \pi} \sigma_{v}} \cdot \exp \left\{-\frac{v^{2}}{2 \sigma_{v}^{2}}\right\}
$$

Dado que se assume a independência entre os dois termos componentes do erro, a função conjunta de densidade de $\mathrm{u}$ e $\mathrm{v}$ é dada pelo produto de suas funções de densidade de probabilidade individuais e pode ser demonstrada como:

$$
f(u, v)=\frac{2}{2 \pi \sigma_{u} \sigma_{v}} \cdot \exp \left\{-\frac{u^{2}}{2 \sigma_{u}^{2}}-\frac{v^{2}}{2 \sigma_{v}^{2}}\right\}
$$

Desde que $\varepsilon=\mathrm{v}-\mathrm{u}$, a função densidade conjunta de u e $\varepsilon$ :

$$
f(u, \varepsilon)=\frac{2}{2 \pi \sigma_{u} \sigma_{v}} \cdot \exp \left\{-\frac{u^{2}}{2 \sigma_{u}^{2}}-\frac{(\varepsilon+u)^{2}}{2 \sigma_{v}^{2}}\right\}
$$

Como a função densidade marginal é obtida através da integração de $\mathrm{f}(\mathrm{u}, \varepsilon)$ em u, isso significa que: 


$$
\begin{aligned}
& \mathrm{f}(\varepsilon)=\int_{0}^{\infty} \mathrm{f}(\mathrm{u}, \varepsilon) \mathrm{du}=\frac{2}{\sqrt{2 \pi} \sigma} \cdot\left[1-\Phi\left(\frac{\varepsilon \lambda}{\sigma}\right)\right] \cdot \exp \left\{-\frac{\varepsilon^{2}}{2 \sigma^{2}}\right\} \\
& \mathrm{f}(\varepsilon)=\frac{2}{\sigma} \cdot \phi\left(\frac{\varepsilon}{\sigma}\right) \cdot \Phi\left(-\frac{\varepsilon \lambda}{\sigma}\right)
\end{aligned}
$$

Onde $\sigma=\left(\sigma_{\mathrm{u}}^{2}+\sigma_{\mathrm{v}}^{2}\right), \lambda=\sigma_{\mathrm{u}} / \sigma_{\mathrm{v}}$ e $\Phi($.$) e \varphi($.$) são a distribuição normal$ cumulativa e função densidade. A reparametrização de $\sigma^{2}{ }_{u}$ e $\sigma^{2}{ }_{v}$ para $\sigma$ e $\lambda$ é conveniente desde que $\lambda$ promova um indicador de contribuição relativa de u e v em $\varepsilon$. Se $\lambda \rightarrow 0$ e também $\sigma_{\mathrm{v}}^{2} \rightarrow+\infty$ ou $\sigma_{\mathrm{u}}^{2} \rightarrow 0$, o componente simétrico de erros é dominado somente por um dos termos na determinação de $\varepsilon$. Assim como, se $\lambda \rightarrow+\infty$ e também $\sigma^{2} \rightarrow 0$ ou $\sigma_{u}^{2} \rightarrow+\infty$, o componente simétrico de erros é dominado somente por um dos termos na determinação de $\varepsilon$.

$\mathrm{Na}$ formulação da fronteira estocástica da função custo, dada pela equação (6) os componentes do termo de erro é dado de acordo com $\varepsilon_{i}=v_{i}+u_{i}$, sendo este assimétrico já que o termo $\mathrm{u}_{\mathrm{i}} \geq 0$.

Se técnicas de máxima verossimilhança são empregadas para obtenção de estimativas dos parâmetros $\beta^{\prime}$ s e dos dois componentes de erros separadamente, de acordo com Kumbhakar \& Lovell (2000), também é possível, através de técnicas de máxima verossimilhança estimar a fronteira estocástica de custo através da forma funcional Cobb-Douglas, assumindo que:

(iv) $\mathrm{v}_{\mathrm{i}} \sim$ iid $\mathrm{N}\left(0, \sigma_{\mathrm{v}}^{2}\right)$;

(v) $\mathrm{u}_{\mathrm{i}} \sim \mathrm{N}^{+}\left(0, \sigma_{\mathrm{u}}^{2}\right)$, não negativa meio-normal; e,

(vi) $v_{\mathrm{i}}$ e $\mathrm{u}_{\mathrm{i}}$ são distribuídos independentemente um do outro e dos regressores.

As funções densidade de $\mathrm{u} \geq 0$ e $\mathrm{v}$ são dadas pelas equações (9) e (10), então a função densidade marginal de $\varepsilon=\mathrm{v}+\mathrm{u}$, sendo $-\infty \leq \varepsilon \leq+\infty$ : 


$$
\begin{aligned}
& f(\varepsilon)=\int_{0}^{\infty} f(u, \varepsilon) d u=\int_{0}^{\infty} \frac{2}{2 \pi \sigma_{u} \sigma_{v}} \cdot \exp \left\{\frac{-u^{2}}{2 \sigma_{u}^{2}}-\frac{(\varepsilon-u)^{2}}{2 \sigma_{v}^{2}}\right\} d u \\
& f(\varepsilon)=\frac{2}{\sqrt{2 \pi} \sigma} \cdot\left[1-\Phi\left(\frac{-\varepsilon \lambda}{\sigma}\right)\right] \cdot \exp \left\{-\frac{\varepsilon^{2}}{2 \sigma^{2}}\right\}=\frac{2}{\sigma} \phi\left(\frac{\varepsilon}{\sigma}\right)\left[1-\Phi\left(-\frac{\varepsilon \lambda}{\sigma}\right)\right] \\
& f(\varepsilon)=\frac{2}{\sigma} \cdot \phi\left(\frac{\varepsilon}{\sigma}\right) \cdot \Phi\left(\frac{\varepsilon \lambda}{\sigma}\right)
\end{aligned}
$$

Onde, similarmente a função densidade de probabilidade marginal de $\varepsilon$ para função de produção, tem-se que, $\sigma=\left(\sigma_{u}^{2}+\sigma_{v}^{2}\right), \lambda=\sigma_{u} / \sigma_{v}$ e $\Phi($.$) e \varphi($.$) são a$ distribuição normal cumulativa e função densidade. A reparametrização de $\sigma^{2}{ }_{\mathrm{u}} \mathrm{e} \sigma_{\mathrm{v}}^{2}$ para $\sigma$ e $\lambda$ é conveniente desde que $\lambda$ promova um indicador de contribuição relativa de $\mathrm{u}$ e $\mathrm{v}$ em $\varepsilon$. Se $\lambda \rightarrow 0$ e também $\sigma^{2}{ }_{v} \rightarrow+\infty$ ou $\sigma_{u}^{2} \rightarrow 0$, o componente simétrico de erros é dominado somente por um dos termos na determinação de $\varepsilon$. Assim como, se $\lambda \rightarrow+\infty \mathrm{e}$ também $\sigma^{2}{ }_{\mathrm{v}} \rightarrow 0$ ou $\sigma_{\mathrm{u}}^{2} \rightarrow+\infty$, o componente simétrico de erros é dominado somente por um dos termos na determinação de $\varepsilon$. O modelo de estimação estocástico de fronteira custo terá pouco poder de explicação se num modelo de mínimos quadrados ordinários (MQO), não houver variação no custo eficiência ou em último caso, num modelo determinístico, não houver erro aleatório. Para que essa verificação seja efetuada, o teste máxima de verossimilhança é aplicado, com a hipótese nula que $\lambda=0$.

Assim a $\mathrm{f}(\varepsilon)$ é assimétrica e distribuída com:

$$
\begin{aligned}
& \mathrm{E}(\varepsilon)=\mathrm{E}(\mathrm{u})=\sigma_{\mathrm{u}} \sqrt{\frac{2}{\pi}} \\
& \mathrm{V}(\varepsilon)=\frac{\pi-2}{\pi} \sigma_{\mathrm{u}}^{2}+\sigma_{\mathrm{v}}^{2}
\end{aligned}
$$

Ressaltando ainda que, Shirota (1996), em sua pesquisa evidencia a diferença na função de produção e de lucro, onde $\varepsilon$ é dado pela diferença entre os termos de erro e na função custo o erro é composto pela soma dos dois componentes. 
A função logarítmica de máxima verossimilhança do modelo de função para uma dada amostra de produtores:

$$
\ln L=\frac{\mathrm{N}}{2} \ln \left(\frac{2}{\pi}\right)-\mathrm{N} \ln \pi+\sum_{\mathrm{i}=1}^{\mathrm{N}}\left[\ln \Phi\left(\frac{\varepsilon_{\mathrm{i}} \lambda}{\sigma}\right)-\frac{1}{2}\left(\frac{\varepsilon_{\mathrm{i}}}{\sigma}\right)\right]
$$

A função logarítimica de máxima verossimilhança pode ser maximizada em relação aos parâmetros e assim é possível se obter as estimativas de todos os parâmetros.

Uma generalização da distribuição meio normal para o termo u que compõe o erro da equação (6), é a distribuição normal-truncada demonstrada por Shirota (1996) e Kumbhakar \& Lovell (2000) e introduzida na literatura por Stevenson (1980).

Assumindo que as distribuições são dadas de acordo com:

(vii) $\mathrm{V}_{\mathrm{i}} \sim \operatorname{iid} \mathrm{N}\left(0, \sigma^{2}{ }_{\mathrm{v}}\right)$;

(viii) $\mathrm{u}_{\mathrm{i}} \sim \mathrm{N}^{+}\left(\mu, \sigma_{\mathrm{u}}^{2}\right)$; e,

(ix) $v_{i}$ e $u_{i}$ são distribuídos independentemente um do outro e dos regressores.

A distribuição normal truncada assume que o termo u segue uma distribuição meio normal que é truncada em zero, assim essa truncagem na distribuição normal irá conter uma parâmetro $\mu$ a ser estimado que será a representação mais flexível da parte de eficiência de acordo com os dados da amostra. ${ }^{9}$

Assim, conforme demonstrado por Shirota (1996), sendo $\mathrm{u}=\mathrm{w}, \mathrm{w} \geq 0$ ou $\mathrm{u}=$ 0 , em caso contrário, para a distribuição meio-normal tem-se que:

$$
\mathrm{W} \sim \mathrm{N}\left(0, \sigma^{2}{ }_{\mathrm{w}}\right)
$$

\footnotetext{
9 Derivação do modelo e das fdp marginais em Kumbhakar \& Lovell (2000) e Shirota (1996).
} 
Se a estrutura adotada para representar os erros de sistemáticos do modelo for a distribuição normal-truncada então:

$$
\mathrm{w} \sim \mathrm{N}\left(\mu_{\mathrm{w}}, \sigma^{2}{ }_{\mathrm{w}}\right)
$$

A função de distribuição de probabilidade e a função logarítimica de máxima verossimilhança de $\varepsilon$, respectivamente são representadas por:

$$
\begin{aligned}
& \mathrm{f}(\varepsilon)=\frac{1}{\sigma} \cdot \phi\left(\frac{\varepsilon-\mu_{\mathrm{w}}}{\sigma}\right) \cdot\left[\Phi\left(\frac{\mu_{\mathrm{w}}}{\sigma \lambda}+\frac{\varepsilon \lambda}{\sigma}\right)\right] \cdot\left[\Phi\left(\frac{\mu_{\mathrm{w}}}{\sigma}\right)\right]^{-1} \\
& \ln \mathrm{L}=-\frac{\mathrm{N}}{2}\left(\ln \sigma^{2}+\ln \pi\right)-\frac{1}{2 \sigma^{2}} \sum_{\mathrm{i}=1}^{\mathrm{N}}\left\{\left(\varepsilon_{\mathrm{i}}-\mu_{\mathrm{w}}\right)^{2}+\ln \left[\Phi\left(\frac{\mu_{\mathrm{w}}}{\lambda}+\varepsilon_{\mathrm{i}} \lambda\right)\right]\right\}-\mathrm{N}
\end{aligned}
$$

Uma vantagem relativa dessa formulação com respeito à distribuição meionormal é a flexibilidade que de acordo com esse método, não impõe a priori a distribuição do termo de erro. Como a distribuições apresentadas são generalizações da normal, é possível aplicar alguns testes nessas distribuições alternativas.

Alguns testes são realizados para verificação da existência e ineficiência com inúmeras hipóteses alternativas. Segundo Coelli et al. (1998), um dos testes é a estatística de Wald (W), que envolve a razãod e verossimilhança para o estimador $\sigma^{2}$ para estimar o erro padronizado. Segundo os mesmos autores essa estatística é realizada desde sua primeira aplicação, realizada por Aigner et al. (1977). De acordo com a parametrização utilizada na estimação do modelo de fronteira estocástica, os testes de hipóteses assumem como hipótese: $\mathrm{H} 0: \lambda=0$, contra $\mathrm{H} 1: \lambda>0$, ou H0: $\gamma=0$, contra $\mathrm{H} 1$ : $\gamma>0 .{ }^{10}$ No teste de Wald, se a Ho não é rejeitada, essa estatística é assintoticamente

\footnotetext{
${ }^{10}$ Em que: $\lambda=\sigma_{\mathrm{u}} / \sigma_{\mathrm{v}} ; \gamma=\sigma_{\mathrm{u}}{ }^{2} / \sigma_{\mathrm{s}}{ }^{2} ; \mathrm{e}, \sigma_{\mathrm{s}}{ }^{2}=\sigma_{\mathrm{u}}{ }^{2}+\sigma_{\mathrm{v}}{ }^{2}$
} 
distribuída como uma variável normal aleatória. Se a variância for igual a zero, então todos os " $\mathrm{u}_{\mathrm{i}} \mathrm{s}$ " serão iguais a zero e que portanto, todas as firmas são plenamente eficientes. Quando a distribuição considerada é a normal-truncada, deve-se observar que $\sigma^{2}$ será obtido através da distribuição de u. Assim, se a hipótese nula não for rejeitada, a estatística W, com k-parâmetros graus de liberdade e as empresas operam em eficiência, ou seja, operam na fronteira custo. Entretanto esse teste não deve ser o único considerado, pois os parâmetros $(\lambda$ e $\gamma)$ a serem testados não devem assumir valor negativo.

No presente estudo são realizados mais dois testes. Considerando modelos que assumem erro idiossincrático (u) com distribuição meio normal, a Razão de Verossimilhança (RV). Através de RV, um teste global de significância é realizado, em que se verifica se o modelo estimado é melhor que um modelo em que todos os coeficientes sejam nulos. A hipótese nula $\mathrm{H} 0:{\sigma_{\mathrm{u}}}^{2}=0$, caso contrário $\mathrm{H} 1:{\sigma_{\mathrm{u}}}^{2}>0$. Isso significa que, se H0 não for rejeitado, então o modelo de fronteira apresentará resultado igual a 1, ou seja, a estimativa de mínimos quadrados ordinários pode ser aplicada como método, com erros normalmente distribuídos e pode-se concluir que o modelo não apresenta ineficiência. Quando se rejeita a H0, conclui-se que a ineficiência está presente na estimativa de fronteira do modelo. Deve-se alertar que esse teste é baseado numa distribuição assintótica de $\sigma_{\mathrm{u}}^{2} \mathrm{e}$ o tamanho da amostra não deve ser pequeno para que não ocorram viés de resultados do teste RV.

No caso de u assumir distribuição normal-truncada, o teste de detecção para presença do termo de ineficiência é dado pelo teste baseado no terceiro momento dos resíduos de mínimos quadrados ordinários. ${ }^{11}$ Intuitivamente, quando $\mu=0$ e $\sigma_{\mathrm{u}}=0$, um modelo com distribuição normal-truncada se reduz a um modelo de regressão linear com erros normalmente distribuídos. Log-Verossimilhança Generalizado (Z) testará se o modelo possui erros normalmente distribuídos como numa regressão linear simples, ou seja, as hipóteses podem ser descritas como H0: não ineficiência e H1: caso contrário.

\footnotetext{
${ }^{11}$ Ver Shirota (1996, p.85)
} 
O próximo passo é obtenção das estimativas de custo eficiência para cada empresa produtora. Deve-se obter estimativa de $\varepsilon_{\mathrm{i}}=\mathrm{u}_{\mathrm{i}}+\mathrm{v}_{\mathrm{i}}$, que obviamente contém informações de $u_{i}$. Kumbhakar \& Lovell (2000), descrevem uma solução para obtenção de $u_{i}$ através da distribuição condicional de $u_{i}$ dado $\varepsilon_{i}$. Essa distribuição condicional é representada pela seguinte equação:

$$
\mathrm{f}(\mathrm{u} \mid \varepsilon)=\frac{\mathrm{f}(\mathrm{u}, \varepsilon)}{\mathrm{f}(\varepsilon)}=\frac{1}{\sqrt{2 \pi \sigma_{*}}} \cdot \exp \left\{-\frac{\left(\mathrm{u}-\mu_{*}\right)^{2}}{2 \sigma_{*}^{2}}\right\} /\left[1-\Phi\left(\frac{-\mu_{*}}{\sigma_{*}}\right)\right]
$$

Em que: $\mu_{*}=\varepsilon \sigma_{\mathrm{u}}^{2} / \sigma^{2}$ e $\sigma^{2}{ }_{*}=\sigma_{\mathrm{u}}^{2} \sigma_{\mathrm{v}}^{2} / \sigma^{2}$. Desde que $\mathrm{f}(\mathrm{u} \mid \varepsilon)$ possua distribuição $\mathrm{N}^{+}\left(\mu_{*}, \sigma^{2}\right.$ ), e a média ou a forma da distribuição pode servir como um ponto estimado de $\mathrm{u}_{\mathrm{i}}$. Pode ser dado por:

$$
\begin{aligned}
\mathrm{E}\left(\mathrm{u}_{\mathrm{i}} \mid \varepsilon_{\mathrm{i}}\right) & =\mu_{* \mathrm{i}}+\sigma_{*}\left[\frac{\phi\left(\mu_{* \mathrm{i}} / \sigma_{*}\right)}{1-\Phi\left(-\mu_{* \mathrm{i}} / \sigma_{*}\right)}\right]=\sigma_{*}\left[\frac{\phi\left(\varepsilon_{\mathrm{i}} \lambda / \sigma\right)}{1-\Phi\left(-\varepsilon_{\mathrm{i}} \lambda / \sigma\right)}+\left(\frac{\varepsilon_{\mathrm{i}} \lambda}{\sigma}\right)\right] \\
\mathrm{M}\left(\mathrm{u}_{\mathrm{i}} \mid \varepsilon_{\mathrm{i}}\right) & =\varepsilon_{\mathrm{i}}\left(\frac{\sigma_{\mathrm{u}}^{2}}{\sigma^{2}}\right), \text { se } \varepsilon_{\mathrm{i}} \geq 0, \\
& =0 \text {, caso contrário }
\end{aligned}
$$

Uma vez estimada $u_{i}$ o custo eficiência $\left(\mathrm{CE}_{\mathrm{i}}\right)$ para cada empresa pode ser obtida através da seguinte equação, considerando que $s=1$, se função de produção e $s=$ -1 , se função custo 


$$
\left.\mathrm{CE}_{\mathrm{i}}=\mathrm{E}\left(\exp \left\{-\mathrm{su}_{\mathrm{i}}\right\} \mid \varepsilon_{\mathrm{i}}\right)=\left[\frac{1-\Phi\left(\sigma_{*}-\mu_{* \mathrm{i}} / \sigma_{*}\right)}{1-\Phi\left(-\mu_{* \mathrm{i}} / \sigma_{*}\right)}\right] \cdot \exp \left\{-\mu_{* \mathrm{i}}+\frac{1}{2} \sigma_{*}^{2}\right)\right\}
$$

E que se o modelo assumir distribuição meio-normal, $\mu_{*_{\mathrm{i}}}=-\mathrm{s} \varepsilon_{\mathrm{i}} \sigma_{\mathrm{u}}^{2} / \sigma^{2}$ e $\sigma *$ $=\sigma_{\mathrm{v}}$. Se o modelo assumir distribuição normal-truncada, $\mu_{*}=-\mathrm{s} \varepsilon_{\mathrm{i}} \sigma_{\mathrm{u}}^{2}+\mu \sigma_{\mathrm{v}}^{2} / \sigma^{2}$ e $\sigma_{*}=$ $\sigma_{\mathrm{u}} \sigma_{\mathrm{v}} / \sigma^{2}$. Através dos resultados das estimativas é possível que o rank das empresas seja realizado.

\subsection{Base de dados e caracterização da amostra}

Após alguns anos de desregulamentação e carência de investimentos, algumas ações no setor de abastecimento e saneamento têm estimulado a modernização do setor com a racionalização da gestão e a busca de eficiência pelos prestadores. $O$ Ministério das Cidades (Brasil, 2004), agrupa políticas de habitação, saneamento ambiental, trânsito e transporte urbano, bem como os programas especiais necessários ao desenvolvimento urbano. O objetivo principal é, junto às esferas do Poder Público, a promoção de inclusão social mediante a articulação, a implantação e a implementação de programas e ações destinados a universalizar o acesso da população urbana à habitação digna, ao saneamento ambiental e à mobilidade que é dada pelo trânsito e transporte público.

Assim, com relação às ações de saneamento, a Secretaria Nacional de Saneamento Ambiental (SNSA), criada no âmbito do Ministério das Cidades, tem como objetivo assegurar os direitos humanos fundamentais de acesso à água potável e à vida em ambiente salubre nas cidades e no campo, mediante a universalização do abastecimento de água e dos serviços de esgotamento sanitário, coleta e tratamento dos resíduos sólidos, drenagem urbana e controle de vetores e reservatórios de doenças transmissíveis. 
A estrutura básica da SNSA é formada pelos Departamentos de Água e Esgotos; de Desenvolvimento e Cooperação Técnica; e de Articulação Institucional. Nessa estrutura, enquadram-se as seguintes ações em andamento: (i) Modernização do Setor Saneamento (PMSS); (ii) Assistência Técnica ao Prosanear (PAT PROSANEAR); (iii) Combate ao Desperdício de Água (PNCDA); e (iv) Gestão de Resíduos Sólidos Urbanos (PROGEST). Além dessas, há as seguintes ações em preparação: Ação Social em Saneamento (PASS/BID) e Saneamento Integrado em Pequenos Municípios (Sede Zero).

O programa PMSS desenvolveu uma série de estudos sobre o setor que ainda gerou o Sistema Nacional de Informações sobre o Saneamento (SNIS) que dispõe de um conjunto de informações sobre os prestadores e os municípios, permitindo entre outras coisas a definição de parâmetros de acompanhamento para as empresas do setor.

Existem diferentes tipos de prestadores de serviços no que diz respeito a abrangência (regionais, microrregionais e locais) como em relação a natureza jurídica (prestadores de direito público ou de direito privado com gestão pública, autarquias, departamentos, serviços autônomos, empresas públicas, entre outros) e empresas privadas. A estrutura diversificada e a disponibilidade de informações por municípios no SNIS permitem tentar comparar o desempenho em relação à eficiência de acordo com o tipo de empresa que melhor atende o consumidor, ou seja, as regionais ou os prestadores locais considerados mais próximas aos consumidores, por pressão de capital social..

Será utilizado o banco de dados do SNIS, formado por informações disponibilizadas por prestadores de serviços. Este sistema começou a ser divulgado em 1995 e o último refere-se ao ano de 2002. O banco de dados é autodeclarativo e tende a apresentar imperfeições decorrentes de erros de preenchimento por parte dos informantes, por desconhecimento, falta de compreensão do que estava sendo perguntado, ou qualquer outro motivo. Outro ponto em relação ao SNIS é que ele ainda não cobre o Universo de prestadores de serviços e municípios, e a amostra se altera ao longo do tempo, tanto pela incorporação de novos prestadores e municípios, assim como 
porque alguns prestadores deixam de responder o questionário. Assim, não é possível encontrar os mesmos informantes em todos os anos.

No ano de 2002, as informações disponíveis para o Brasil em relação aos prestadores de serviços foram compostas por 279 prestadores, sendo 25 de abrangência regional, 6 microrregional e 248 local. Em número de municípios, compõem a amostra 1821 municípios, sendo 1573 atendidos por prestadores regionais ou microrregionais e 248 atendidos por empresas locais, demonstrando uma representatividade elevada dos prestadores e dos respectivos municípios atendidos pelos serviços.

O presente trabalho será realizado com base em informações referentes ao Estado de São Paulo, no ano de 2002. De acordo com a Fundação Sistema Estadual de Análise de Dados (SEADE) (2004), existem 645 municípios no estado todo. Desses somente 197 municípios responderam ao questionário do SNIS, sendo que 149 municípios possuem empresas com abrangência regional e 48 municípios possuem empresas prestadoras de serviços de saneamento e abastecimento de abrangência local e não existindo informações sobre municípios que possuem empresas de abrangência microrregional já que esse tipo de empresa não ocorre no estado.

Deve-se considerar que, devido ao fato das informações do SNIS apresentarem algumas imperfeições causadas pela falta de preenchimento e/ou ainda alguns erros, optou-se pela eliminação de 18 municípios da amostra. Os municípios eliminados foram: Engenheiro Coelho, Jaguariúna e São Carlos por apresentarem problemas nas informações de custo. Nas cidades de São João do Pau d'alho, Osasco e Socorro, devido às informações sobre produção não se encontraram completas. Com referência aos fatores de produção, as cidades eliminadas foram Álvaro de Carvalho, Caieiras, Cajamar, Canas, Diadema, Embaúba, Oriente, Paulistânia, Pirapora do Bom Jesus, Rio Grande da Serra, São Caetano do Sul. O último município retirado da amostra, apesar de apresentar todas as informações, foi o município de São Paulo, que por ser o maior de todos no estado e conseqüentemente apresentar os valores informados muito maiores que podem gerar tendências nas análises a serem realizadas. 
Assim a amostra é composta por 179 municípios, dos quais 137 apresentam empresas prestadoras de serviços regionais e 42 municípios com prestadoras de serviços de abrangência local.

Serão realizadas dez modelagens de fronteira custo, estimados através do ferramental econométrico, com erro composto e forma funcional Cobb-Douglas. Serão analisadas as possíveis combinações de produtos na fronteira da função custo, para o mesmo nível de fatores.

Em estudo realizado por Estache \& Martin (2002), estimou-se a variável dependente de Custo Operacional, através das despesas com trabalhadores, energia, materiais e em alguns casos, gastos com importação de água. Segundo Shirota (1996), uma observação adicional importante relativo a esse tipo de estudo, diz respeito a agregação de variáveis, o que é, e em análises empíricas de funções custo, usual que diferentes variáveis sejam resultado de agregações.

As variáveis independentes enquadram-se em dois grupos: produtos e preço de fatores de produção, onde:

- Produtos são referentes ao abastecimento de água e esgotamento sanitário, que foram combinadas conforme a similaridade de mensuração das características físicas, já que o setor analisado é caracterizado como multiproduto. As informações sobre os produtos utilizados para a análise foram os seguintes, com relação a abastecimento de água: quantidade de ligações ativas de água à rede pública (qlaa), extensão total da malha de distribuição de água (era) e volume de água macromedido (vam), e com relação ao esgotamento sanitário: quantidade de ligações ativas de esgoto à rede pública (qlae), extensão total da malha de esgoto (ere). Os quatro últimos modelos utilizam a combinação dos produtos gerando a variável (ligacao), dada pela soma da qlaa e qlee; e a variável (extensão), dada pela soma da era e ere.

- Preços de fatores devem ser considerados para a análise do setor de acordo com o modelo empírico a ser estimado foram: média anual de salário de 
pessoal próprio (dmpp), preços de produtos químicos (dpq), preço da energia elétrica (dee), preço de serviços de terceiros (dst).

- Variável binária para captar o tipo de prestadores de serviços conforme a abrangência (dummy, com valor 1 quando a empresa for de abrangência regional e 0 caso contrário. Como no Estado de São Paulo só existem empresas regionais e locais, o valor 0 refere-se às empresas de abrangência local)

A variável dependente, ou seja, a variável custo considerada nos modelos estimados nomeada de dex_1, é composta pela soma do custo total para o ano de 2002 com salários (dmpp), produtos químicos (dpq), energia elétrica (dee) e serviços de terceiros $(\mathrm{dst})$.

A apresentação das equações que representam as funções que serão estimadas, assim como a descrição de cada um dos modelos analisados estão apresentadas no item 3.4 do presente trabalho.

Apesar da riqueza de informações disponibilizadas pelas empresas no banco de dados do SNIS, devem-se levar em consideração algumas restrições impostas ao presente trabalho no tocante as estimativas realizadas neste trabalho. Foi possível ser estimado somente a variável de preços de salário como preços dos fatores, representada pela razão do custo total anual dos salários com pessoal próprio e o número de trabalhadores da empresa.

Com relação ao preço do trabalho realizado por terceiros, realizou-se categorização do nível de terceirização dos serviços no setor de saneamento. A terceirização de serviços engloba também a contratação de mão-de-obra entre outras contratações. Essa diferente gama de possíveis terceirizações dentro das empresas de saneamento em casa município, durante o período de um ano, dificulta a análise e impossibilita a determinação exata do preço dos serviços de terceiros, fazendo com que a categorização, como sugerido, seja uma alternativa para a inclusão desta variável na análise. Esta variável é indicada pela proporção média de gastos com serviços 
terceirizados pelas prestadoras do Estado de São Paulo no total dos gastos operacionais é de 0,41 .

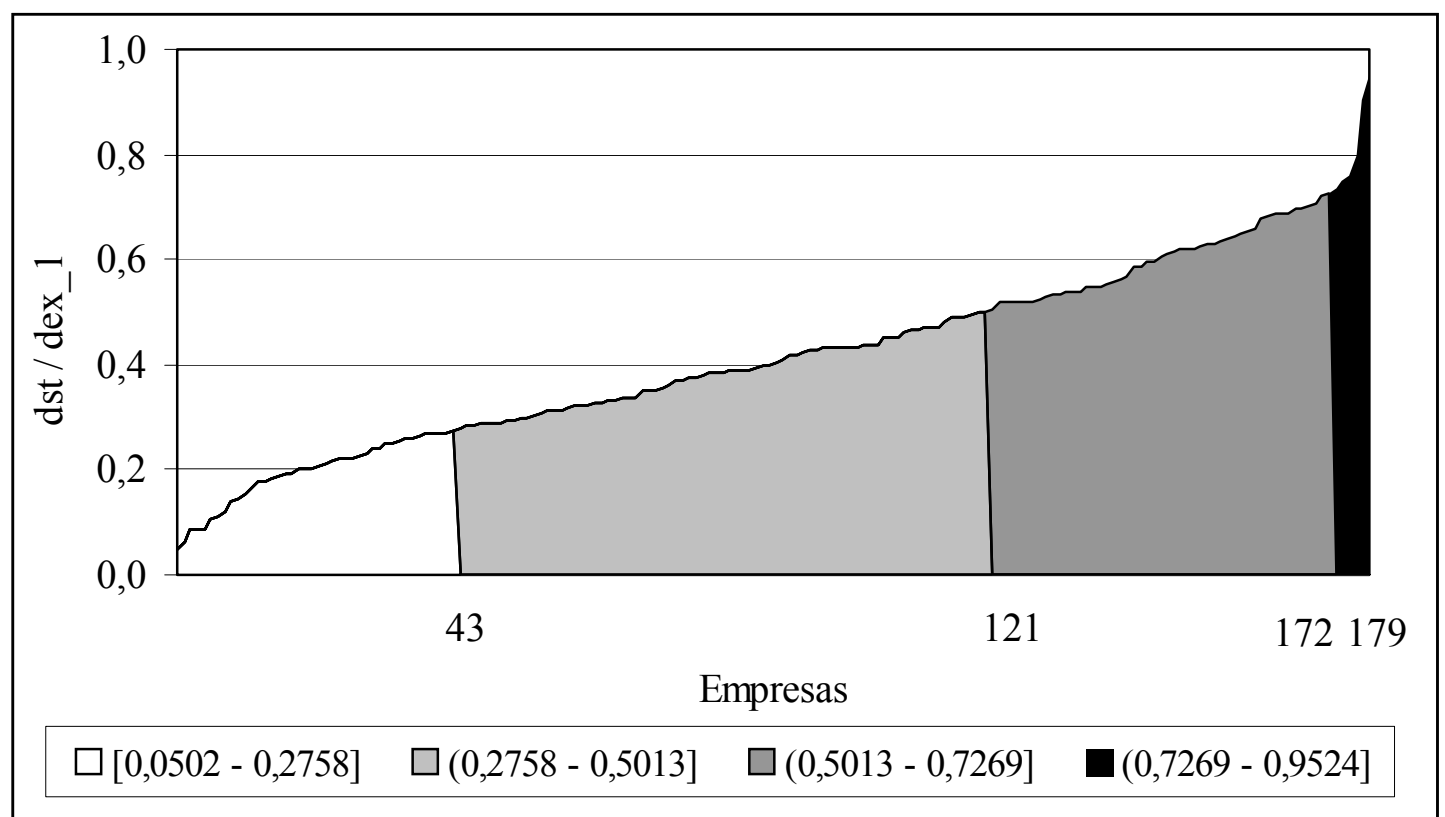

Figura 5 - Distribuição das empresas de acordo com a participação das despesas com serviços terceirizados no custo operacional, 2002

Assim, conforme observado na Figura 5 acima, a maior concentração de municípios e empresas que realizam gastos com serviço de terceiros, aproximadamente na faixa de 0,20 à 0,70 , com relação ao dex_1. A categorização foi realizada para quatro classes conforme pode ser observado nas figuras 5 e 6 . 


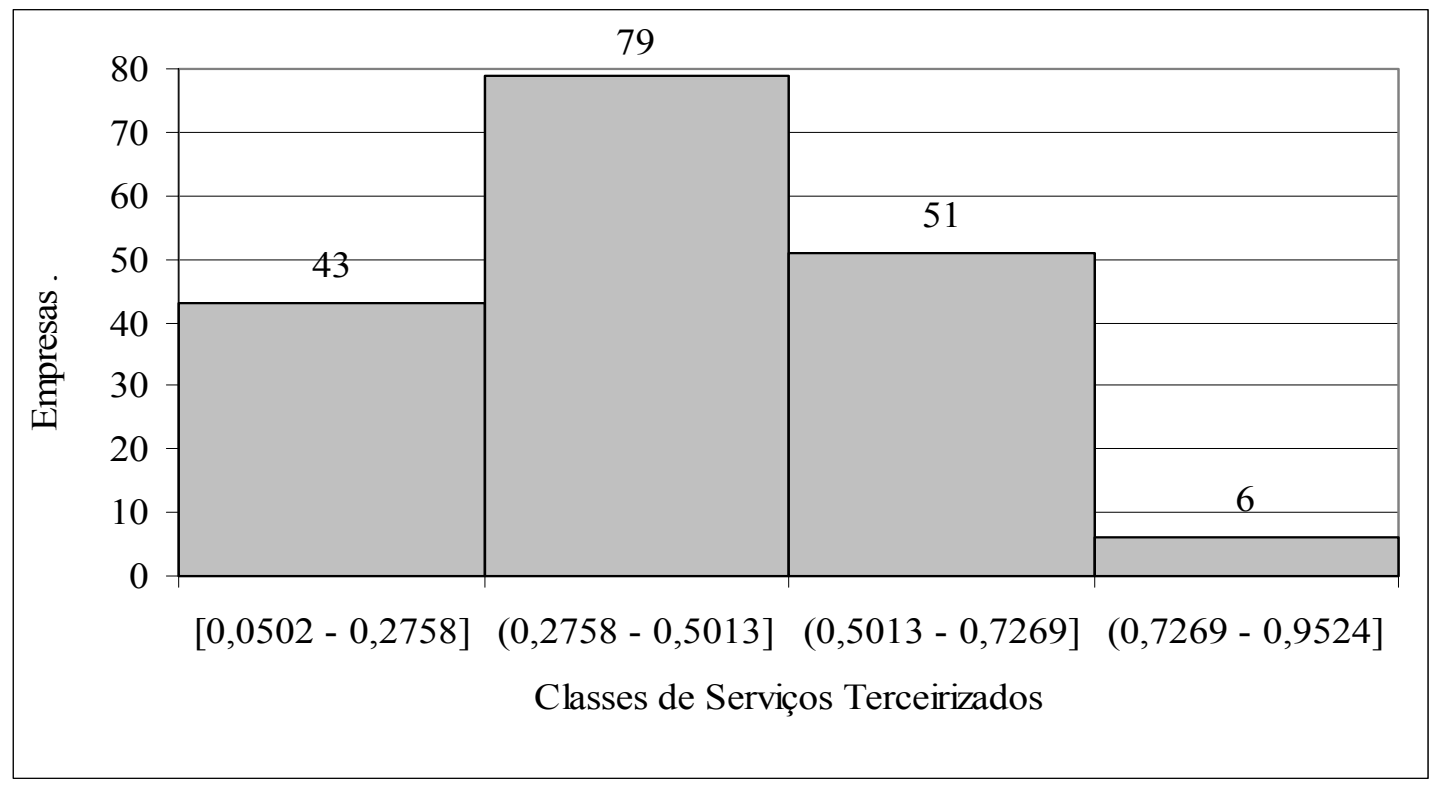

Figura 6 - Distribuição das empresas de saneamento básico acordo com as classes de participação de serviços de terceirizados sobre o custo operacional, 2002

$\mathrm{Na}$ primeira classe verifica-se a existência de 43 municípios, ou seja, categorizados na classe entre 0,05 a 0,27, sendo 29 municípios com empresas de serviços regionais. Ainda analisando a amostra existem 130 municípios entre a segunda e a terceira classes categorizadas entre 0,2758 e 0,7269 dos gastos totais anuais com serviços de terceiros sobre o custo operacional, sendo que 107 desses municípios possuem empresas de abrangência regionais. Na última categoria, 6 municípios apresentaram empresas com serviços terceirizados maior que a proporção de 0,72 do custo operacional, sendo 1 município somente prestador regional. Essas categorias foram incorporadas ao modelo através de variáveis binárias, tendo como referência a última classe, onde as empresas terceirizam a maior parte dos serviços. As variáveis binárias são: classe 1 (com valor 1 se a empresa do município pertencer a classe 1 , e 0 caso contrário), classe 2 (com valor 1 se a empresa do município pertencer a classe 2, e 0 caso contrário) e classe 3 (com valor 1 se a empresa do município pertencer a classe 3 , e 0 caso contrário). 
Apesar do banco disponibilizar valores dos gastos totais no ano com os fatores de produção, os preços dos produtos químicos e preço da energia nas empresas prestadoras não puderam ser estimados devido à falta de informações sobre quantidades de produtos e a quantidade de megawatts de energia consumidos pelas empresas.

Alguns produtos utilizados, de acordo com informações no sitio da SABESP, assim como as disponibilizadas pelas empresas de serviços de saneamento básico, Serviço Municipal de Água e Esgoto (SEMAE) de São José do Rio Preto e Piracicaba, em geral no tratamento de água são utilizados: ácido fluossilícico, cal hidratada, cloro liquefeito, hipoclorito de sódio, sulfato de alumínio e ortopolifosfato. No tratamento de esgoto em geral utilizam-se produtos como cal hidratada, hipoclorito de sódio e cloreto férrico e polímeros catiônicos.

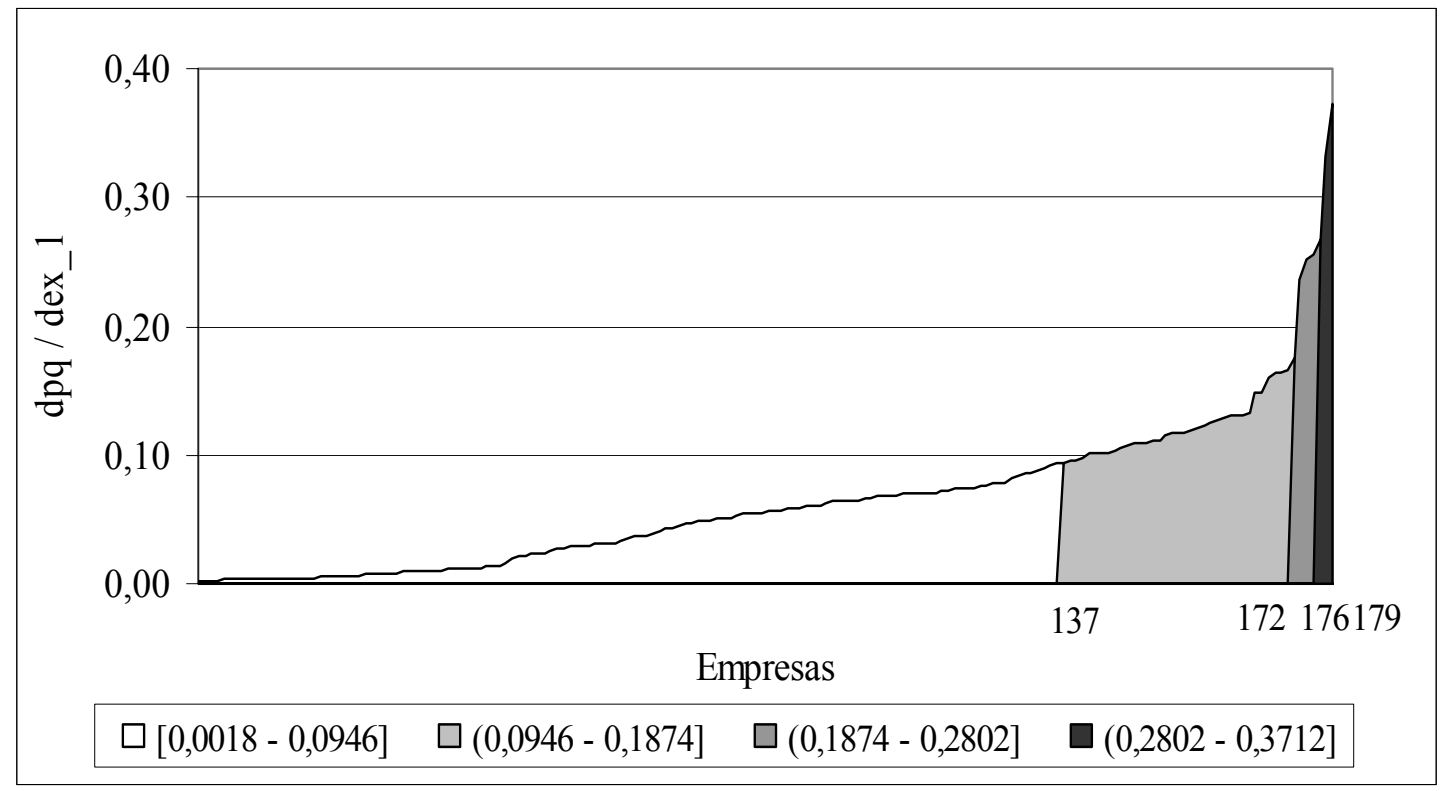

Figura 7 - Distribuição das empresas de acordo com a participação das despesas com produtos químicos no custo operacional, 2002 
A figura 7 demonstra a proporção das despesas das empresas com produtos químicos de acordo com a classificação dada pelos quatro intervalos classificatórios de gastos com esse fator de produção. Os determinantes da quantidade de produtos químicos são as análises realizadas pelo laboratório existente na própria estação, ou seja, depende da qualidade da água bruta analisada. A qualidade da água está em função de sua concentração coliformes fecais e metal pesado, concentração de oxigênio dissolvido, demanda biológica e química de oxigênio, contaminação por bactérias entre outros parâmetros determinados pela lei ambiental, de acordo com Kamogawa (2004).

Uma bacia hidrográfica é um sistema que integra as conformações de relevo e drenagem e é a unidade de gestão dos recursos hídricos. Uma ressalva a ser considerada, no tocante a localização do município de uma bacia hidrográfica, é de que a qualidade da água melhora ou piora de acordo com a carga de água não tratada despejada no leito do rio. Ou seja, municípios que devolvem a água tratada ao meio hídrico gerarão menor externalidades negativas aos municípios que se localizam à frente no leito do rio, comparados aos que não tratam. No presente trabalho, a questão da externalidade negativa quanto a localização dos municípios não entra no escopo da análise. Para que essa consideração fosse incorporada à análise, seria preciso a utilização de uma variável categórica e qualitativa do meio ambiente, o que exige uma observação muito específica de cada municípios pertencente a determinada bacia.

Dadas as considerações acima e como o SNIS não divulga as quantidades utilizadas e também os preços dos produtos empregados nos tratamentos de água e esgoto, considera-se que não variam ao longo do ano de 2002 no Estado de São Paulo, sendo a falta de dados uma forte restrição imposta ao modelo. 


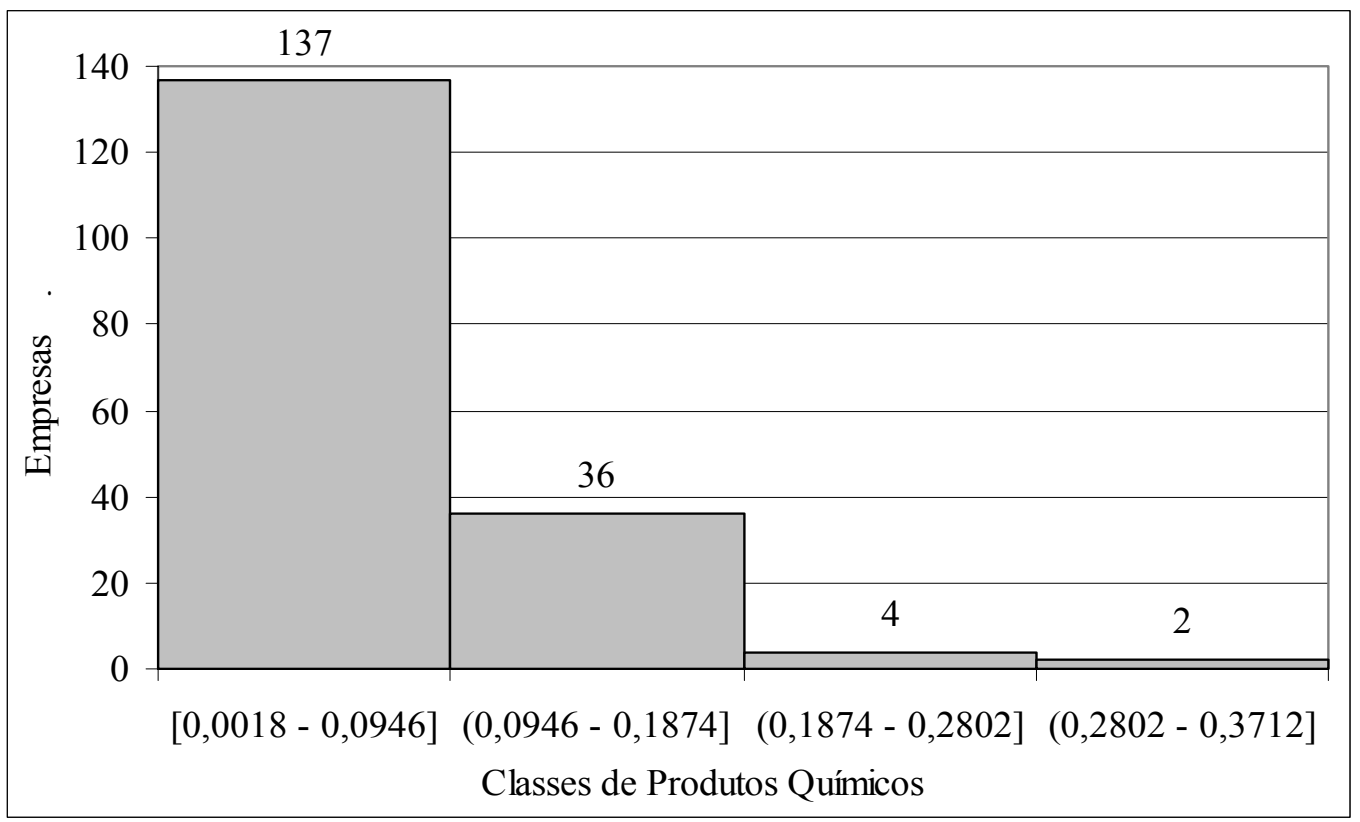

Figura 8 - Distribuição das empresas de saneamento básico acordo com as classes de participação produtos químicos sobre o custo operacional, 2002

Supõe-se que a retirada da variável preço de produtos químicos não tenha grandes impactos na análise de custo. Como é possível observar na figura 8 , maioria das empresas dos municípios do estado, ou seja, 137 apresentaram gastos realizados com produtos químicos em relação ao custo operacional total abaixo dos $10 \%$. De fato, essa suposição sobre o impacto é hipotética, já que como dito anteriormente, essa análise seria possível somente se informações ou sobre quantidades ou sobre preços existissem para cada município. Em estudos futuros, a existência dessa poderia contribuir para realização de análise de eficiência dos fatores, como a realizada por Farrell (1957) ou também por Shirota (1996).

Com relação a energia elétrica, Agência Nacional de Energia Elétrica (ANEEL), autarquia em regime especial, vinculada ao Ministério de Minas e Energia (MME) e criada pela Lei 9.427 de 26 de dezembro de 1996, tem como atribuições: regular e fiscalizar a geração, a transmissão, a distribuição e a comercialização da energia elétrica, visando o atendimento de reclamações, tanto de agentes, assim como de 
consumidores com equilíbrio entre as partes e em beneficio da sociedade; mediar os conflitos de interesses entre os agentes do setor elétrico e entre estes e os consumidores; conceder, permitir e autorizar instalações e serviços de energia; garantir tarifas justas; zelar pela qualidade do serviço; exigir investimentos; estimular a competição entre os operadores e assegurar a universalização dos serviços (Brasil, 2004). Assim, a ANEEL conceitua as tarifas cobradas dos consumidores finais estruturam-se tanto por nível de tensão (alta, média e baixa) como por classe de consumo (residencial, industrial, comercial, rural, serviços públicos, poderes públicos, iluminação pública). Os consumidores ligados em alta tensão têm a possibilidade de escolher tarifas diferenciadas por horários de consumo e por época do ano (período úmido e período seco). Para os consumidores da classe residencial, ligados em baixa tensão, dependendo de seu nível de consumo foram criadas faixas onde são aplicadas tarifas conforme os níveis sociais dos consumidores.

A categoria de consumo chamada de Serviço Público engloba o fornecimento de energia elétrica para motores, máquina e cargas para a operação da rede pública de saneamento básico. Assim, esta classificação utilizada pelas concessionárias de energia elétrica é subdivida em duas subcategorias; uma delas é tração elétrica (trens e metrôs explorados pelos governos estadual e federal) e a outra é água, saneamento básico e esgoto. De janeiro a dezembro referentes ao ano de 2002, a tarifa média por classe de consumo na região sudeste apresentou um valor de R\$ 107,89 por megawatt/hora.

A não inclusão da variável preço da energia elétrica no modelo pode ser justificada, pela não divulgação dos preços por cada empresa. É importante destacar que a média varia de acordo com contratos que cada empresa prestadora de serviço faz com sua concessionária de energia elétrica e isso pode distorcer a tarifa média prevista para o ano. Foi impossível captar essa distorção através dos modelos utilizados na presente pesquisa, pois não existem informações no SNIS, tanto sobre a quantidade gasta de energia, quanto sobre os contratos das empresas de saneamento e as concessionárias de energia. 


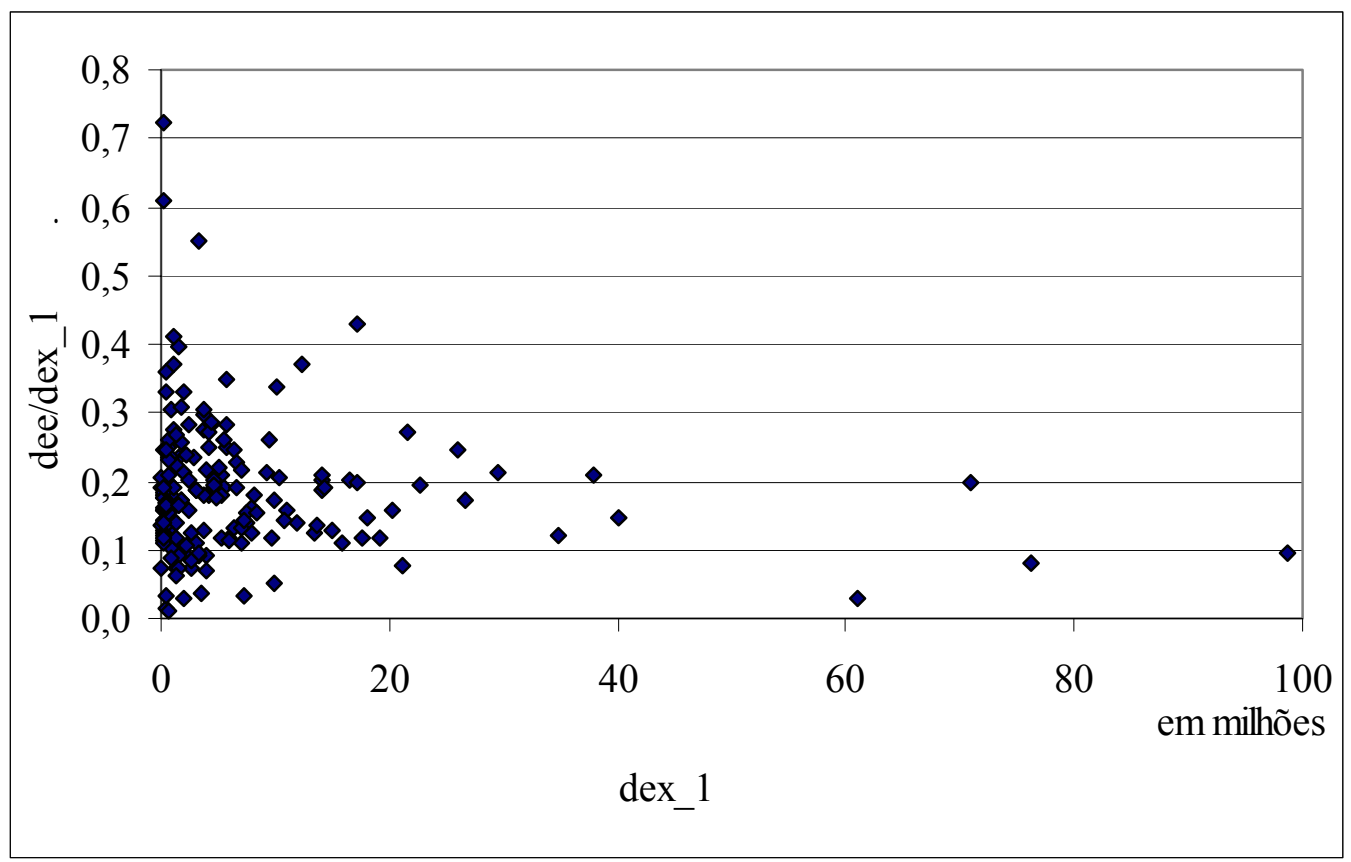

Figura 9 - Relação entre custo operacional (dex_1) com a razão entre despesas com energia elétrica (dee) no custo operacional (dex_1), em 2002

Assim, conforme se observa na figura 9, os gastos em energia frente ao custo operacional total das prestadoras de serviços se concentra num intervalo entre os $0,05 \mathrm{e}$ 0,40 . Isso demonstra que essa despesa tem um peso sobre os custos, mas que não podem ser captados na análise empírica devido a não variação dos preços da energia no ano, conforme dados da ANEEL.

Esses ajustes e estimativas foram realizados por serem necessários tanto para correção dos problemas encontrados com os dados da amostra, como para adequação para estimação do modelo proposto. Naturalmente, os ajustes foram cuidadosamente executados de forma a não violar a teoria. Todas as informações de valores monetários estão expressas em reais de 2002. 


\subsection{Estimação da fronteira da função custo}

Os modelos de fronteira estocástica de custo estimados, com forma funcional dada pela Cobb-Douglas, através da metodologia da máxima verossimilhança, possuem como variável dependente o custo operacional total representado pela variável dex_1. As variáveis independentes de preço e de controle são: variável de preço da mão de obra (dmpp), as variáveis paramétricas das categorias de proporção de serviços de terceiros no total do custo operacional é representada pelas variáveis binárias (classe 1, classe $2 \mathrm{e}$ classe 3). A variável de controle foi parametrizada para indicar o tipo de abrangência das empresas através da (dummy). Quanto as variáveis de produto, essas foram combinadas de forma a verificar a eficiência das empresas no modelo.

Assim, de acordo com a descrição das variáveis da amostra realizada no capítulo 3.3, foram estimados modelos com duas combinações de produtos, ambas analisadas com distribuição meio-normal e normal-truncada. A amostra é composta de 179 observações. Os modelos de fronteira estocástica para função custo estimados podem ser descritos conforme as equações abaixo:

i. Index_1 $=\alpha+\beta_{1} \operatorname{lnvam}+\gamma_{1} \operatorname{lndmpp}+\gamma_{2}$ classe $1+\gamma_{3}$ classe $2+\gamma_{4}$ classe $3+\delta$ dummy $+(\mathrm{u}+\mathrm{v})$; sendo $\mathrm{u} \sim \mathrm{N}^{+}\left(0, \sigma_{\mathrm{u}}^{2}\right)$, ou seja, assume-se que o erro sistêmico tem distribuição meio-normal.

ii. Index_1 $=\alpha+\beta_{1} \operatorname{lnvam}+\gamma_{1} \operatorname{lndmpp}+\gamma_{2}$ classe $1+\gamma_{3}$ classe $2+\gamma_{4}$ classe $3+\delta$ dummy $+(\mathrm{u}+\mathrm{v})$; sendo $\mathrm{u} \sim \mathrm{N}^{+}\left(\mu, \sigma_{\mathrm{u}}^{2}\right)$, ou seja, assume-se que o erro sistêmico tem distribuição normal-truncada.

iii. Index_1 $=\alpha+\beta_{1}$ lnqlaa $+\beta_{2}$ lnqlae $+\gamma_{1} \operatorname{lndmpp}+\gamma_{2}$ classe $1+\gamma_{3}$ classe $2+\gamma_{4}$ classe $3+\delta$ dummy $+(\mathrm{u}+\mathrm{v})$; sendo $\mathrm{u} \sim \mathrm{N}^{+}\left(0, \sigma_{\mathrm{u}}^{2}\right)$.

iv. Index_1 $=\alpha+\beta_{1}$ lnqlaa $+\beta_{2}$ lnqlae $+\gamma_{1} \operatorname{lndmpp}+\gamma_{2}$ classe $1+\gamma_{3}$ classe $2+\gamma_{4}$ classe $3 \delta$ dummy $+(\mathrm{u}+\mathrm{v})$; sendo $\mathrm{u} \sim \mathrm{N}^{+}\left(\mu, \sigma_{\mathrm{u}}^{2}\right)$.

v. Index_1 $\_\alpha+\beta_{1}$ lnera $+\beta_{2}$ lnere $+\gamma_{1} \operatorname{lndmpp}+\gamma_{2}$ classe $1+\gamma_{3}$ classe $2+\gamma_{4}$ classe $3+\delta$ dummy $+(\mathrm{u}+\mathrm{v})$; sendo $\mathrm{u} \sim \mathrm{N}^{+}\left(0, \sigma_{\mathrm{u}}^{2}\right)$. 
vi. Index_1 $=\alpha+\beta_{1}$ lnera $+\beta_{2}$ lnere $+\gamma_{1} \operatorname{lndmpp}+\gamma_{2}$ classe $1+\gamma_{3}$ classe $2+\gamma_{4}$ classe $3+\delta$ dummy $+(\mathrm{u}+\mathrm{v})$; sendo $\mathrm{u} \sim \mathrm{N}^{+}\left(\mu, \sigma^{2}{ }_{\mathrm{u}}\right)$.

vii. Index_1 $=\alpha+\beta_{1} \operatorname{lnligacao}+\gamma_{1} \operatorname{lndmpp}+\gamma_{2}$ classe $1+\gamma_{3}$ classe $2+\gamma_{4}$ classe $3+\delta$ dummy $+(\mathrm{u}+\mathrm{v})$; sendo $\mathrm{u} \sim \mathrm{N}^{+}\left(0, \sigma_{\mathrm{u}}^{2}\right)$.

viii. Index_1 $=\alpha+\beta_{1} \operatorname{lnligacao}+\gamma_{1} \operatorname{lndmpp}+\gamma_{2}$ classe $1+\gamma_{3}$ classe $2+\gamma_{4}$ classe $3+\delta$ dummy $+(\mathrm{u}+\mathrm{v})$; sendo $\mathrm{u} \sim \mathrm{N}^{+}\left(\mu, \sigma_{\mathrm{u}}^{2}\right)$.

ix. Index_1 $=\alpha+\beta_{1}$ lnextensao $+\gamma_{1} \operatorname{lndmpp}+\gamma_{2}$ classe $1+\gamma_{3}$ classe $2+\gamma_{4}$ classe $3+$ $\delta$ dummy $+(\mathrm{u}+\mathrm{v})$; sendo $\mathrm{u} \sim \mathrm{N}^{+}\left(0, \sigma^{2}{ }_{\mathrm{u}}\right)$.

x. Index_1 $\_\alpha+\beta_{1}$ lnextensao $+\gamma_{1} \operatorname{lndmpp}+\gamma_{2}$ classe $1+\gamma_{3}$ classe $2+\gamma_{4}$ classe $3+$ $\delta$ dummy $+(\mathrm{u}+\mathrm{v})$; sendo $\mathrm{u} \sim \mathrm{N}^{+}\left(\mu, \sigma_{\mathrm{u}}^{2}\right)$.

Para esse estudo foram utilizados 5 (cinco) definições diferentes para produto: (vam), (qlaa) e (qlae), (era) e (ere), (ligacao) e por fim, (extensao). Os modelos i. e ii. utilizam somente um produto na estimativa, volume de água (vam), isso porque as informações referentes ao volume de esgoto produzido são porcentagens estimadas do volume de água. Nos modelos iii. e iv. a análise de eficiência realiza-se sobre a combinação de produtos quantidades de ligações ativas de água (lnqlaa) e esgoto (Inqlae). Outra combinação de produtos utilizada refere-se a extensão da rede de água (lnera) e esgoto (lnere), nos modelos v. e vi. Nos quatro últimos modelos optou-se pela criação de variáveis que refletissem a combinação das variáveis através de uma única variável de produto. A variável (ligação) foi obtida através da soma da qlaa e qlae e a variável (extensão), através da soma da era e era. A criação dessas variáveis de produto se justifica pela possível existência de multicolinearidade ${ }^{12}$ entre as variáveis de água e esgoto. Assim, os modelos são compostos pelas variáveis já descritas e a distribuição do erro sistêmico está indicado nas tabelas de resultados como: $\left({ }^{a}\right)$ quando se assume meionormal, sendo $\mathrm{u} \sim \mathrm{N}^{+}\left(0, \sigma_{\mathrm{u}}^{2}\right)$; e $\left(^{b}\right)$ quando se assumir normal-truncada, sendo $\mathrm{u} \sim$ $\mathrm{N}^{+}\left(\mu, \sigma_{u}^{2}\right)$.

\footnotetext{
${ }^{12}$ Muticolinearidade refere-se a situação em que há uma relação linear exata ou aproximada entre as variáveis independentes (Gujarati, 2000).
} 


\section{RESULTADOS E DISCUSSÃO}

\subsection{Análise da regressão}

Nos modelos i. e ii. foram estimados apenas com o produto, volume de água produzido (vam). Como já escrito anteriormente, optou-se por retirar do modelo a variável de produto referente a volume de esgoto, pois este é obtido pela porcentagem de água produzida. Os resultados podem ser observados nas tabelas 1 e 2 a seguir:

Tabela 1. Coeficientes estimados para a fronteira estocástica função custo ${ }^{\mathrm{a}}$, modelo i.

\begin{tabular}{|c|c|c|c|c|c|c|}
\hline Variáveis & $\begin{array}{c}\text { Estimativa } \\
(1) \\
\end{array}$ & $\begin{array}{c}\text { Desvio } \\
\text { padrão } \\
\text { (2) }\end{array}$ & $\begin{array}{l}Z \\
(3) \\
\end{array}$ & $\begin{array}{c}P>|z| \\
(4)\end{array}$ & \multicolumn{2}{|c|}{$\begin{array}{l}\text { Intervalo de confiança* } \\
\text { (5) }\end{array}$} \\
\hline lnvam & 0,7976075 & 0,022876 & 34,87 & 0,000 & 0,7527714 & 0,8424436 \\
\hline lndmpp & 0,214953 & 0,0669448 & 3,21 & 0,001 & 0,0837436 & 0,3461624 \\
\hline classe 1 & $-0,543981$ & 0,1835484 & $-2,96$ & 0,003 & $-0,9037292$ & $-0,1842328$ \\
\hline classe 2 & $-0,0646932$ & 0,1743374 & $-0,37$ & 0,711 & $-0,4063882$ & 0,2770018 \\
\hline classe 3 & 0,1372601 & 0,174649 & 0,79 & 0,432 & $-0,2050456$ & 0,4795658 \\
\hline dummy & $-0,1786402$ & 0,1321396 & $-1,35$ & 0,176 & $-0,4376291$ & 0,0803488 \\
\hline constante & 6,244431 & 0,6883609 & 9,07 & 0,000 & 4,895269 & 7,593594 \\
\hline $\ln \sigma_{v}^{2}$ & $-1,879454$ & 0,1057179 & $-17,78$ & 0,000 & $-2,086657$ & $-1,67225$ \\
\hline $\ln \sigma_{u}^{2}$ & $-9,770286$ & & & & & \\
\hline$\sigma_{\mathrm{v}}$ & 0,3907346 & 0,0206538 & & & 0,3522802 & 0,4333866 \\
\hline$\sigma_{\mathrm{u}}$ & 0,007558 & & & & & \\
\hline$\sigma^{2}$ & 0,1527306 & & & & & \\
\hline
\end{tabular}


Tabela 1. Coeficientes estimados para a fronteira estocástica função custo ${ }^{\mathrm{a}}$, modelo i.

\begin{tabular}{cccccc}
\hline Variáveis & Estimativa & $\begin{array}{c}\text { Desvio } \\
\text { padrão }\end{array}$ & $\mathrm{Z}$ & $\mathrm{P}>|\mathrm{z}|$ & Intervalo de confiança* \\
& $(1)$ & $(2)$ & $(3)$ & $(4)$ & $(5)$ \\
\hline
\end{tabular}

$\lambda \quad 0,0193432$

Wald $\left[\chi_{(6)}^{2}\right] \quad 2793,14 \quad \operatorname{Prob}\left[\chi_{(6)}^{2}\right] \quad 0,000$

$\operatorname{RV}\left(\sigma_{\mathrm{u}}=0\right) \quad 0 \quad \operatorname{Prob}\left[\chi_{(1)}^{2}\right] \quad 1$

a erro sistemático com distribuição meio-normal

* denota significância ao nível de 5\%

No modelo i., dos parâmetros estimados, a classe2, classe3 e dummy, não apresentaram resultados significantes, a 5\% de significância. Na análise dos coeficientes, mesmo não sendo significativos estatisticamente, a classe 3 apresentou sinais positivo, contrário ao esperado. Como um aumento de vam, dmpp, aumentariam o custo de produção, assim como quanto menor o grau de tercerização dos serviços, maior o custo, dado que o as classes estão sendo comparadas classe com maior porcentagem de serviços terceirizados entre $(0,7269-0,9524]$. O coeficiente da variável dummy apresenta sinal negativo, o que significa que para empresas regionais, um aumento do custo teriam um menor impacto que um aumento de custos para empresas locais.

Os termos que compõem o erro do modelo podem ser observados na tabela e somente o erro aleatório (v), mostra-se significativo. Esse resultado conduz à análise do teste RV, que confirma que o modelo estimado não é significativo, já que não rejeita a H0 de que $\sigma_{\mathrm{u}}=0$.

O modelo ii. estimado impõem a distribuição normal-truncada ao erro u. 
Tabela 2. Coeficientes estimados para a fronteira estocástica função custo ${ }^{\mathrm{b}}$, modelo ii.

\begin{tabular}{|c|c|c|c|c|c|c|}
\hline Variáveis & $\begin{array}{c}\text { Estimativa } \\
\text { (1) } \\
\end{array}$ & $\begin{array}{c}\text { Desvio } \\
\text { padrão } \\
\text { (2) }\end{array}$ & $\begin{array}{l}\mathrm{Z} \\
(3)\end{array}$ & $\begin{array}{c}P>|z| \\
(4)\end{array}$ & \multicolumn{2}{|c|}{$\begin{array}{l}\text { Intervalo de confiança* } \\
\qquad(5)\end{array}$} \\
\hline lnvam & 0,7976076 & 0,022876 & 34,87 & 0,000 & 0,7527715 & 0,8424437 \\
\hline lndmpp & 0,2149538 & 0,0669448 & 3,21 & 0,001 & 0,0837445 & 0,3461631 \\
\hline classe 1 & $-0,54398$ & 0,1835482 & $-2,96$ & 0,003 & $-0,9037279$ & $-0,1842321$ \\
\hline classe 2 & $-0,0646924$ & 0,1743372 & $-0,37$ & 0,711 & $-0,4063871$ & 0,2770023 \\
\hline classe 3 & 0,1372607 & 0,1746488 & 0,79 & 0,432 & $-0,2050447$ & 0,4795661 \\
\hline dummy & $-0,1786411$ & 0,1321395 & $-1,35$ & 0,176 & $-0,4376299$ & 0,0803476 \\
\hline constante & 6,24662 & 0,7336828 & 8,51 & 0,000 & 4,808628 & 7,684612 \\
\hline$\mu$ & $-0,1020466$ & 9,488977 & $-0,01$ & 0,991 & $-18,7001$ & 18,49601 \\
\hline $\ln \sigma^{2}$ & $-1,876672$ & 0,3041538 & $-6,17$ & 0,000 & $-2,472803$ & $-1,280542$ \\
\hline ilgt $\gamma$ & $-5,899502$ & 106,775 & $-0,06$ & 0,956 & $-215,1746$ & 203,3756 \\
\hline$\sigma^{2}$ & 0,1530987 & 0,0465656 & & & 0,0843481 & 0,2778867 \\
\hline$\gamma$ & 0,0027333 & 0,2910523 & & & $3,56 \mathrm{e}-94$ & 1 \\
\hline$\sigma_{u}^{2}$ & 0,0004185 & 0,044679 & & & $-0,0871508$ & 0,0879878 \\
\hline$\sigma_{\mathrm{v}}^{2}$ & 0,1526803 & 0,0162404 & & & 0,1208497 & 0,1845109 \\
\hline Wald $\left[\chi_{(6)}^{2}\right]$ & 2793,14 & $\operatorname{Prob}\left[\chi_{(6)}^{2}\right]$ & 0,000 & & & \\
\hline Teste Z & $-2,254$ & Prob $>|z|$ & 0,988 & & & \\
\hline
\end{tabular}

${ }^{\mathrm{b}}$ erro sistemático com distribuição normal-truncada

* denota significância ao nível de 5\%

Os parâmetros e os coeficientes do modelo ii. apresentaram resultados semelhantes ao anterior, mesmo u assumindo distribuição normal-truncada. E assim, como o modelo i., no teste $\mathrm{Z}$, a H0 de eficiência neste modelo não é rejeitada. 
Os coeficientes do teste $\mathrm{W}$, para as seis variáveis, tanto em i., quanto em ii., apresentaram-se altamente significativo, rejeitando-se a H0, o que poderia sugerir a não existência de empresas plenamente eficientes nesse modelo.

Apesar de não violar nenhuma hipótese de regressão (estimadores nãoviesados e consistentes), referindo-se apenas à situação em que existe uma relação linear entre as variáveis independentes, segundo Gujarati (2000), foi realizado um teste para detecção da multicolinearidade para todos os modelos.

O problema de multicolinearidade, segundo Pereira ${ }^{13}$ citado por Lima (2003), que embora represente uma potencial falta de precisão na estimativa dos parâmetros, não implica que necessariamente em perda de acurácia na análise. A acurácia diz respeito à capacidade da medida em representar bem o objetivo medido, diferente da precisão, que diz respeito à fineza com que se realiza a medida.

A primeira verificação realizada foi a estimação da matriz de correlação entre as variáveis dos modelos i. e ii., e os valores mais próximos de $|1|$, representam o maior grau de correlação entre as variáveis e pode ser observado na tabela 3 a seguir:

Tabela 3. Matriz de correlação das variáveis dos modelos i. e ii.

\begin{tabular}{ccccccc}
\hline & lnvam & lndmpp & classe1 & classe2 & classe3 & dummy \\
\hline lnvam & 1,0000 & & & & & \\
lndmpp & $-0,2347$ & 1,0000 & & & & \\
classe1 & $-0,4045$ & $-0,2011$ & 1,0000 & & & \\
classe2 & 0,0353 & 0,0779 & $-0,4998$ & 1,0000 & & \\
classe3 & 0,2488 & 0,1618 & $-0,3549$ & $-0,5610$ & 1,0000 & \\
dummy & $-0,4808$ & 0,7789 & $-0,7789$ & 0,1735 & 0,0282 & 1,0000 \\
\hline
\end{tabular}

${ }^{13}$ PEREIRA, J.C.R. Análise de dados qualitativos: estratégias metodológicas para as ciências da saúde, humanas e sociais. São Paulo: Edusp, 2001. 156p. 
Greene (1993), descreve o cálculo do Índice Condicional (IC), para o diagnóstico da multicolinearidade, e o define de acordo com a seguinte fórmula:

$$
\mathrm{IC}=\sqrt{\frac{\text { autovalor máximo }}{\text { autovalor mínimo }}}
$$

$\mathrm{O}$ valor entre 10 e 30 indica multicolinearidade moderada a alta e acima de 30, grave. Um dos pontos fracos desse teste, é que a obtenção dos autovalores depende diretamente da escala dos dados. Como objetivo de detectar a multicolinearidade, uma alternativa adotada no presente trabalho, na tentativa de minimizar esse problema de diferença de escala de dados entre as variáveis dos modelos, estimou-se a razão de cada observação pela média de cada variável para que o IC fosse aplicado.

Para i. e ii. o valor obtido foi 7,10, o que não indica fortes problemas de multicolinearidade entre as variáveis destes modelos, ou seja, não há perda de acurácia.

Nos modelos iii. e iv. estimados, o objetivo principal foi analisar a eficiência econômica da combinação de produtos quantidade de ligações ativas de água à rede pública (qlaa) e quantidade de ligações ativas de esgoto à rede pública (qlae), com distribuição do erro sistemático meio-normal e normal-truncado, respectivamente. Sob $5 \%$ de significância, analisando os coeficientes de produto do modelo, Inqlaa, Inqlae, apresentaram-se significativos e sinais positivos, ou seja, o custo operacional das empresas de saneamento e abastecimento serão maiores quanto mais ligações de abastecimento de água e esgotamento sanitário existirem.

De acordo com os coeficientes estimados, nesta modelagem iii., apesar de não significativas estatisticamente, as variáveis: dummy apresenta valor positivo, sugerindo que o custo operacional das empresas será menor se as prestadoras de serviços forem de abrangência municipal; lndmpp indica o que era esperado, que os custos operacionais serão maiores quanto maior os salários médios de pessoal próprio das empresas; e as variáveis classe2 e classe3 não apresentam resultados significativos e 
sinais iguais aos modelos anteriores, ou seja, pode-se dizer que o custo operacional das empresas não é influenciado pelas classes que determinam os limites dos intervalos dos gastos com terceiros.

Tabela 4. Coeficientes estimados para a fronteira estocástica função custo ${ }^{a}$, modelo iii.

\begin{tabular}{|c|c|c|c|c|c|c|}
\hline Variáveis & $\begin{array}{c}\text { Estimativa } \\
\text { (1) }\end{array}$ & $\begin{array}{c}\text { Desvio } \\
\text { padrão } \\
\text { (2) }\end{array}$ & $\begin{array}{l}\mathrm{Z} \\
(3)\end{array}$ & $\begin{array}{c}P>|z| \\
(4)\end{array}$ & \multicolumn{2}{|c|}{$\begin{array}{l}\text { Intervalo de confiança* } \\
\qquad(5)\end{array}$} \\
\hline lnqlaa & 0,210989 & 0,0560677 & 11,08 & 0,000 & 0,5112082 & 0,7309896 \\
\hline Inqlae & 0,3119676 & 0,0569017 & 5,48 & 0,000 & 0,2004422 & 0,4234929 \\
\hline lndmpp & 0,11847141 & 0,0685785 & 1,73 & 0,084 & $-0,159373$ & 0,2528855 \\
\hline classe 1 & $-0,452748$ & 0,1849637 & $-2,45$ & 0,014 & $-0,8152703$ & $-0,0902258$ \\
\hline classe 2 & $-0,0751219$ & 0,1792328 & $-0,42$ & 0,675 & $-0,4264117$ & 0,2761679 \\
\hline classe 3 & 0,2252451 & 0,175053 & 1,29 & 0,198 & $-0,1178525$ & 0,5683427 \\
\hline dummy & 0,0283527 & 0,1302943 & 0,22 & 0,828 & $-0,2270194$ & 0,2837249 \\
\hline constante & 4,626194 & 0,7544492 & 6,13 & 0,000 & 3,1475 & 6,104887 \\
\hline $\ln \sigma_{v}^{2}$ & $-2,652628$ & 0,2609239 & $-10,17$ & 0,000 & $-3,164029$ & $-2,141226$ \\
\hline $\ln \sigma_{u}^{2}$ & $-1,516236$ & 0,2829614 & $-5,36$ & 0,000 & $-2,07083$ & $-0,9616414$ \\
\hline$\sigma_{\mathrm{v}}$ & 0,265454 & 0,0346316 & & & 0,2055606 & 0,3427983 \\
\hline$\sigma_{\mathrm{u}}$ & 0,4685475 & 0,0662904 & & & 0,3550794 & 0,6182758 \\
\hline$\sigma^{2}$ & 0,2900026 & 0,0512389 & & & 0,1895762 & 0,3904289 \\
\hline$\lambda$ & 1,765082 & 0,0935556 & & & 1,581714 & 1,948446 \\
\hline Wald $\left[\chi_{(7)}^{2}\right]$ & 2929,92 & $\operatorname{Prob}\left[\chi_{(7)}^{2}\right]$ & 0,000 & & & \\
\hline $\operatorname{RV}\left(\sigma_{\mathrm{u}}=0\right)$ & 9,97 & $\operatorname{Prob}\left[\chi_{(1)}^{2}\right]$ & 0,001 & & & \\
\hline
\end{tabular}

a erro sistemático com distribuição meio-normal

* denota significância ao nível de 5\% 
Os termos que compõem o erro do modelo podem ser observados na tabela e mostram-se significativos. Assim, analisando o erro parametrizado da função de verossimilhança e representado pelas através das variáveis $\lambda$ e $\sigma$, os coeficientes não tendem a zero e isso significa que um dos erros domina a distribuição dos erros da função $\varepsilon$. Se confrontado com o teste RV, confirma-se a existência de ineficiência deste modelo considerando o erro sistemático e numa distribuição assintótica, apresentará uma estatística dada pela mistura de distribuições $\chi^{2}$.

Através da estatística apresentada na tabela 4, rejeita-se o teste $\mathrm{W}$ para as 7 variáveis do modelo, assim como RV para a variável $\mathrm{u}$, ou seja, não existem empresas plenamente eficientes nesse modelo, a $5 \%$ de significância e distribuição $\chi^{2}$.

O modelo iv. estimado, apresentado na tabela 5, utiliza a mesma combinação de variáveis de produto, mas assumindo que o erro sistêmico tem distribuição normaltruncada. O comportamento dos coeficientes são parecidos com o de iii., com exceção do sinal da dummy, que neste modelo negativo, indicando que empresas municipais poderiam apresentar um custo maior de produção.

Tabela 5. Coeficientes estimados para a fronteira estocástica função custo ${ }^{\mathrm{b}}$, modelo iv.

\begin{tabular}{lcccccc}
\hline \multicolumn{1}{c}{ Variáveis } & $\begin{array}{c}\text { Estimativa } \\
\text { pesvio }\end{array}$ & $\begin{array}{c}\text { Dadrão } \\
(1)\end{array}$ & $\begin{array}{c}\mathrm{Z} \\
(2)\end{array}$ & $\begin{array}{c}\mathrm{P}>|\mathrm{z}| \\
(3)\end{array}$ & \multicolumn{2}{c}{ Intervalo de confiança* } \\
\hline lnqlaa & 0,7408997 & 0,0513623 & 14,42 & 0,000 & 0,6402218 & 0,8415581 \\
lnqlae & 0,2118759 & 0,0496907 & 4,26 & 0,000 & 0,114439 & 0,3091679 \\
lndmpp & 0,1794864 & 0,0624373 & 2,87 & 0,004 & 0,0571115 & 0,3018612 \\
classe 1 & $-0,3644325$ & 0,1808597 & $-2,02$ & 0,044 & $-0,718911$ & $-0,0099539$ \\
classe 2 & $-0,155149$ & 0,1745512 & $-0,09$ & 0,929 & $-0,3576219$ & 0,3265992 \\
classe 3 & 0,2261338 & 0,01709511 & 1,32 & 0,186 & $-0,1089243$ & 0,5611919 \\
dummy & $-0,0313522$ & 0,1193148 & $-0,26$ & 0,793 & $-0,2652048$ & 0,2025005 \\
constante & 3,878709 & 0,6751002 & 5,75 & 0,000 & 2,555537 & 5,201881 \\
$\mu$ & $-346,2562$ & 243,7056 & $-1,42$ & 0,155 & $-823,9104$ & 131,398
\end{tabular}




\begin{tabular}{|c|c|c|c|c|c|c|}
\hline Variáveis & $\begin{array}{c}\text { Estimativa } \\
(1) \\
\end{array}$ & $\begin{array}{c}\text { Desvio } \\
\text { padrão } \\
(2)\end{array}$ & $\begin{array}{c}Z \\
(3)\end{array}$ & $\begin{array}{c}P>|z| \\
(4)\end{array}$ & \multicolumn{2}{|c|}{$\begin{array}{c}\text { Intervalo de confiança* } \\
\text { (5) }\end{array}$} \\
\hline $\ln \sigma^{2}$ & 4,438228 & 0,6825308 & 6,50 & 0,000 & 3,100493 & 5,775964 \\
\hline ilgt $\gamma$ & 7,046538 & 0,7032935 & 10,02 & 0,000 & 5,668108 & 8,424968 \\
\hline$\sigma^{2}$ & 84,62489 & 57,75909 & & & 22,20889 & 322,4552 \\
\hline$\gamma$ & 0,9991303 & 0,0006111 & & & 0,9965575 & 0,9997807 \\
\hline$\sigma_{u}^{2}$ & 84,55139 & 57,75904 & & & $-28,65433$ & 197,7569 \\
\hline$\sigma_{\mathrm{v}}^{2}$ & 0,0735949 & 0,0125304 & & & 0,0490357 & 0,0981541 \\
\hline Wald $\left[\chi_{(7)}^{2}\right]$ & 3434,84 & $\operatorname{Prob}\left[\chi_{(7)}^{2}\right]$ & 0,000 & & & \\
\hline Teste $\mathrm{Z}$ & 5,005 & Prob $>|z|$ & 0,000 & & & \\
\hline
\end{tabular}

Os termos que compõem o erro do modelo podem ser observados na tabela e mostram-se significativos. Assim, analisando o erro parametrizado da função de verossimilhança e representado pelas através das variáveis $\gamma=\sigma^{2} / \sigma^{2}{ }_{u}$ e $\sigma_{u}^{2}=\sigma^{2}{ }_{v}+\sigma^{2}$. Assim, de acordo com os coeficientes e isso significa que a distribuição dos erros da função $\varepsilon$ são dados por uma mistura de distribuições $\chi^{2}$, visto que tanto o erro sistêmico quanto o erro aleatório apresentaram estimativas significativas. Sendo a distribuição normal-truncada uma generalização da meio-normal, essa distribuição será dada pela $\left(\mu, \sigma^{2}\right)$, predeterminando que $\mu=0$. Essa distribuição, segundo Coelli et al. (1998), pode ter várias formas, dependendo do tamanho e do sinal de $\mu$, apresentou um valor negativo, próximo a -1 não significativa a $5 \%$ de significância.

A correlação entre as variáveis dos modelos iii. e iv. pode ser observada através da matriz de correlação na tabela 6 a seguir: 
Tabela 6. Matriz de correlação das variáveis dos modelos iii. e iv.

\begin{tabular}{cccccccc}
\hline & lnqlaa & Inqlae & lndmpp & classe1 & classe2 & classe3 & dummy \\
Inqlaa & 1,0000 & & & & & & \\
lnqlae & 0,9031 & 1,0000 & & & & & \\
lndmpp & $-0,1274$ & $-0,3139$ & 1,0000 & & & & \\
classe1 & $-0,4433$ & $-0,3684$ & $-0,2011$ & 1,0000 & & & \\
classe2 & 0,0587 & 0,0887 & 0,0779 & $-0,4998$ & 1,0000 & & \\
classe3 & 0,2621 & 0,1615 & 0,1618 & $-0,3549$ & $-0,5610$ & 1,0000 & \\
dummy & $-0,4168$ & $-0,5354$ & 0,7789 & $-0,1207$ & 0,1735 & 0,0282 & 1,0000 \\
\hline
\end{tabular}

A tabela 6 demonstra a existência de correlação entre as variáveis qlaa e qlae. Essa indicação leva a uma análise mais cautelosa de multicolinearidade através da estimativa do IC nestes modelos que apresentou o valor de 12,43, mas que não representa perda total de acurácia. $\mathrm{O}$ teste $\mathrm{W}$ foi rejeitado, como nos casos anteriores, ou seja, as empresas não atuam exatamente na fronteira custo neste modelo.

Os modelos v. e vi. utilizou a combinação de variáveis de produtos: era e ere, assumindo que o componente erro sistemático tenha distribuição meio-normal e normal-truncada respectivamente.

Conforme a tabela 7 e 8 , os coeficientes estimados apresentam resultados semelhantes, tanto nas estatísticas, quanto nos valores e sinais dos coeficientes. Classe2, apresentou sinal esperado, classe 3 apresentou sinal oposto ao esperado e dummy valor negativo sugere que o custo operacional das empresas será maior se as prestadoras de serviços forem de abrangência municipal, sendo que todos não são significativos estatisticamente. A variável lndmpp indica que os custos operacionais serão maiores quanto maior os salários médios de pessoal próprio das empresas. 
Tabela 7. Coeficientes estimados para a fronteira estocástica função custo ${ }^{\mathrm{a}}$, modelo v.

\begin{tabular}{|c|c|c|c|c|c|c|}
\hline Variáveis & $\begin{array}{c}\text { Estimativa } \\
(1) \\
\end{array}$ & $\begin{array}{c}\text { Desvio } \\
\text { padrão } \\
(2)\end{array}$ & $\begin{array}{l}Z \\
(3) \\
\end{array}$ & $\begin{array}{c}P>|z| \\
(4)\end{array}$ & \multicolumn{2}{|c|}{$\begin{array}{l}\text { Intervalo de confiança* } \\
\text { (5) }\end{array}$} \\
\hline lnera & 0,7648556 & 0,0521899 & 14,66 & 0,000 & 0,6626241 & 0,8670871 \\
\hline lnere & 0,2825897 & 0,0546227 & 5,17 & 0,000 & 0,1755311 & 0,3896483 \\
\hline lndmpp & 0,3024271 & 0,0614979 & 4,92 & 0,000 & 0,1818935 & 0,4229608 \\
\hline classe 1 & $-0,5964834$ & 0,1711231 & $-3,49$ & 0,000 & $-0,9318785$ & $-0,2610883$ \\
\hline classe 2 & $-0,2595294$ & 0,1656091 & $-1,57$ & 0,117 & $-0 ., 584117$ & 0,0650582 \\
\hline classe 3 & 0,0711499 & 0,1628422 & 0,44 & 0,662 & $-0,2480149$ & 0,3903147 \\
\hline dummy & $-0,0001065$ & 0,1243424 & 0,00 & 0,999 & $-0,2438131$ & 0,2436 \\
\hline constante & 6,404431 & 0,6626563 & 9,66 & 0,000 & 5,105648 & 7,703213 \\
\hline $\ln \sigma_{v}^{2}$ & $-2,588504$ & 0,329343 & $-7,86$ & 0,000 & $-3,234005$ & $-1,943004$ \\
\hline $\ln \sigma_{u}^{2}$ & $-1,885348$ & 0,4867811 & $-3,87$ & 0,000 & $-2,839414$ & $-0,9312669$ \\
\hline$\sigma_{\mathrm{v}}$ & 0,2741028 & 0,0451369 & & & 0,1984928 & 0,3785141 \\
\hline$\sigma_{\mathrm{u}}$ & 0,3895862 & 0,0948216 & & & 0,2417849 & 0,6277374 \\
\hline$\sigma^{2}$ & 0,2269097 & 0,0544494 & & & 0,120191 & 0,3336285 \\
\hline$\lambda$ & 1,421314 & 0,1352787 & & & 1,156173 & 1,686456 \\
\hline Wald $\left[\chi_{(7)}^{2}\right]$ & 3384,35 & $\operatorname{Prob}\left[\chi_{(7)}^{2}\right]$ & 0,000 & & & \\
\hline $\operatorname{RV}\left(\sigma_{\mathrm{u}}=0\right)$ & 1,65 & $\operatorname{Prob}\left[\chi_{(1)}^{2}\right]$ & 0,100 & & & \\
\hline
\end{tabular}

a erro sistemático com distribuição meio-normal

* denota significância ao nível de 5\%

De acordo com a tabela 7 , os termos que compõem o erro mostram-se significativos. Assim, analisando o erro parametrizado da função de verossimilhança e representado pelas através das variáveis $\lambda$ e $\sigma$, os coeficientes não tenderão a zero e isso significa que um dos erros domina a distribuição dos erros da função $\varepsilon$. Confrontado 
com o teste RV, observa-se que o modelo não é significativo, ou seja, aceita-se H0, podendo indicar existência de eficiência neste modelo.

As estimativas são apresentadas na tabela 8 a seguir, assumindo agora a distribuição normal-truncada para o erro sistêmico:

Tabela 8. Coeficientes estimados para a fronteira estocástica função custo ${ }^{\mathrm{b}}$, modelo vi.

\begin{tabular}{|c|c|c|c|c|c|c|}
\hline Variáveis & $\begin{array}{c}\text { Estimativa } \\
\text { (1) }\end{array}$ & $\begin{array}{c}\text { Desvio } \\
\text { padrão } \\
(2)\end{array}$ & $\begin{array}{l}\mathrm{Z} \\
(3)\end{array}$ & $\begin{array}{c}P>|z| \\
(4)\end{array}$ & \multicolumn{2}{|c|}{$\begin{array}{l}\text { Intervalo de confiança* } \\
\qquad(5)\end{array}$} \\
\hline lnera & 0,7604641 & 0,0534042 & 14,24 & 0,000 & 0,6557937 & 0,8651345 \\
\hline lnere & 0,2875914 & 0,0562514 & 5,11 & 0,000 & 0,1773406 & 0,3978421 \\
\hline lndmpp & 0,30668 & 0,0621524 & 4,93 & 0,000 & 0,1848636 & 0,4284965 \\
\hline classe 1 & $-0,593251$ & 0,1735042 & $-3,42$ & 0,001 & $-0,933313$ & $-0,253189$ \\
\hline classe 1 & $-0,2591003$ & 0,1680875 & $-1,54$ & 0,123 & $-0,5885459$ & 0,0703452 \\
\hline classe 2 & 0,0711898 & 0,1652235 & 0,43 & 0,667 & $-0,2526422$ & 0,3950218 \\
\hline classe 3 & $-0,, 43604$ & 0,1242022 & $-0,04$ & 0,972 & $-0,2477922$ & 0,2390714 \\
\hline constante & 6,393974 & 0,6658966 & 9,60 & 0,000 & 5,08884 & 7,699107 \\
\hline$\mu$ & $-0,3647705$ & 1,404325 & $-0,26$ & 0,795 & $-3,117196$ & 2,387655 \\
\hline $\ln \sigma^{2}$ & $-1,176203$ & 1,038771 & $-1,13$ & 0,258 & $-3,212157$ & 0,85975 \\
\hline ilgt $\gamma$ & 1,088966 & 1,387781 & 0,78 & 0,433 & $-1,631034$ & 3,808965 \\
\hline$\sigma^{2}$ & 0,3084476 & 0,3204064 & & & 0,0402697 & 2,362578 \\
\hline$\gamma$ & 0,7681869 & 0,2614624 & & & 0,1636887 & 0,9783098 \\
\hline$\sigma_{u}^{2}$ & 0,2307764 & 0,3172766 & & & $-0,3910742$ & 0,8526271 \\
\hline$\sigma_{\mathrm{v}}^{2}$ & 0,0776712 & 0,0257713 & & & 0,0271604 & 0,1281819 \\
\hline Wald $\left[\chi_{(7)}^{2}\right]$ & 3394,22 & $\operatorname{Prob}\left[\chi_{(7)}^{2}\right]$ & 0,000 & & & \\
\hline Teste $\mathrm{Z}$ & 0,895 & Prob $>|z|$ & 0,186 & & & \\
\hline
\end{tabular}

${ }^{\mathrm{b}}$ erro sistemático com distribuição normal-truncada 
* denota significância ao nível de 5\%

Os termos que compõem o erro do modelo podem ser observados na tabela e mostram-se não significativos. Assim, analisando o erro parametrizado da função de verossimilhança e representado pelas através das variáveis $\gamma=\sigma^{2} / \sigma_{u}^{2}$ e $\sigma_{u}^{2}=\sigma_{v}^{2}+\sigma^{2}$. Sendo a distribuição normal-truncada, a distribuição será dada pela $\left(\mu, \sigma^{2}\right)$, predeterminando que $\mu=0$. A estimativa de dessa média apresentou uma estatística não significativa, e coeficiente negativo.

Através do teste $\mathrm{W}$ rejeita-se a $\mathrm{H} 0$, indicando que nesse modelo não existem empresas que são plenamente eficientes. Mas como se observa no teste $\mathrm{Z}$, a H0 não é rejeitada, o que contradiz o teste global W. Apesar das estimativas dos coeficientes de produto, extensão da rede de abastecimento e de esgoto apresentam resultados significativos implicando em custo operacional está diretamente ligado combinação dessas variáveis de produto, esses resultados estão apresentados num modelo não significativo de acordo com $\mathrm{Z}$.

A matriz de correlação é apresentada na tabela 9 a seguir, como sendo a primeira análise para detecção de multicolinearidade.

Tabela 9. Matriz de correlação das variáveis dos modelos v. e vi.

\begin{tabular}{cccccccc}
\hline & lnera & lnere & lndmpp & classe1 & classe2 & classe3 & dummy \\
\hline lnera & 1,0000 & & & & & & \\
lnere & 0,9122 & 1,0000 & & & & & \\
lndmpp & $-0,2588$ & $-0,3874$ & 1,0000 & & & & \\
classe1 & $-0,4128$ & $-0,3280$ & $-0,2011$ & 1,0000 & & & \\
classe2 & 0,0619 & 0,0942 & 0,0779 & $-0,4998$ & 1,0000 & & \\
classe3 & 0,2291 & 0,1298 & 0,1618 & $-0,3549$ & $-0,5610$ & 1,0000 & \\
dummy & $-0,4170$ & $-0,5985$ & 0,7789 & $-0,1207$ & 0,1735 & 0,0282 & 1,0000 \\
\hline
\end{tabular}


A matriz indica que existe forte correlação entre era e ere. Para verificação de multicolinearidade nos modelos que utilizam essas variáveis foi calculada a estimativa do IC para as variáveis deste modelo resultaram no valor 9,69, o que não indica multicolinearidade forte.

Os resultados dos modelos vii. e viii., são apresentados nas tabelas 10 e 11 . A definição do produto nesses modelos é ligacao, dada pela soma dos produtos qlaa e qlae.

Tabela 10. Coeficientes estimados para a fronteira estocástica função custo ${ }^{\mathrm{a}}$, modelo vii.

\begin{tabular}{|c|c|c|c|c|c|c|}
\hline Variáveis & $\begin{array}{c}\text { Estimativa } \\
(1)\end{array}$ & $\begin{array}{c}\text { Desvio } \\
\text { padrão } \\
(2)\end{array}$ & $\begin{array}{l}Z \\
(3) \\
\end{array}$ & $\begin{array}{c}P>|z| \\
(4)\end{array}$ & \multicolumn{2}{|c|}{$\begin{array}{c}\text { Intervalo de confiança* } \\
\text { (5) }\end{array}$} \\
\hline Inligacao & 0,9613527 & 0,023265 & 41,32 & 0,000 & 0,9157541 & 1,0069516 \\
\hline lndmpp & 0,1906902 & 0,0576299 & 3,31 & 0,001 & 0,0777377 & 0,3036428 \\
\hline classe 1 & $-0,4603539$ & 0,1581596 & $-2,91$ & 0,004 & $-0,7703409$ & $-0,1503668$ \\
\hline classe 2 & $-0,1414646$ & 0,1497532 & $-0,94$ & 0,345 & $-0,4349755$ & 0,1520463 \\
\hline classe 3 & 0,1416655 & 0,1501679 & 0,94 & 0,345 & $-0,1526582$ & 0,4359892 \\
\hline dummy & $-0,0028385$ & 0,1152182 & $-0,02$ & 0,980 & $-0,2286621$ & 0,2229851 \\
\hline constante & 3,353758 & 0,6085829 & 5,51 & 0,000 & 2,160958 & 4,546559 \\
\hline $\ln \sigma_{v}^{2}$ & $-2,181985$ & 0,105769 & $-20,63$ & 0,000 & $-2,389289$ & $-1,974682$ \\
\hline $\ln \sigma_{u}^{2}$ & $-8,573525$ & & & & & \\
\hline$\sigma_{\mathrm{v}}$ & 0,3358829 & 0,0177638 & & & 0,3028117 & 0,3725661 \\
\hline$\sigma_{\mathrm{u}}$ & 0,0137494 & & & & & \\
\hline$\sigma^{2}$ & 0,1130064 & & & & & \\
\hline$\lambda$ & 0,040935 & & & & & \\
\hline Wald $\left[\chi_{(6)}^{2}\right]$ & 3841,23 & $\operatorname{Prob}\left[\chi_{(6)}^{2}\right]$ & 0,000 & & & \\
\hline $\operatorname{RV}\left(\sigma_{u}=0\right)$ & 0 & $\operatorname{Prob}\left[\chi_{(1)}^{2}\right]$ & 1 & & & \\
\hline
\end{tabular}


a erro sistemático com distribuição meio-normal

* denota significância ao nível de 5\%

No modelo vii., assim como no modeloi., dos parâmetros estimados, a classe2, classe3 e dummy, não apresentaram resultados significantes, a $5 \%$ de significância. $\mathrm{Na}$ análise dos coeficientes, mesmo não sendo significativo estatisticamente, classe3 também apresentou sinais positivo, contrário ao esperado. Como um aumento de ligacao, dmpp aumentariam o custo de produção, assim como quanto menor o grau de tercerização dos serviços, maior o custo, dado que o as classes estão sendo comparadas classe com maior porcentagem de serviços terceirizados. O coeficiente da variável dummy apresenta sinal negativo, o que significa que para empresas regionais, um aumento do custo teriam um menor impacto que um aumento de custos para empresas locais.

Os termos que compõem o erro do modelo podem ser observados na tabela e somente o erro aleatório (v), mostra-se significativo. Esse resultado conduz à análise do teste $\mathrm{RV}$, confirmando a não rejeita a $\mathrm{H} 0$ de que $\sigma_{\mathrm{u}}=0$.

O modelo viii estimado impõem a distribuição normal-truncada ao erro u. Os parâmetros e os coeficientes apresentaram resultados semelhantes ao modelo anterior.

Tabela 11. Coeficientes estimados para a fronteira estocástica função custo ${ }^{\mathrm{b}}$, modelo viii.

\begin{tabular}{lcccccc}
\hline \multicolumn{1}{c}{ Variáveis } & $\begin{array}{c}\text { Estimativa } \\
\text { pesvio } \\
\text { padrão }\end{array}$ & $\begin{array}{c}\mathrm{Z} \\
(1)\end{array}$ & $\begin{array}{c}\mathrm{P}>|\mathrm{z}| \\
(3)\end{array}$ & \multicolumn{2}{c}{ Intervalo de confiança* } \\
\hline lnligacao & 0,9613529 & 0,0232649 & 41,32 & 0,000 & 0,9157546 & 1,0069517 \\
lndmpp & 0,1906938 & 0,0576298 & 3,31 & 0,001 & 0,0777407 & 0,3036454 \\
classe 1 & $-0,46035$ & 0,1581591 & $-2,91$ & 0,004 & $-0,7703361$ & $-0,1503639$ \\
classe 2 & $-0,1414614$ & 0,1497536 & $-0,94$ & 0,345 & $-0,4349727$ & 0,1520507 \\
classe 3 & 0,1416683 & 0,1501688 & 0,94 & 0,345 & $-0,1526555$ & 0,4359921
\end{tabular}


Tabela 11. Coeficientes estimados para a fronteira estocástica função custo ${ }^{\mathrm{b}}$, modelo viii.

\begin{tabular}{|c|c|c|c|c|c|c|}
\hline Variáveis & $\begin{array}{c}\text { Estimativa } \\
(1) \\
\end{array}$ & $\begin{array}{c}\text { Desvio } \\
\text { padrão } \\
\text { (2) }\end{array}$ & $\begin{array}{l}\mathrm{Z} \\
(3) \\
\end{array}$ & $\begin{array}{c}P>|z| \\
(4)\end{array}$ & \multicolumn{2}{|c|}{$\begin{array}{c}\text { Intervalo de confiança* } \\
(5)\end{array}$} \\
\hline dummy & $-0,0028415$ & 0,115217 & $-0,02$ & 0,980 & $-0,2286649$ & 0,2229811 \\
\hline constante & 3,356137 & 0,7651852 & 4,39 & 0,000 & 1,856401 & 4,855872 \\
\hline$\mu$ & $-0,0603406$ & 4,958969 & $-0,01$ & 0,990 & $-9,779742$ & 9,659061 \\
\hline $\ln \sigma^{2}$ & $-2,176205$ & 0,4501795 & $-4,83$ & 0,000 & $-3,05854$ & $-1,293869$ \\
\hline ilgt $\gamma$ & $-5,159827$ & 82,87299 & $-0,06$ & 0,950 & $-167,5879$ & 157,2682 \\
\hline$\sigma^{2}$ & 0,1131714 & 0,0510825 & & & 0,0469562 & 0,2742078 \\
\hline$\gamma$ & 0,0057099 & 0,4704953 & & & $1,65 \mathrm{e}-73$ & 1 \\
\hline$\sigma_{u}^{2}$ & 0,0006479 & 0,0536701 & & & $-0,1045435$ & 0,1058393 \\
\hline$\sigma_{\mathrm{v}}^{2}$ & 0,1128235 & 0,0134398 & & & 0,0864819 & 0,1391659 \\
\hline Wald $\left[\chi_{(6)}^{2}\right]$ & 3841,27 & $\operatorname{Prob}\left[\chi_{(6)}^{2}\right]$ & 0,000 & & & \\
\hline Teste Z & $-0,264$ & Prob $>|z|$ & 0,604 & & & \\
\hline
\end{tabular}

${ }^{\mathrm{b}}$ erro sistemático com distribuição normal-truncada

* denota significância ao nível de 5\%

E assim, como o modelo i., no teste $\mathrm{Z}$, a $\mathrm{H} 0$ não é rejeitada, o que indica a existência de eficiência neste modelo.

Os coeficientes do teste $\mathrm{W}$, para as seis variáveis, tanto em vii., quanto em viii., apresentaram-se altamente significativos, rejeitando-se a $\mathrm{H} 0$, o que pode indicar a não existência de empresas plenamente eficientes nesse modelo. 
A matriz de correlação entre as variáveis dos modelos vii. e viii., e os valores mais próximos de $|1|$, representam o maior grau de correlação entre as variáveis e pode ser observado na tabela 12 a seguir:

Tabela 12. Matriz de correlação das variáveis dos modelos vii. e viii.

\begin{tabular}{ccccccc}
\hline & lnligacao & lndmpp & classe1 & classe2 & classe3 & dummy \\
\hline lnligacao & 1,0000 & & & & & \\
lndmpp & $-0,2455$ & 1,0000 & & & & \\
classe1 & $-0,4205$ & $-0,2011$ & 1,0000 & & & \\
classe2 & 0,0648 & 0,0779 & $-0,4998$ & 1,0000 & & \\
classe3 & 0,2316 & 0,1618 & $-0,3549$ & $-0,5610$ & 1,0000 & \\
dummy & $-0,4808$ & 0,7789 & $-0,7789$ & 0,1735 & 0,0282 & 1,0000 \\
\hline
\end{tabular}

O cálculo do IC não detectou colinearidade forte entre as variáveis do modelo, pois o valor encontrado foi de 7,22.

No modelo ix. e x., a variável produto extensao foi criada através da soma da era e ere. Os parâmetros estimados, a classe2, classe3 e dummy, não apresentaram resultados significantes e mesmo não significativos estatisticamente, a classe3 apresentou sinais positivo, contrário ao esperado. Um aumento de extensao, dmpp, aumentariam o custo de produção, assim como quanto menor o grau de tercerização dos serviços, maior o custo. A dummy apresenta sinal positivo, o que significa que para empresas regionais, um aumento do custo teriam um impacto maior que um aumento de custos para empresas locais.

Os termos que compõem o erro do modelo podem ser observados na tabela e ambos os erros são significativos. Esse resultado conduz à análise do teste RV, que confirma que o modelo estimado é significativo, já que rejeita a $\mathrm{H} 0$ de que $\sigma_{\mathrm{u}}=0$ e indica que existe algum tipo de ineficiência neste modelo. 
Tabela 13. Coeficientes estimados para a fronteira estocástica função custo ${ }^{a}$, modelo ix.

\begin{tabular}{|c|c|c|c|c|c|c|}
\hline Variáveis & $\begin{array}{c}\text { Estimativa } \\
\text { (1) }\end{array}$ & $\begin{array}{c}\text { Desvio } \\
\text { padrão } \\
\text { (2) }\end{array}$ & $\begin{array}{l}\mathrm{Z} \\
(3)\end{array}$ & $\begin{array}{c}P>|z| \\
(4)\end{array}$ & \multicolumn{2}{|c|}{$\begin{array}{l}\text { Intervalo de confiança* } \\
\qquad(5)\end{array}$} \\
\hline lnextensao & 1,052888 & 0,0275298 & 38,25 & 0,000 & 0,9989314 & 1,106846 \\
\hline lndmpp & 0,3025339 & 0,0601258 & 5,03 & 0,000 & 0,1846895 & 0,4203784 \\
\hline classe 1 & $-0,5118053$ & 0,1689913 & $-3,03$ & 0,002 & $-0,8430222$ & $-0,1805884$ \\
\hline classe 2 & $-0,1620087$ & 0,1636546 & $-0,99$ & 0,322 & $-0,4827658$ & 0,1587485 \\
\hline classe 3 & 0,1781305 & 0,161441 & 1,10 & 0,270 & $-0,1382881$ & 0,4945491 \\
\hline dummy & 0,00860022 & 0,1224987 & 0,07 & 0,944 & $-0,2314928$ & 0,2486932 \\
\hline constante & 5,548147 & 0,6445196 & 8,61 & 0,000 & 4,284912 & 6,811382 \\
\hline $\ln \sigma_{\mathrm{v}}^{2}$ & $-2,784574$ & 0,3014838 & $-9,24$ & 0,000 & $-3,375471$ & $-2,193676$ \\
\hline $\ln \sigma_{u}^{2}$ & $-1,598299$ & 0,3091419 & $-5,17$ & 0,00 & $-2,204206$ & $-0,9923918$ \\
\hline$\sigma_{\mathrm{v}}$ & 0,2485063 & 0,0374603 & & & 0,1849378 & 0,3339252 \\
\hline$\sigma_{\mathrm{u}}$ & 0,4497113 & 0,0695123 & & & 0,3321718 & 0,6088424 \\
\hline$\sigma^{2}$ & 0,2639957 & 0,0501012 & & & 0,1657992 & 0,3621921 \\
\hline$\lambda$ & 1,809657 & 0,100696 & & & 1,612297 & 2,007018 \\
\hline Wald $\left[\chi_{(6)}^{2}\right]$ & 3366,56 & $\operatorname{Prob}\left[\chi_{(6)}^{2}\right]$ & 0,000 & & & \\
\hline $\operatorname{RV}\left(\sigma_{u}=0\right)$ & 4,78 & $\operatorname{Prob}\left[\chi_{(1)}^{2}\right]$ & 0,014 & & & \\
\hline
\end{tabular}

a erro sistemático com distribuição meio-normal

* denota significância ao nível de 5\%

O modelo x. estimado impõe a distribuição normal-truncada ao erro u. Os coeficientes apresentam-se semelhantes ao modelo anterior. E assim, no teste Z, a H0 é rejeitada, o que indica a existência de ineficiência neste modelo. 
Tabela 14. Coeficientes estimados para a fronteira estocástica função custo ${ }^{\mathrm{b}}$, modelo x.

\begin{tabular}{|c|c|c|c|c|c|c|}
\hline Variáveis & $\begin{array}{c}\text { Estimativa } \\
\text { (1) }\end{array}$ & $\begin{array}{l}\text { Desvio } \\
\text { padrão } \\
\text { (2) }\end{array}$ & $\begin{array}{l}Z \\
(3)\end{array}$ & $\begin{array}{c}P>|z| \\
\quad(4)\end{array}$ & \multicolumn{2}{|c|}{$\begin{array}{l}\text { Intervalo de confiança* } \\
\qquad(5)\end{array}$} \\
\hline lnextensao & 1,053669 & 0,027555 & 38,24 & 0,000 & 0,9996624 & 1,107676 \\
\hline lndmpp & 0,3081595 & 0,0598622 & 5,15 & 0,000 & 0,1908317 & 0,4254872 \\
\hline classe 1 & $-0,4931273$ & 0,1764184 & $-2,80$ & 0,005 & $-0,8389019$ & $-0,1473536$ \\
\hline classe 2 & $-0,1496918$ & 0,1702756 & $-0,88$ & 0,379 & $-0,4834259$ & 0,1840424 \\
\hline classe 3 & 0,1875908 & 0,1677155 & 1,12 & 0,263 & $-0,1411254$ & 0,5163071 \\
\hline dummy & 0,00044611 & 0,1218012 & 0,00 & 0,997 & $-0,2382799$ & 0,2391726 \\
\hline constante & 5,523594 & 0,6405282 & 8,62 & 0,000 & 4,268182 & 6,779006 \\
\hline$\mu$ & $-0,6066263$ & 1,610588 & $-0,38$ & 0,706 & $-3,763322$ & 2,550069 \\
\hline $\ln \sigma^{2}$ & $-0,8628902$ & 1,017468 & $-0,85$ & 0,396 & $-2,857092$ & 1,131311 \\
\hline ilgt $\gamma$ & 1,6849452 & 1,166042 & $-1,45$ & 0,148 & $-0,6004561$ & 3,970346 \\
\hline$\sigma^{2}$ & 0,4219408 & 0,4293115 & & & 0,0574355 & 3,0997197 \\
\hline$\gamma$ & 0,8435582 & 0,1538823 & & & 0,3542394 & 0,9814825 \\
\hline$\sigma_{u}^{2}$ & 0,3559316 & 0,4246499 & & & $-0,4763669$ & 1,18823 \\
\hline$\sigma_{\mathrm{v}}^{2}$ & 0,0660092 & 0,0197089 & & & 0,0273804 & 0,104638 \\
\hline Wald $\left[\chi_{(6)}^{2}\right]$ & 3394,96 & $\operatorname{Prob}\left[\chi_{(6)}^{2}\right]$ & 0,000 & & & \\
\hline Teste $Z$ & 1,8594 & Prob $>|z|$ & 0,031 & & & \\
\hline
\end{tabular}

${ }^{\mathrm{b}}$ erro sistemático com distribuição normal-truncada

* denota significância ao nível de 5\%

Os coeficientes do teste $\mathrm{W}$, tanto em ix., quanto em x., apresentaram-se altamente significativo, rejeitando-se a $\mathrm{H} 0$, o que pode indicar a não existência de empresas plenamente eficientes nesse modelo. 
Tabela 15. Matriz de correlação das variáveis dos modelos ix. e x.

\begin{tabular}{ccccccc}
\hline & lnextensao & lndmpp & classe1 & classe2 & classe3 & dummy \\
\hline lnextensao & 1,0000 & & & & & \\
lndmpp & $-0,3022$ & 1,0000 & & & & \\
classe1 & $-0,3935$ & $-0,2011$ & 1,0000 & & & \\
classe2 & 0,0728 & 0,0779 & $-0,4998$ & 1,0000 & & \\
classe3 & 0,1996 & 0,1618 & $-0,3549$ & $-0,5610$ & 1,0000 & \\
dummy & $-0,5390$ & 0,7789 & $-0,7789$ & 0,1735 & 0,0282 & 1,0000 \\
\hline
\end{tabular}

Conforme a tabela 15, a matriz de correlação indica uma investigação sobre multicolinearidade que possa existir. Assim, o IC foi estimado, resultando no valor de 7,51, o que não indica problemas graves.

\subsection{Ordenação dos municípios}

De acordo com Kumbhakar \& Lovell (2000), estimando a distribuição de $\mathrm{u}_{\mathrm{i}}$ condicional a $\varepsilon_{i}$, é possível calcular o custo eficiência e cada empresa da indústria, como demonstrado no capítulo 3.2. Assim, a ordenação decrescente de eficiência dos municípios pode ser apresentado conforme as tabelas no anexo A e anexo B, para os quatro modelos com resultados significativos.

Como o modelos iii. e iv. apresentaram resultados significativos, na tabela no anexo A, observa-se o resultado dos $\mathrm{CE}_{\mathrm{i}}$ 's e a ordenação das empresas de forma decrescente de eficiência.

Na tabela do anexo B, através dos modelos ix. e x., estimou-se e ordenou-se os $\mathrm{CE}_{\mathrm{i}}$ 's de cada empresa. Esses modelos utilizam uma variável produto (extensao), dado pela soma da extensão da rede de água e extensão da rede de esgoto.

As mudanças de ordenação dos municípios, de acordo com os resultados obtidos neste trabalho, indicam que a mensuração da eficiência pode ser afetada pela 
maneira de mensuração do produto.

No modelo multiproduto com erro assumindo distribuição normal truncada a variável dmpp não apresentou resultado significativo. Somente as variáveis qlaaa, qlae e classe1. Isso indica que um aumento no custo tem relação direta com aumento das qlaa e qlae.

O sinal da variável classel apresentou sinal oposto ao esperado, pois a interpretação que pode ser realizada neste caso é de que o produto o custo (dex_1) irá aumentar inversamente à empresa estar num nível de terceirização menor. No modelo em que se assume a distribuição normal truncada do erro sistêmico, o mesmo acontece, com exceção da dmpp, que é significativa.

Nos modelos com um único produto, o comportamento das variáveis foi semelhante aos modelos multiproduto, para as duas formas de distribuição dos erros sistêmicos.

Em todos os modelos, os coeficientes da classificação dos serviços de terceiros, classe2 e classe3, não foram significativos. Isso também aconteceu com a variável binária que determina o tipo de abrangência da empresa.

Isso significa que a escolha do produto analisado é importante e sensível à análise de eficiência ou ineficiência, assim como os sinais dos coeficientes podem variar de acordo com a distribuição do erro sistêmico. Assim a ordenação dos municípios também foi diferente, pois as empresas podem apresentar eficiência conforme a determinação e escolha do produto. 


\section{CONCLUSÕES}

$\mathrm{Na}$ maior parte dos municípios do Estado de São Paulo, o serviço de saneamento básico é feito pela SABESP que é uma empresa de abrangência regional. As empresas de âmbito local atendem somente $25 \%$ do total de municípios deste Estado.

Apesar da existência de uma política governamental, em âmbito federal, voltada para o atendimento universal desse tipo de serviço, é frustrante observar que até o momento - ocorre um aprofunda falta de coordenação, tanto no tocante à regulação quanto no que se refere à uniformização dos serviços desse setor. Aliás, como foi destacado ao longo do presente trabalho, a preocupação com a expansão dos serviços de abastecimento de água e da coleta de esgotos pode ser demonstrada através dos programas governamentais de modernização no final dos anos 90 e ainda buscam aplicação eficaz tanto no Estado de São Paulo, quanto no Brasil.

Em razão disso, tem havido um interesse crescente e uma discussão acalorada sobre eficiência das empresas que atuam no setor. O presente trabalho procura contribuir ao debate, medindo e quantificando o nível de a eficiência das empresas de saneamento do Estado de São Paulo, através da estimação de fronteira estocástica.

Os resultados obtidos permitem concluir que essas empresas apresentam um grande intervalo quanto ao nível de eficiência em relação às fronteiras de custo estimadas. Assim, teoricamente, isso indica que existe um significativo potencial para o aprimoramento gerencial das empresas, buscando uma redução de custo (para os mesmos níveis de prestação de serviços) ou, alternativamente, elas poderiam - com o mesmo custo - expandir os serviços prestados.

As ineficiências observadas podem ter origem em causas diversas. De um lado, podem refletir razões fora do controle humano. Altos custos na obtenção de água para abastecimento e/ou dificuldades na implantação das redes de água e esgoto 
(causada por variáveis topográficas ou geológicas) são exemplos dessa natureza. Por outro lado, as ineficiências podem estar relacionadas com fatores humanos. Deficiências gerenciais na administração das empresas de saneamento básico e a falta de fiscalização do uso correto dos recursos orçamentários dessas empresas são, tipicamente, as principais fontes do desperdício e malversão no uso de recursos, resultando no conseqüente aumento dos custos e aparecimento de ineficiências.

Considerando a crônica escassez de recursos financeiros para investimento e manutenção dos serviços públicos no Brasil, o aumento do nível de eficiência dessas empresas seria extremamente benéfico para a sociedade como um todo.

Do ponto de vista do tomador de decisões do governo, um estudo como o realizado no presente trabalho, poderia auxiliar em suas escolhas, buscando maior nível de eficiência. Com isso, poder-se-ia conseguir a redução de tarifas com manutenção dos níveis atuais de serviços ou a melhora no sistema de saneamento, com níveis atuais de serviços ou melhora no sistema de saneamento, com os níveis atuais.

É interessante observar ainda que, de acordo com as estimativas obtidas, não parece haver diferenças significativas de eficiência entre as empresas de saneamento básico coma atuação regional em relação a local. Os resultados obtidos não são conclusivos. Isso significa que tanto a SABESP quanto as empresas de serviços municipais atuam de mesma forma no sistema de saneamento com relação a custos operacionais ou que ainda não existiriam vantagens em ser uma grande empresa, pois isso não implicaria em eficiência e vice-versa. Certamente, esse ponto deve ser melhor analisado em estudos futuros, utilizando dados mais precisos e detalhados do que os disponíveis para o presente estudo.

Apesar dos esforços empenhados neste trabalho, alerta-se que o presente trabalho apresenta algumas limitações que devem ser consideradas. A fonte de dados, SNIS, utilizada para realização das estimativas não apresentaram valores de quantidades ou preços de fatores para da empresa. Em publicações futuras, essas variáveis deveriam ser incorporadas no SNIS. Isso permitira que os estudos sobre eficiência das empresas de saneamento básico fossem muito mais detalhados e precisos, fornecendo informações muito melhores do ponto de vista econômico e gerencial. Além disso, para os tomadores 
de decisão da área política, essas informações seriam muito mais úteis no processo de alocação de recursos e de mensuração dos resultados obtidos.

Como sugestão para futuros estudos, seria recomendável testar outras formas funcionais além da Cobb-Douglas, utilizada no presente trabalho. Entre outras, a translog seria uma forma alternativa interessante que apresenta algumas vantagens como flexibilidade e comportamento consistente com vários aspectos teóricos importantes da microeconomia. Ela pode, ainda, ser base de estimações empíricas de custo e de eficiência em sistemas de equações.

Finalmente, para aprimorar os estudos nessa área, é imprescindível a disponibilidade de dados fidedignos das empresas prestadoras dos serviços de saneamento básico, incluindo as informações sobre investimentos realizados na infraestrutura já existente e dados sobre quantidades e preços pagãos pelos diversos fatores de produção utilizados no processo de prestação de serviços. 
ANEXOS 
ANEXO A - Ordenação dos municípios eficientes, para os modelos iii. e iv.

\begin{tabular}{|c|c|c|c|c|}
\hline \multicolumn{5}{|c|}{ Quantidade de ligações ativas de água e esgoto } \\
\hline \multirow{4}{*}{$\mathrm{N}^{\mathrm{o}}$} & \multirow{4}{*}{ Tipo* } & \multirow{4}{*}{ Municípios } & \multicolumn{2}{|c|}{$\mathrm{CE}_{\mathrm{i}}$} \\
\hline & & & \multicolumn{2}{|c|}{ Distribuição de $u_{i}$} \\
\hline & & & & Normal \\
\hline & & & $\begin{array}{l}\text { Meio Normal } \\
\text { (iii.) }\end{array}$ & $\begin{array}{c}\text { Truncada } \\
\text { (iv.) }\end{array}$ \\
\hline 1 & 0 & Salto & 1,081135 & 1,062495 \\
\hline 2 & 0 & Mauá & 1,112824 & 1,079009 \\
\hline 3 & 1 & Gabriel Monteiro & 1,115627 & 1,082950 \\
\hline 4 & 1 & Nova Guataporanga & 1,117215 & 1,083830 \\
\hline 5 & 0 & Moji das Cruzes & 1,120251 & 1,084460 \\
\hline 6 & 1 & Oscar Bressane & 1,122793 & 1,085383 \\
\hline 7 & 0 & S.Bernardo do Campo & 1,129317 & 1,087558 \\
\hline 8 & 1 & Bento de Abreu & 1,135110 & 1,091965 \\
\hline 9 & 1 & Assis & 1,152443 & 1,094517 \\
\hline 10 & 1 & Praia Grande & 1,162947 & 1,107094 \\
\hline 11 & 0 & Leme & 1,176113 & 1,108287 \\
\hline 12 & 0 & Birigui & 1,176691 & 1,114087 \\
\hline 13 & 1 & Ipero & 1,183502 & 1,116413 \\
\hline 14 & 1 & Palmares Paulista & 1,186771 & 1,118243 \\
\hline 15 & 1 & Sud Mennucci & 1,188004 & 1,119724 \\
\hline 16 & 1 & Avai & 1,188558 & 1,122047 \\
\hline 17 & 1 & Jandira & 1,192352 & 1,123235 \\
\hline 18 & 1 & Echaporã & 1,193962 & 1,123341 \\
\hline 19 & 1 & Piratininga & 1,194596 & 1,124081 \\
\hline 20 & 1 & Arealva & 1,194633 & 1,124119 \\
\hline 21 & 1 & Bernardino de Campos & 1,199649 & 1,124457 \\
\hline 22 & 0 & Catanduva & 1,204462 & 1,125508 \\
\hline 23 & 1 & Coroados & 1,206337 & 1,126447 \\
\hline 24 & 1 & Paranapanema & 1,207281 & 1,126711 \\
\hline 25 & 1 & Luiziânia & 1,211315 & 1,126903 \\
\hline 26 & 1 & Fartura & 1,217644 & 1,127496 \\
\hline 27 & 1 & Ferraz de Vasconcelos & 1,218194 & 1,127759 \\
\hline 28 & 1 & Pindamonhangaba & 1,218252 & 1,130296 \\
\hline 29 & 1 & Cajobi & 1,221874 & 1,133067 \\
\hline 30 & 1 & Catiguá & 1,224870 & 1,134669 \\
\hline 31 & 1 & Capão Bonito & 1,224936 & 1,136303 \\
\hline 32 & 1 & Taboão da Serra & 1,227850 & 1,136665 \\
\hline 33 & 1 & Ibiúna & 1,228816 & 1,137745 \\
\hline
\end{tabular}


ANEXO A - Ordenação dos municípios eficientes, para os modelos iii. e iv.

\begin{tabular}{|c|c|c|c|c|}
\hline \multicolumn{5}{|c|}{ Quantidade de ligações ativas de água e esgoto } \\
\hline \multirow[b]{3}{*}{$\mathrm{N}^{\mathrm{o}}$} & \multirow[b]{3}{*}{ Tipo* } & \multirow[b]{3}{*}{ Municípios } & \multicolumn{2}{|c|}{$\mathrm{CE}_{\mathrm{i}}$} \\
\hline & & & \multicolumn{2}{|c|}{ Distribuição de $u_{i}$} \\
\hline & & & $\begin{array}{c}\text { Meio Normal } \\
\text { (iii.) }\end{array}$ & $\begin{array}{c}\text { Normal } \\
\text { Truncada } \\
\text { (iv.) }\end{array}$ \\
\hline 34 & 1 & Itaí & 1,235029 & 1,140128 \\
\hline 35 & 1 & Peruíbe & 1,239600 & 1,140189 \\
\hline 36 & 0 & Itu & 1,240976 & 1,140218 \\
\hline 37 & 0 & Tupi Paulista & 1,242720 & 1,141225 \\
\hline 38 & 1 & Piacatu & 1,244215 & 1,145988 \\
\hline 39 & 1 & Areiópolis & 1,244370 & 1,149556 \\
\hline 40 & 0 & Mogi Guaçu & 1,246878 & 1,150000 \\
\hline 41 & 1 & Duartina & 1,255088 & 1,153010 \\
\hline 42 & 1 & Ribeirão do Sul & 1,255585 & 1,154101 \\
\hline 43 & 1 & Gália & 1,256530 & 1,154871 \\
\hline 44 & 1 & Tatuí & 1,258208 & 1,158252 \\
\hline 45 & 1 & Macaúba & 1,261649 & 1,160103 \\
\hline 46 & 1 & Queluz & 1,266832 & 1,161490 \\
\hline 47 & 1 & Poá & 1,269778 & 1,162215 \\
\hline 48 & 1 & Mongaguá & 1,275907 & 1,162611 \\
\hline 49 & 1 & Itapevi & 1,277106 & 1,164733 \\
\hline 50 & 0 & Indaiatuba & 1,279416 & 1,170191 \\
\hline 51 & 1 & Várzea Paulista & 1,287412 & 1,170663 \\
\hline 52 & 1 & Miguelópolis & 1,292647 & 1,173613 \\
\hline 53 & 0 & Marília & 1,301005 & 1,174332 \\
\hline 54 & 0 & Sorocaba & 1,305806 & 1,178240 \\
\hline 55 & 1 & Lorena & 1,313314 & 1,178642 \\
\hline 56 & 1 & Taubaté & 1,314302 & 1,179952 \\
\hline 57 & 1 & Francisco Morato & 1,314565 & 1,182061 \\
\hline 58 & 0 & Pirassununga & 1,315200 & 1,183126 \\
\hline 59 & 1 & Cabriúva & 1,318958 & 1,183370 \\
\hline 60 & 1 & Lourdes & 1,320239 & 1,184308 \\
\hline 61 & 0 & Dracena & 1,320959 & 1,185912 \\
\hline 62 & 1 & Registro & 1,322297 & 1,186706 \\
\hline 63 & 1 & Botucatu & 1,327971 & 1,188567 \\
\hline 64 & 1 & Vargem Gde. Paulista & 1,331063 & 1,189948 \\
\hline 65 & 0 & Limeira & 1,342399 & 1,191228 \\
\hline 66 & 1 & Lavrinhas & 1,344468 & 1,192578 \\
\hline
\end{tabular}


ANEXO A - Ordenação dos municípios eficientes, para os modelos iii. e iv. Quantidade de ligações ativas de água e esgoto

\begin{tabular}{|c|c|c|c|c|}
\hline \multirow[b]{3}{*}{$\mathrm{N}^{\mathrm{o}}$} & \multirow[b]{3}{*}{ Tipo* } & \multirow[b]{3}{*}{ Municípios } & \multicolumn{2}{|c|}{$\mathrm{CE}_{\mathrm{i}}$} \\
\hline & & & \multicolumn{2}{|c|}{ Distribuição de $u_{i}$} \\
\hline & & & $\begin{array}{l}\text { Meio Normal } \\
\text { (iii.) }\end{array}$ & $\begin{array}{c}\text { Normal } \\
\text { Truncada } \\
\text { (iv.) }\end{array}$ \\
\hline 67 & 0 & S. José do Rio Preto & 1,348106 & 1,194429 \\
\hline 68 & 1 & Itaquaquecetuba & 1,355096 & 1,199034 \\
\hline 69 & 1 & Bragança Paulista & 1,356412 & 1,205624 \\
\hline 70 & 1 & Lupércio & 1,358453 & 1,206177 \\
\hline 71 & 1 & Cachoeira Paulista & 1,358939 & 1,206821 \\
\hline 72 & 1 & Lins & 1,361312 & 1,207882 \\
\hline 73 & 1 & Itatiba & 1,361506 & 1,208237 \\
\hline 74 & 1 & Ibirá & 1,362507 & 1,209355 \\
\hline 75 & 1 & Cajuru & 1,362736 & 1,210181 \\
\hline 76 & 1 & Piraju & 1,368645 & 1,214162 \\
\hline 77 & 1 & Tupã & 1,372900 & 1,215198 \\
\hline 78 & 1 & Novo Horizonte & 1,373115 & 1,219050 \\
\hline 79 & 1 & Taciba & 1,380063 & 1,220164 \\
\hline 80 & 1 & Jales & 1,380318 & 1,221268 \\
\hline 81 & 0 & Ourinhos & 1,390898 & 1,222022 \\
\hline 82 & 1 & Monte Aprazível & 1,391988 & 1,225734 \\
\hline 83 & 1 & Embu & 1,393530 & 1,225885 \\
\hline 84 & 1 & Carapicuíba & 1,397670 & 1,226847 \\
\hline 85 & 1 & Santo Anastácio & 1,398887 & 1,227700 \\
\hline 86 & 0 & Sta. Bárbara d'Oeste & 1,401573 & 1,227709 \\
\hline 87 & 1 & Embu Guaçu & 1,402189 & 1,229017 \\
\hline 88 & 1 & Monte Mor & 1,404348 & 1,231055 \\
\hline 89 & 1 & Adamantina & 1,407027 & 1,231869 \\
\hline 90 & 1 & Óleo & 1,409081 & 1,233770 \\
\hline 91 & 1 & Ubirajara & 1,410460 & 1,235409 \\
\hline 92 & 0 & Pedreira & 1,417513 & 1,235976 \\
\hline 93 & 1 & Fernandópolis & 1,417717 & 1,237486 \\
\hline 94 & 0 & Moji Mirim & 1,421226 & 1,238233 \\
\hline 95 & 1 & Paulínia & 1,424950 & 1,238690 \\
\hline 96 & 1 & Agudos & 1,427067 & 1,239421 \\
\hline 97 & 0 & Americana & 1,429827 & 1,240559 \\
\hline 98 & 1 & Igarapava & 1,433128 & 1,243499 \\
\hline 99 & 1 & São Manuel & 1,434460 & 1,243903 \\
\hline 100 & 1 & Salto de Pirapora & 1,434690 & 1,244647 \\
\hline
\end{tabular}


ANEXO A - Ordenação dos municípios eficientes, para os modelos iii. e iv.

\begin{tabular}{|c|c|c|c|c|}
\hline \multicolumn{5}{|c|}{ Quantidade de ligações ativas de água e esgoto } \\
\hline \multirow{4}{*}{$\mathrm{N}^{\mathrm{o}}$} & \multirow{4}{*}{ Tipo* } & \multirow{4}{*}{ Municípios } & \multicolumn{2}{|c|}{$\mathrm{CE}_{\mathrm{i}}$} \\
\hline & & & \multicolumn{2}{|c|}{ Distribuição de $u_{i}$} \\
\hline & & & & Normal \\
\hline & & & $\begin{array}{l}\text { Meio Normal } \\
\text { (iii.) }\end{array}$ & $\begin{array}{c}\text { Truncada } \\
\text { (iv.) }\end{array}$ \\
\hline 101 & 1 & Itapetininga & 1,435175 & 1,246117 \\
\hline 102 & 1 & Colômbia & 1,435381 & 1,247235 \\
\hline 103 & 1 & Capela do Alto & 1,436028 & 1,248071 \\
\hline 104 & 1 & Espírito Sto. do Pinhal & 1,436620 & 1,248709 \\
\hline 105 & 1 & Guararema & 1,446165 & 1,253382 \\
\hline 106 & 1 & Itapeva & 1,446604 & 1,254035 \\
\hline 107 & 0 & Bauru & 1,449340 & 1,256620 \\
\hline 108 & 0 & Guaratinguetá & 1,453543 & 1,257365 \\
\hline 109 & 1 & Taguaí & 1,455767 & 1,261632 \\
\hline 110 & 1 & Guariba & 1,457414 & 1,263963 \\
\hline 111 & 1 & General Salgado & 1,458661 & 1,266236 \\
\hline 112 & 1 & Sta. Rosa de Viterbo & 1,463248 & 1,269002 \\
\hline 113 & 1 & S. Luis do Paraitinga & 1,473451 & 1,271413 \\
\hline 114 & 1 & Serra Azul & 1,482862 & 1,271810 \\
\hline 115 & 0 & Mairinque & 1,484977 & 1,275994 \\
\hline 116 & 1 & Caraguatatuba & 1,487419 & 1,276749 \\
\hline 117 & 0 & Cosmópolis & 1,490776 & 1,279562 \\
\hline 118 & 1 & Arujá & 1,502845 & 1,285066 \\
\hline 119 & 1 & Alto Alegre & 1,506485 & 1,285831 \\
\hline 120 & 0 & Rio Claro & 1,526860 & 1,288525 \\
\hline 121 & 1 & Sarutaia & 1,529904 & 1,289445 \\
\hline 122 & 1 & Cardoso & 1,533633 & 1,289992 \\
\hline 123 & 0 & Valinhos & 1,536419 & 1,293933 \\
\hline 124 & 1 & Dourado & 1,537843 & 1,294443 \\
\hline 125 & 1 & Suzano & 1,540605 & 1,295675 \\
\hline 126 & 1 & São Roque & 1,540874 & 1,295908 \\
\hline 127 & 1 & Presidente Alves & 1,557550 & 1,296468 \\
\hline 128 & 1 & Itanhaém & 1,560163 & 1,305541 \\
\hline 129 & 1 & Presidente Prudente & 1,566718 & 1,311516 \\
\hline 130 & 1 & Biritiba Mirim & 1,570960 & 1,313412 \\
\hline 131 & 1 & S. Jose dos Campos & 1,572324 & 1,315296 \\
\hline 132 & 0 & Barretos & 1,582356 & 1,316492 \\
\hline 133 & 1 & Franca & 1,583469 & 1,318463 \\
\hline
\end{tabular}


ANEXO A - Ordenação dos municípios eficientes, para os modelos iii. e iv.

\begin{tabular}{|c|c|c|c|c|}
\hline \multicolumn{5}{|c|}{ Quantidade de ligações ativas de água e esgoto } \\
\hline \multirow{4}{*}{$\mathrm{N}^{\mathrm{o}}$} & \multirow{4}{*}{ Tipo* } & \multirow{4}{*}{ Municípios } & \multicolumn{2}{|c|}{$\mathrm{CE}_{\mathrm{i}}$} \\
\hline & & & \multicolumn{2}{|c|}{ Distribuição de $u_{i}$} \\
\hline & & & & Normal \\
\hline & & & $\begin{array}{c}\text { Meio Normal } \\
\text { (iii.) }\end{array}$ & $\begin{array}{c}\text { Truncada } \\
\text { (iv.) }\end{array}$ \\
\hline 134 & 1 & Itupeva & 1,586057 & 1,319455 \\
\hline 135 & 1 & Araçariguama & 1,587076 & 1,320759 \\
\hline 136 & 1 & Bananal & 1,598007 & 1,322073 \\
\hline 137 & 1 & Alvinlândia & 1,602231 & 1,324020 \\
\hline 138 & 0 & Jacareí & 1,603105 & 1,334535 \\
\hline 139 & 1 & Guarujá & 1,603726 & 1,338362 \\
\hline 140 & 1 & Ribeirão Pires & 1,619552 & 1,338801 \\
\hline 141 & 1 & Santa Mercedes & 1,645739 & 1,338810 \\
\hline 142 & 1 & São Vicente & 1,655387 & 1,341304 \\
\hline 143 & 1 & Bertioga & 1,655982 & 1,346257 \\
\hline 144 & 1 & Timburi & 1,668614 & 1,366098 \\
\hline 145 & 1 & Salesópolis & 1,670426 & 1,366292 \\
\hline 146 & 0 & Paulicéia & 1,672194 & 1,384919 \\
\hline 147 & 1 & Santana de Parnaíba & 1,689082 & 1,401234 \\
\hline 148 & 1 & Araçoiaba da Serra & 1,695871 & 1,406485 \\
\hline 149 & 1 & Pongaí & 1,700362 & 1,408007 \\
\hline 150 & 1 & Buritizal & 1,718015 & 1,408960 \\
\hline 151 & 1 & Roseira & 1,726833 & 1,418202 \\
\hline 152 & 0 & Piracicaba & 1,730812 & 1,431065 \\
\hline 153 & 1 & Águas de São Pedro & 1,748553 & 1,434370 \\
\hline 154 & 0 & Araraquara & 1,750909 & 1,447410 \\
\hline 155 & 0 & Nova Odessa & 1,778200 & 1,454108 \\
\hline 156 & 0 & Vinhedo & 1,799772 & 1,460487 \\
\hline 157 & 1 & Monteiro Lobato & 1,805887 & 1,463866 \\
\hline 158 & 1 & S. Lourenço da Serra & 1,808139 & 1,489046 \\
\hline 159 & 1 & Campos do Jordão & 1,825244 & 1,492257 \\
\hline 160 & 1 & Cotia & 1,846360 & 1,498641 \\
\hline 161 & 0 & Guarulhos & 1,880037 & 1,516460 \\
\hline 162 & 0 & Jundiaí & 1,887807 & 1,523944 \\
\hline 163 & 1 & Santópolis do Aguapeí & 1,898336 & 1,530485 \\
\hline 164 & 1 & Barueri & 1,903388 & 1,533918 \\
\hline 165 & 0 & Araçatuba & 1,906642 & 1,613701 \\
\hline 166 & 1 & Itapecerica da Serra & 1,939126 & 1,614579 \\
\hline
\end{tabular}


ANEXO A - Ordenação dos municípios eficientes, para os modelos iii. e iv.

\begin{tabular}{ccccc}
\hline & \multicolumn{3}{c}{ Quantidade de ligações ativas de água e esgoto } \\
\cline { 3 - 5 } & & & \multicolumn{2}{c}{$\mathrm{CE}_{\mathrm{i}}$} \\
\cline { 3 - 5 } $\mathrm{N}^{\mathrm{o}}$ & Tipo* & Municípios & Distribuição de $\mathrm{u}_{\mathrm{i}}$ \\
& & & Meio Normal & $\begin{array}{c}\text { Normal } \\
\text { Truncada } \\
\text { (iiv.) }\end{array}$ \\
\hline 167 & 1 & Campo Limpo Paulista & 1,993439 & 1,618185 \\
168 & 1 & Mairiporã & 2,039168 & 1,650400 \\
169 & 0 & Ribeirão Preto & 2,050434 & 1,729834 \\
170 & 1 & Franco da Rocha & 2,081564 & 1,732490 \\
171 & 1 & Alumínio & 2,120323 & 1,748053 \\
172 & 1 & Hortolândia & 2,175272 & 1,754802 \\
173 & 0 & Santo André & 2,179943 & 1,767306 \\
174 & 1 & Rubiácea & 2,205791 & 1,781227 \\
175 & 1 & Cubatão & 2,222939 & 1,852479 \\
176 & 1 & Juquitiba & 2,333969 & 1,917989 \\
177 & 0 & Campinas & 2,517008 & 2,037258 \\
178 & 1 & Santos & 3,084283 & 2,918139 \\
179 & 0 & Ouro Verde & 10,713420 & 33,168910 \\
\hline
\end{tabular}

* Serviço Regional $=1$, Serviço Local $=0$ 
ANEXO B - Ordenação dos municípios eficientes, para os modelos x. e ix.

\begin{tabular}{|c|c|c|c|c|}
\hline \multirow[b]{4}{*}{$\mathrm{N}^{\mathrm{o}}$} & \multicolumn{3}{|c|}{ Extensão total das redes } & \\
\hline & \multirow[b]{3}{*}{ Tipo* } & \multirow[b]{3}{*}{ Municípios } & \multicolumn{2}{|c|}{$\mathrm{CE}_{\mathrm{i}}$} \\
\hline & & & \multicolumn{2}{|c|}{ Distribuição de $\mathrm{u}_{\mathrm{i}}$} \\
\hline & & & $\begin{array}{c}\text { Meio } \\
\text { Normal } \\
\text { (ix.) }\end{array}$ & $\begin{array}{c}\text { Normal } \\
\text { Truncada } \\
\text { (x.) }\end{array}$ \\
\hline 1 & 1 & Gabriel Monteiro & 1,083730 & 1,076162 \\
\hline 2 & 1 & Oscar Bressane & 1,092240 & 1,083068 \\
\hline 3 & 0 & Salto & 1,098235 & 1,087953 \\
\hline 4 & 0 & S. Bernardo do Campo & 1,121926 & 1,106429 \\
\hline 5 & 1 & Ipero & 1,124090 & 1,108731 \\
\hline 6 & 1 & Bento de Abreu & 1,127123 & 1,110499 \\
\hline 7 & 1 & Paulínia & 1,135871 & 1,117583 \\
\hline 8 & 1 & Peruíbe & 1,137096 & 1,120686 \\
\hline 9 & 0 & Moji das Cruzes & 1,147987 & 1,126807 \\
\hline 10 & 1 & Assis & 1,156239 & 1,134750 \\
\hline 11 & 1 & Arealva & 1,157519 & 1,134844 \\
\hline 12 & 1 & Praia Grande & 1,158514 & 1,135629 \\
\hline 13 & 1 & Pindamonhangaba & 1,161090 & 1,137883 \\
\hline 14 & 0 & Leme & 1,161676 & 1,138445 \\
\hline 15 & 0 & Mauá & 1,162762 & 1,140457 \\
\hline 16 & 1 & Itanhaém & 1,165714 & 1,141005 \\
\hline 17 & 1 & Capão Bonito & 1,167272 & 1,142047 \\
\hline 18 & 1 & Luiziania & 1,170015 & 1,144651 \\
\hline 19 & 1 & Coroados & 1,170768 & 1,145079 \\
\hline 20 & 1 & Avaí & 1,170830 & 1,145363 \\
\hline 21 & 1 & Bernardino de Campos & 1,171464 & 1,145374 \\
\hline 22 & 1 & Arujá & 1,172775 & 1,145737 \\
\hline 23 & 1 & Hortolândia & 1,186508 & 1,156920 \\
\hline 24 & 1 & Vargem Gde. Paulista & 1,188728 & 1,158744 \\
\hline 25 & 1 & Guararema & 1,193117 & 1,162453 \\
\hline 26 & 1 & Ibiúna & 1,194280 & 1,162513 \\
\hline 27 & 1 & Nova Guataporanga & 1,196173 & 1,163379 \\
\hline 28 & 1 & Mongaguá & 1,208933 & 1,174229 \\
\hline 29 & 1 & Ferraz de Vasconcelos & 1,215591 & 1,178057 \\
\hline 30 & 1 & Lourdes & 1,218004 & 1,179237 \\
\hline 31 & 1 & Itaí & 1,220647 & 1,183178 \\
\hline 32 & 0 & Birigui & 1,221413 & 1,183911 \\
\hline 33 & 1 & Caraguatatuba & 1,230438 & 1,191083 \\
\hline
\end{tabular}


ANEXO B - Ordenação dos municípios eficientes, para os modelos x. e ix.

\begin{tabular}{|c|c|c|c|c|}
\hline \multicolumn{5}{|c|}{ Extensão total das redes } \\
\hline \multirow[b]{3}{*}{$\mathrm{N}^{\mathrm{o}}$} & \multirow[b]{3}{*}{ Tipo* } & \multirow[b]{3}{*}{ Municípios } & \multicolumn{2}{|c|}{$\mathrm{CE}_{\mathrm{i}}$} \\
\hline & & & \multicolumn{2}{|c|}{ Distribuição de $u_{i}$} \\
\hline & & & $\begin{array}{c}\text { Meio } \\
\text { Normal } \\
\text { (ix.) }\end{array}$ & $\begin{array}{c}\text { Normal } \\
\text { Truncada } \\
\text { (x.) }\end{array}$ \\
\hline 34 & 1 & Itaquaquecetuba & 1,231660 & 1,192309 \\
\hline 35 & 1 & Echaporã & 1,238130 & 1,196355 \\
\hline 36 & 1 & Piratininga & 1,238268 & 1,197023 \\
\hline 37 & 0 & Pirassununga & 1,243104 & 1,199830 \\
\hline 38 & 1 & Óleo & 1,247392 & 1,201548 \\
\hline 39 & 1 & Lavrinhas & 1,247629 & 1,201713 \\
\hline 40 & 1 & Francisco Morato & 1,250119 & 1,205044 \\
\hline 41 & 0 & Ourinhos & 1,251112 & 1,205825 \\
\hline 42 & 0 & Mogi Guaçu & 1,252021 & 1,207081 \\
\hline 43 & 1 & Ibirá & 1,252808 & 1,207698 \\
\hline 44 & 1 & Botucatu & 1,252828 & 1,207901 \\
\hline 45 & 0 & S. Jose do Rio Preto & 1,254706 & 1,208178 \\
\hline 46 & 1 & São Roque & 1,255203 & 1,208928 \\
\hline 47 & 0 & Bauru & 1,255665 & 1,209198 \\
\hline 48 & 1 & Paranapanema & 1,260021 & 1,211046 \\
\hline 49 & 1 & Santa Mercedes & 1,262213 & 1,213177 \\
\hline 50 & 0 & Limeira & 1,262919 & 1,214426 \\
\hline 51 & 1 & Fartura & 1,267171 & 1,218202 \\
\hline 52 & 1 & Itapevi & 1,268192 & 1,218273 \\
\hline 53 & 1 & Monte Mor & 1,268595 & 1,218957 \\
\hline 54 & 1 & Jandira & 1,268995 & 1,220099 \\
\hline 55 & 1 & Tatuí & 1,271899 & 1,222893 \\
\hline 56 & 1 & Embu Guaçu & 1,272532 & 1,222934 \\
\hline 57 & 1 & Sud Mennucci & 1,274270 & 1,225578 \\
\hline 58 & 0 & Guaratinguetá & 1,283284 & 1,231435 \\
\hline 59 & 1 & Alto Alegre & 1,286608 & 1,235217 \\
\hline 60 & 0 & Itu & 1,286672 & 1,236257 \\
\hline 61 & 1 & Piacatu & 1,293967 & 1,239021 \\
\hline 62 & 0 & Tupi Paulista & 1,296587 & 1,240091 \\
\hline 63 & 1 & Taubaté & 1,296731 & 1,240122 \\
\hline 64 & 0 & Catanduva & 1,298429 & 1,241163 \\
\hline 65 & 1 & Novo Horizonte & 1,302253 & 1,244082 \\
\hline 66 & 1 & Salto de Pirapora & 1,302628 & 1,246758 \\
\hline
\end{tabular}


ANEXO B - Ordenação dos municípios eficientes, para os modelos x. e ix.

\begin{tabular}{|c|c|c|c|c|}
\hline \multirow[b]{4}{*}{$\mathrm{N}^{\mathrm{o}}$} & \multicolumn{3}{|c|}{ Extensão total das redes } & \\
\hline & \multirow[b]{3}{*}{ Tipo* } & \multirow[b]{3}{*}{ Municípios } & \multicolumn{2}{|c|}{$\mathrm{CE}_{\mathrm{i}}$} \\
\hline & & & \multicolumn{2}{|c|}{ Distribuição de $u_{i}$} \\
\hline & & & $\begin{array}{c}\text { Meio } \\
\text { Normal } \\
\text { (ix.) }\end{array}$ & $\begin{array}{c}\text { Normal } \\
\text { Truncada } \\
\text { (x.) }\end{array}$ \\
\hline 67 & 1 & Lorena & 1,307731 & 1,251176 \\
\hline 68 & 1 & Gália & 1,308010 & 1,251303 \\
\hline 69 & 1 & Campos do Jordão & 1,308222 & 1,251424 \\
\hline 70 & 1 & Jales & 1,308280 & 1,251561 \\
\hline 71 & 0 & Sorocaba & 1,310205 & 1,251813 \\
\hline 72 & 1 & Registro & 1,311483 & 1,257753 \\
\hline 73 & 1 & General Salgado & 1,321156 & 1,258179 \\
\hline 74 & 1 & Águas de São Pedro & 1,324816 & 1,264217 \\
\hline 75 & 1 & Piraju & 1,325833 & 1,266257 \\
\hline 76 & 0 & Paulicéia & 1,328093 & 1,267411 \\
\hline 77 & 1 & Miguelópolis & 1,330143 & 1,269309 \\
\hline 78 & 0 & Americana & 1,334348 & 1,271664 \\
\hline 79 & 1 & Várzea Paulista & 1,334528 & 1,272047 \\
\hline 80 & 1 & Colômbia & 1,335906 & 1,273131 \\
\hline 81 & 1 & Cajobi & 1,336021 & 1,273760 \\
\hline 82 & 1 & Cachoeira Paulista & 1,336628 & 1,275026 \\
\hline 83 & 0 & Marilia & 1,338771 & 1,275426 \\
\hline 84 & 1 & Macatuba & 1,340422 & 1,276719 \\
\hline 85 & 0 & Valinhos & 1,341607 & 1,277041 \\
\hline 86 & 1 & Palmares Paulista & 1,344378 & 1,277234 \\
\hline 87 & 1 & Presidente Prudente & 1,348860 & 1,283020 \\
\hline 88 & 1 & Duartina & 1,355685 & 1,289665 \\
\hline 89 & 1 & Areiópolis & 1,360342 & 1,289943 \\
\hline 90 & 1 & Santa Rosa de Viterbo & 1,363044 & 1,293992 \\
\hline 91 & 1 & Taciba & 1,363510 & 1,294456 \\
\hline 92 & 0 & Moji Mirim & 1,364393 & 1,295255 \\
\hline 93 & 1 & Ribeirão do Sul & 1,368480 & 1,296524 \\
\hline 94 & 0 & Vinhedo & 1,370026 & 1,299063 \\
\hline 95 & 1 & Monte Aprazível & 1,371476 & 1,301752 \\
\hline 96 & 1 & Fernandópolis & 1,375308 & 1,304215 \\
\hline 97 & 1 & Suzano & 1,376397 & 1,304897 \\
\hline 98 & 0 & Dracena & 1,380896 & 1,304905 \\
\hline 99 & 1 & Cardoso & 1,388623 & 1,314813 \\
\hline
\end{tabular}


ANEXO B - Ordenação dos municípios eficientes, para os modelos x. e ix.

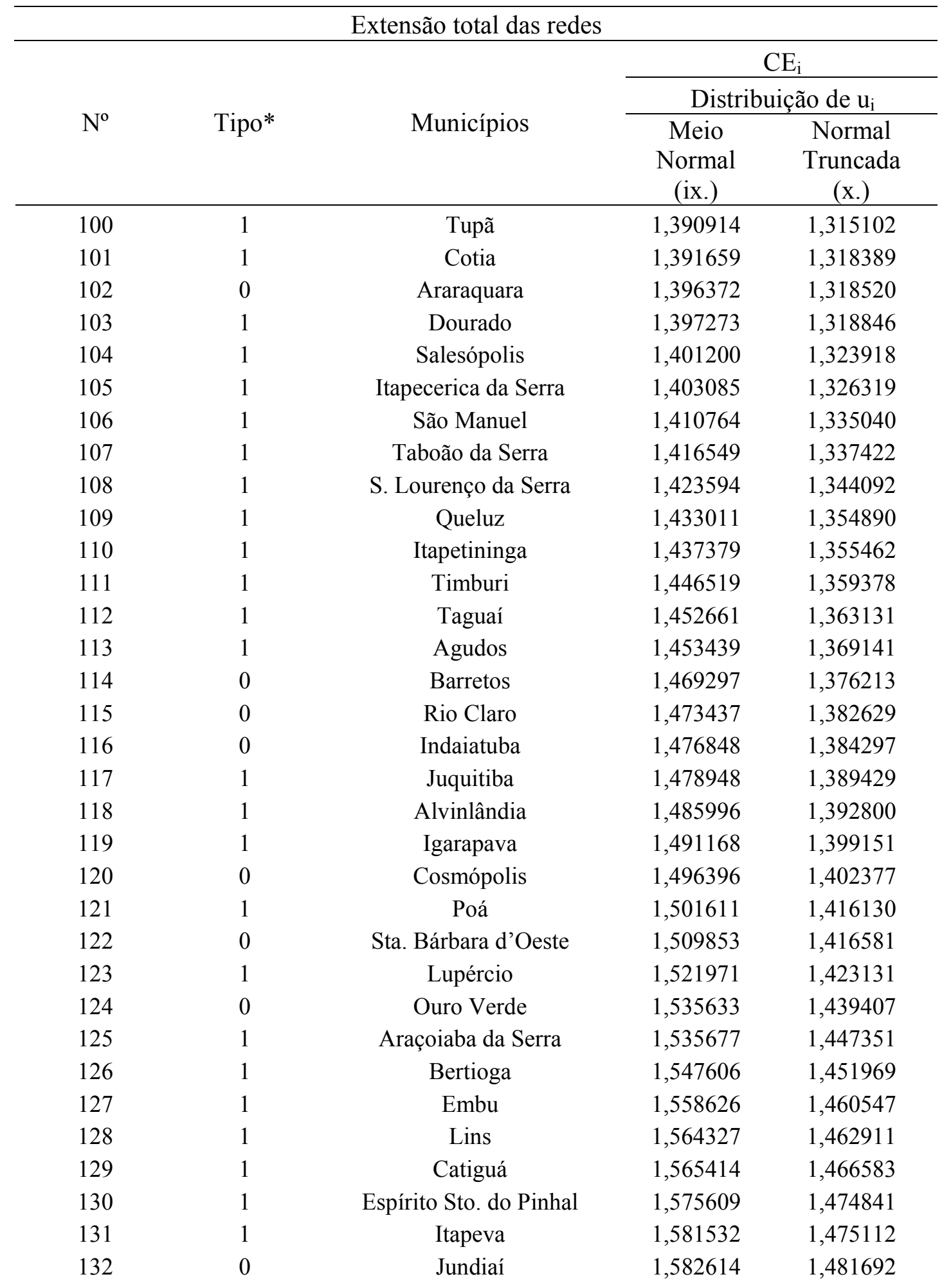


ANEXO B - Ordenação dos municípios eficientes, para os modelos x. e ix.

\begin{tabular}{|c|c|c|c|c|}
\hline \multirow[b]{4}{*}{$\mathrm{N}^{\mathrm{o}}$} & \multirow[b]{4}{*}{ Tipo* } & \multicolumn{3}{|l|}{ Extensão total das redes } \\
\hline & & \multirow[b]{3}{*}{ Municípios } & \multicolumn{2}{|c|}{$\mathrm{CE}_{\mathrm{i}}$} \\
\hline & & & \multicolumn{2}{|c|}{ Distribuição de $u_{i}$} \\
\hline & & & $\begin{array}{c}\text { Meio } \\
\text { Normal } \\
\text { (ix.) }\end{array}$ & $\begin{array}{c}\text { Normal } \\
\text { Truncada } \\
\text { (x.) }\end{array}$ \\
\hline 133 & 1 & Ribeirão Pires & 1,586086 & 1,486678 \\
\hline 134 & 1 & Cajuru & 1,596878 & 1,492608 \\
\hline 135 & 1 & Serra Azul & 1,600740 & 1,496615 \\
\hline 136 & 1 & Rubiácea & 1,604483 & 1,498514 \\
\hline 137 & 1 & Santana de Parnaíba & 1,606346 & 1,499746 \\
\hline 138 & 1 & Guarujá & 1,614626 & 1,505106 \\
\hline 139 & 1 & Pongaí & 1,615420 & 1,508447 \\
\hline 140 & 0 & Jacareí & 1,629490 & 1,513878 \\
\hline 141 & 1 & Guariba & 1,634276 & 1,529921 \\
\hline 142 & 1 & Santo Anastácio & 1,645184 & 1,535001 \\
\hline 143 & 1 & Presidente Alves & 1,648241 & 1,538272 \\
\hline 144 & 1 & Ubirajara & 1,649478 & 1,539009 \\
\hline 145 & 1 & Franca & 1,649878 & 1,541496 \\
\hline 146 & 0 & Piracicaba & 1,657666 & 1,545007 \\
\hline 147 & 0 & Campinas & 1,662050 & 1,545082 \\
\hline 148 & 1 & Roseira & 1,665401 & 1,559156 \\
\hline 149 & 1 & Carapicuíba & 1,667060 & 1,559981 \\
\hline 150 & 1 & Adamantina & 1,709282 & 1,601712 \\
\hline 151 & 1 & Itatiba & 1,803704 & 1,691073 \\
\hline 152 & 0 & Mairinque & 1,833448 & 1,716826 \\
\hline 153 & 1 & Bananal & 1,855894 & 1,743761 \\
\hline 154 & 1 & Santópolis do Aguapeí & 1,860370 & 1,746465 \\
\hline 155 & 0 & Araçatuba & 1,863830 & 1,750633 \\
\hline 156 & 1 & Buritizal & 1,874533 & 1,757463 \\
\hline 157 & 1 & Campo Limpo Paulista & 1,877158 & 1,760270 \\
\hline 158 & 1 & Cabriúva & 1,953638 & 1,839705 \\
\hline 159 & 1 & Barueri & 1,956831 & 1,839972 \\
\hline 160 & 1 & São José dos Campos & 1,964944 & 1,845790 \\
\hline 161 & 1 & Monteiro Lobato & 2,045351 & 1,939592 \\
\hline 162 & 1 & São Vicente & 2,062857 & 1,941390 \\
\hline 163 & 0 & Nova Odessa & 2,086822 & 1,959169 \\
\hline 164 & 1 & Sarutaia & 2,112945 & 1,993780 \\
\hline 165 & 1 & Franco da Rocha & 2,134558 & 2,024398 \\
\hline
\end{tabular}


ANEXO B - Ordenação dos municípios eficientes, para os modelos x. e ix.

\begin{tabular}{ccccc}
\hline & & Extensão total das redes & \multicolumn{2}{c}{$\mathrm{CE}_{\mathrm{i}}$} \\
\cline { 3 - 5 } $\mathrm{N}^{\mathbf{0}}$ & & & \multicolumn{2}{c}{ Distribuição de $\mathrm{u}_{\mathrm{i}}$} \\
\cline { 3 - 5 } & Tipo* $^{*}$ & Municípios & $\begin{array}{c}\text { Meio } \\
\text { Normal } \\
\text { (ix.) }\end{array}$ & $\begin{array}{c}\text { Normal } \\
\text { Truncada } \\
(\mathrm{x} .)\end{array}$ \\
\hline 166 & 1 & & 2,193553 & 2,085596 \\
167 & 0 & Capela do Alto & 2,197678 & 2,095587 \\
168 & 0 & Guarulhos & 2,210326 & 2,097207 \\
169 & 0 & Pedreira & 2,321377 & 2,214452 \\
170 & 1 & Ribeirão Preto & 2,328554 & 2,230310 \\
171 & 1 & Bragança Paulista & 2,352692 & 2,256786 \\
172 & 1 & Biritiba Mirim & 2,355191 & 2,261905 \\
173 & 0 & S. Luis do Paraitinga & 2,360762 & 2,275744 \\
174 & 1 & Santo André & 2,423448 & 2,314161 \\
175 & 1 & Alumínio & 2,491994 & 2,410594 \\
176 & 1 & Mairiporã & 2,540863 & 2,441117 \\
177 & 1 & Itupeva & 2,800229 & 2,728480 \\
178 & 1 & Santos & 2,837809 & 2,767946 \\
179 & 1 & Cubatão & 3,056664 & 3,005266 \\
\hline
\end{tabular}

* Serviço Regional $=1$, Serviço Local $=0$ 


\section{REFERÊNCIAS BIBLIOGRÁFICAS}

AIGNER, D.J.; LOVELL, S.F.; SHIMIDT, P. Formulation and estimation of stochastic frontier production function models. Journal of Econometrics, v.6, n.1, p.21-37, 1977.

AMARAL, A.M.P. Consumo total e residencial de água tratada: aplicação de um modelo de séries temporais em Piracicaba. Piracicaba, 2000. 92p. Tese (Doutorado) - Escola Superior de Agricultura “Luiz de Queiroz”, Universidade de São Paulo.

BANCO MUNDIAL (BID). Latin America \& Caribean. http://www.worldbank.org (6 July 2002)

BANCO MUNDIAL (BID). Relatório sobre o desenvolvimento mundial 1992: desenvolvimento e meio ambiente. Rio de Janeiro: Fundação Getúlio Vargas, 1992. $305 \mathrm{p}$.

BRAEUTIGAM, R.R. Optimal policies for natural monopolies. In: SCHMALENSEE, R.; WILLIG, R.D. Handbook of industrial organization. New York: North-Holland, 1989. v.2, p.1290-1346.

BRASIL. Ministério das Cidades. Sistema Nacional de Informação sobre Saneamento. (SNIS). Diagnóstico dos serviços de água e esgoto 2002. Brasília, 2002. http://www.snis.gov.br (5 jan. 2004)

BRASIL. Ministério das Cidades. Sistema Nacional de Saneamento Ambiental (SNSA). Cenário. http://www.cidades.gov.br (5 jan. 2004)

BRASIL. Ministério da Fazenda. Tesouro Nacional (TN). Despesas do governo por ano e atividade. http://www.stnfazenda.gov.br (5 jan. 2004) 
BRASIL. Ministério das Minas e Energia. Agência Nacional de Energia Elétrica (ANEEL). Tarifas praticadas. Brasília, 2002. http://www.aneel.gov.br (15 jan. 2004)

BRASIL. Ministério da Saúde. Fundação Nacional da Saúde (FUNASA). Notícias. http://www.funasa.gov.br/sitefunasa/not/not2004/not141.htm (20 jun. 2004)

BRASIL. Leis, decretos, etc. Lei no 8080 de 19 de setembro de 1990. Diário Oficial da União, 20 set. 1990. Artigo 2. Dispõe sobre Fundo Nacional da Saúde e o Conselho de Municípios. http://conselho.saude.gov.br/legislacao/ reginter.htm (3 fev. 2004)

BRASIL. Ministério da Saúde. Sistema Único de Saúde. Anuário estatístico de saúde do Brasil 2001. http://www.portal.saude.sp.gov.br/saude/aplicacoes/anuario2001/ index.cfm (5 nov. 2003)

BAUMOL, W.J.; WILLIG, R.D. Fixed costs, sunk costs, entry barriers, and sustainability of monopoly. The Quarterly Journal of Economics, v.96, n.3, p.405-431, 1981.

BAUMOL, W.J.; PANZAR, R.D.; WILLIG, R.D. Contestable markets and the theory of industry structure. San Diego: Harcourt Brace Jovanovich, 1982. 538p.

CARMO, C.M.; TÁVORA JÚNIOR, J.L. Avaliação da eficiência técnica das empresas de saneamento brasileiras utilizando a metodologia DEA. In: ENCONTRO NACIONAL DE ECONOMIA, 31., Porto Seguro, 2003. Anais. Belo Horizonte: ANPEC, 2003. http://www.anpec.org.br (4 mar. 2004)

COELLI, T.; RAO, D.S.; BATTESE, G.E. An introduction to efficiency and productivity analysis. New York: Kluwer Academic Publishers, 1998. 275p.

COMPANHIA METROPOLITANA DE SANEAMENTO BÁSICO (SABESP). Sabesp ensina: básico. http://www.sabesp.com.br (3 jun. 2003)

ESTACHE, A.; MARTÍN, A.R. How different is the efficiency of public and private water companies in Asia? The World Bank Economic Review, v.16, n.1, p.139$148,2002$.

FARRELL, M.J. The measurement of productive efficiency. Journal of the Royal Statistical Society, v.120, series A, p.253-290, 1957. 
FUNDAÇÃO INSTITUTO BRASILEIRO DE GEOGRAFIA E ESTATÍSTICA (IBGE). Pesquisa nacional de saneamento básico (PNSB): abastecimento de água, esgotamento sanitário, drenagem urbana e limpeza urbana e coleta de lixo no Brasil (compact disc). Rio de Janeiro, 2000.

FUNDAÇÃO SISTEMA ESTADUAL DE ANÁLISE DE DADOS (SEADE). Anuário estatístico 2002: caracterização do território: divisão, posição e extensão. http://www.seade.gov.br (12 fev. 2004)

GREENE, W.H. Econometric analysis. Englewood Cliffs: Pretence-Hall, 1993. 791p.

GUJARATI, D.N. Econometria básica. São Paulo: Makron Books, 2000. 846p.

HELLER, L. Saúde e saneamento. Brasília: ORGANIZAÇÃO PAN-AMERICANA DA SAÚDE (OPAS), Escritório Regional da Organização Mundial da Saúde, 1997. $97 \mathrm{p}$.

HELLER, L. Environmental determinants of infectious and parasitic diseases. Memórias do Instituto Oswaldo Cruz, v.93, p.7-12, 1998. Suplemento, 1.

HELlER, L.; COLOSIMO, E.A.; ANTUNES, C.M.F. Environmental sanitation conditions and health impact: a case-control study. Revista da Sociedade Brasileira de Medicina Tropical, v.36, n.1, p.41-50, jan./fev. 2003.

KAMOGAWA, L.F.O. Crescimento econômico e degradação ambiental: uma aplicação do modelo EKC no Brasil. Piracicaba, 2004. 141p. Dissertação (Mestrado) - Escola Superior de Agricultura “Luiz de Queiroz”, Universidade de São Paulo.

KUMBHAKAR, S.C.; LOVELL, C.A.K. Stochastic frontier analysis. Cambridge: University Press, 2000. 333p.

LIMA, R.A.S. Informação, capital social e mercado de crédito rural. Piracicaba, 2003. 236p. Tese (Doutorado) - Escola Superior de Agricultura "Luiz de Queiroz", Universidade de São Paulo.

MEEUSEN, W.; VAN DEN BROEK, J. Efficiency estimation from Coob-Douglas production functions with composed error. International Economic Review, v.18, n.2, p.435-444, June 1977. 
MENDONÇA, M.J.C.; GUTIERREZ, M.B.S.; SACHSIDA, A. et al. Demanda por saneamento no Brasil: uma aplicação do modelo logit multinomial. In: ENCONTRO NACIONAL DE ECONOMIA, 31., Porto Seguro, 2003. Anais. Belo Horizonte: ANPEC, 2003. http://www.anpec.org.br (4 mar. 2004)

MOTTA, R.S.; MENDES, A.P.F.; MENDES, F.E. et al. Perdas e serviços ambientais do recurso água para uso doméstico. Rio de Janeiro: Instituto de Pesquisa Econômica Aplicada (IPEA), 1992. 39p. (Texto para discussão, 258)

MOITA, R.M.S. Regulação por incentivos: a universalização dos serviços de saneamento básico. São Paulo, 2000. 86p. Dissertação (Mestrado) - Faculdade de Economia, Administração e Contabilidade, Universidade de São Paulo.

ORGANIZAÇÃO MUNDIAL DE SAÚDE (OMS). Países. http://www.oms.org.br (9 out. 2003)

ORGANIZAÇÃO MUNDIAL DE SAÚDE (OMS). Helth Impact Assesment (HIA). http://www.who.int.hia/evidence/doh/en/index5.html (13 Dec. 2003)

ORGANIZAÇÃO MUNDIAL DE SAÚDE (OMS). Guidelines for drinking-water quality: volume 1 recommendations. 2.ed. Geneva, 1993. http://www.oms.org.br (9 Oct. 2002)

ORGANIZAÇÃO PAN-AMERICANA DE SAÚDE (OPAS). Centenial news \& information: press information. http://www.paho.org/English/DPI/100/ 100feature39.html (10 Dec. 2002)

PINILLA, A.A. (Coord.). La medición de la eficiencia y la productividad. 1.ed. Madrid: Pirámide, 2001. 362p.

PONZETO, A.L. Saneamento básico no Brasil: década de 90: relação entre investimento e saúde. São Paulo, 2002. 33p. Monografia (Graduação) - Faculdade Oswaldo Cruz.

RANDALL, A. Resource economics: an econominc approach to natural resource and environmental policy. 2.ed. New York: John Wiley \& Sons, 1987. 434p.

SHIROTA, R. Efficiency in financial intermediation: a study of the Chilean banking industry. Ohio, 1996. 138p. Dissertation (Ph.D.) - The Ohio State University. 
SILVA, E.R. O curso da água na história: simbologia, moralidade e gestão de recursos hídricos. Rio de Janeiro, 1998. 201p. Tese (Doutorado) - Escola Nacional de Saúde Pública, Fundação Oswaldo Cruz.

SILVA, H.K.S.; ALVES, R.F.F. O saneamento das águas no Brasil. Brasília: Secretaria de Política Urbana (SEPURB), 2002. http://www.cf.org.br/cf2004/saneamento.doc (4 maio 2004)

SOARES, S.R.A.; BERNARDES, R.S.; CORDEIRO NETO, O.M. Relações entre saneamento, saúde pública e meio ambiente: elementos para formulação de um modelo de planejamento de saneamento. Caderno de Saúde Pública, v.18, n.6, p.1713-1724, nov./dez. 2002.

SOUZA, D.P.H. Avaliação de métodos paramétricos e não paramétricos na análise da eficiência da produção de leite. Piracicaba, 2003. 136p. Tese (Doutorado) - Escola Superior de Agricultura “Luiz de Queiroz”, Universidade de São Paulo.

STEVENSON, R.E. Likelihood function for generalized stochastic frontier estimation. Journal of Econometrics, v.13, n.1, p.57-66, 1980.

TUROLLA, F.A. Provisão e operação de infra-estrutura no Brasil: setor de saneamento. São Paulo, 1999. 94p. Dissertação (Mestrado) - Escola de Administração de Empresas de São Paulo, Fundação Getúlio Vargas.

TUROLLA, F.A. Política de saneamento básico: avanços recentes e opções futuras de política s públicas. Brasília: IPEA, dez. 2002. 26p. (Texto para discussão, 922)

UNITED NATIONS OF CHILDREN'S FUNDATION (UNICEF). Sanitation for all: promoting dignity and human rights. New York, Jan. 2000a. 18p. http: unicef.org/infobycountry/index.html (9 Feb. 2003a)

UNITED NATIONS OF CHILDREN'S FUNDATION (UNICEF). Waterfront: programme division water, environment and sanitation. New York, Apr. 2000b. n.14. 32p. http: unicef.org/wes/index_documents.html (25 Feb. 2003b)

\section{UNITED NATIONS EDUCATIONAL SCIENTIFIC AND CULTURAL} ORGANIZATION (UNESCO). Programa mundial de evaluacion de los recursos hídricos: año internacional del água dulce 2003. http://www.unesco.org/water/wwap/index_es.shtml (26 Mayo 2004) 